\title{
Towards a Better Understanding of High-Growth Technology Firms
}

Sasha Greig

\begin{abstract}
A thesis submitted to Victoria University of Wellington
in partial fulfilment of the requirements for the degree of

Master of Commerce in Management
\end{abstract}

Victoria University of Wellington 


\section{Abstract}

High-growth has long been of interest to management academics, as they seek to understand how uncharacteristically high periods of revenue or employment growth occur, and the effects they have on firms, and the wider economy. However, despite the ongoing interest in the field, there have not been conclusive studies that are able to piece together all of the factors that may play a role in the occurrence of high-growth, and therefore there is still relatively little understanding of how and when high-growth occurs, and what control firms may have over such growth.

This mixed-methodology research uses both quantitative analysis of high-growth patterns, and qualitative interviews with relevant firms to explore the factors commonly associated with high-growth. This allows for a better understanding of how high-growth may occur. The findings indicate that high-growth is typically the product of interactions between a range of factors. The most influential factor on high-growth appears to be the competence, expertise, and experience of those managing the firm, either in a directorial or managerial capacity. The findings also indicate that, while high-growth may not be entirely predictable, there are commonalities between the high-growth patterns that technology firms experience, such as the receiving of patents, or even inclusion in the TIN100 database. Overall, this research found that there appears to be much greater diversity in high-growth than previous literature tends to suggest.

The research concludes with practical implications of these findings for firms and managers of these findings, as well as suggesting directions for future research in the field.

Key Words: High-Growth, Growth theory, innovation, technology, instability, revenue 


\section{Acknowledgements}

In undergoing this thesis, I have been supported by a number of people who have provided me with guidance. In the first instance, thank you to Sally Davenport and Urs Daellenbach for your endless wisdom in this subject, and the curiosity in my work, which motivated me to continue. This thesis would not have eventuated without your enthusiasm, knowledge, and advice. Thank you also to the other excellent teachers I was lucky enough to have during my Masters, who provided me with the foundations to feel confident approaching this thesis, and the knowledge and skills that allow me to be a better researcher, manager, and learner. To the rest of the Victoria University School of Management Staff, thank you for always patiently answering my questions, and going out of your way to make this experience a positive one.

To Catherine, thank you for your dedicated proofreading, I feel like we went through this degree together, and I could not have achieved what I have without you. Thank you for your advice, and questions that forced me to clarify my thinking and be a better writer. To Mum and Dad, thank you for you endless support and curiosity, thank you for the arguments that tested my knowledge, and thank you for always believing that I could do this, even if I did not. Thank you to my colleagues who allowed and encouraged me to take this opportunity, and who showed real interest in this part of my life.

Finally, a big thank you must go to Michael, who patiently listened to my endless discussions of not just this thesis, but the rest of my Master's courses as well. Who was never short of words of encouragement, wisdom, and support, at times when I needed them most, and who made this undertaking feel achievable the entire way through. I can honestly say this would have been much harder without you. 


\section{Table of Contents}

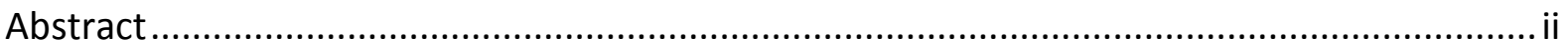

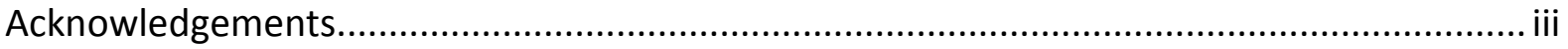

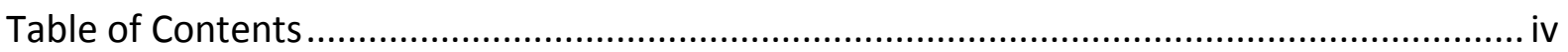

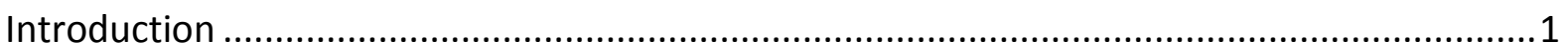

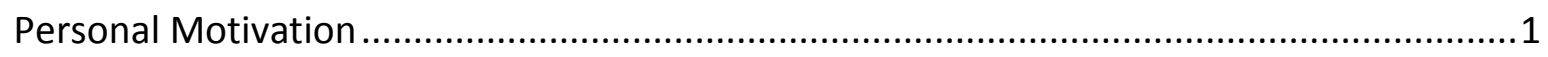

Understanding and Defining High Growth............................................................... 1

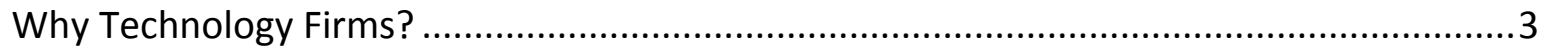

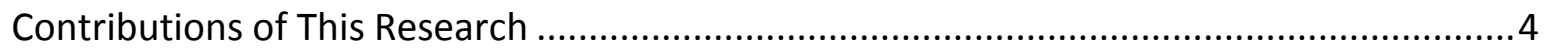

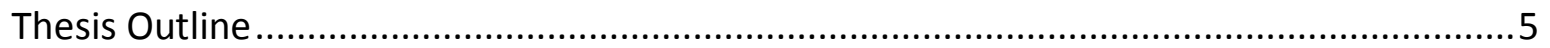

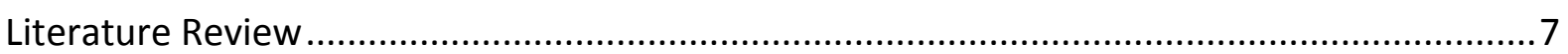

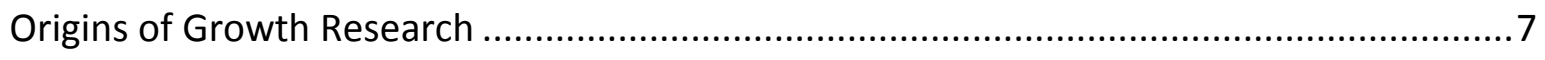

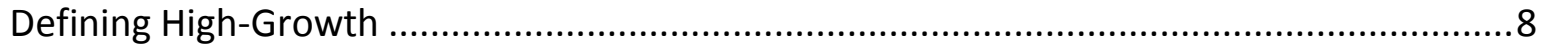

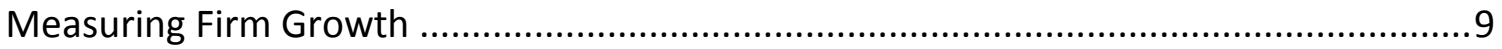

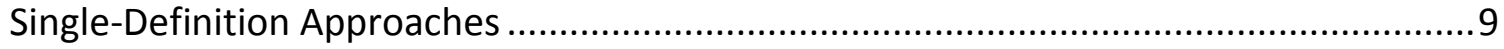

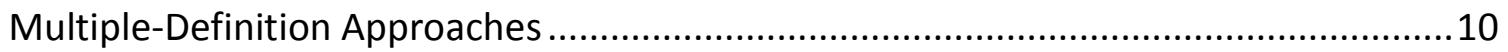

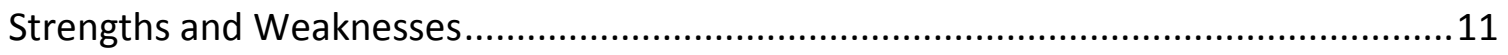

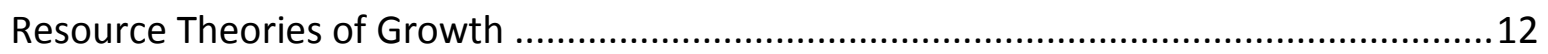

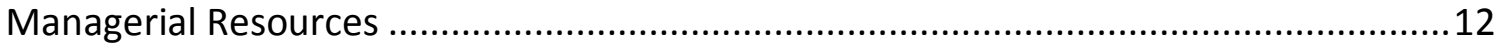

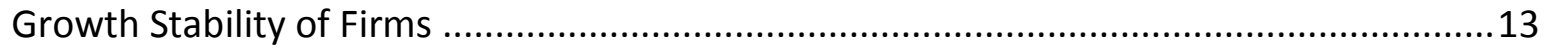

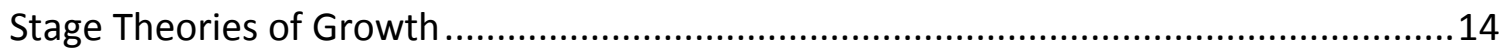

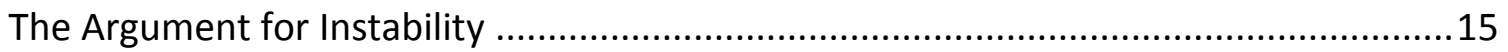

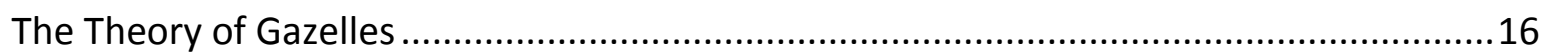

Measuring High Growth in Gazelles ..................................................................... 17

Stage Theories Applied to Gazelles ....................................................................... 17

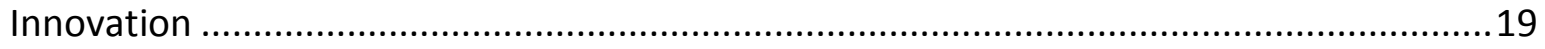

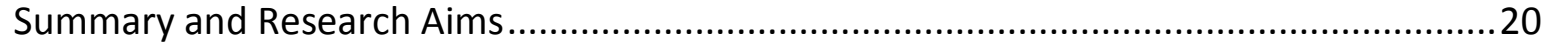

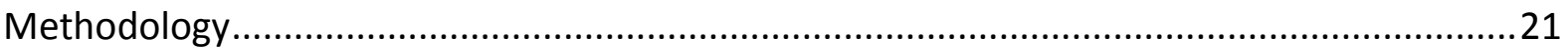

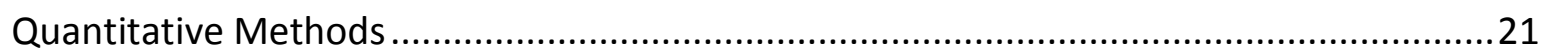

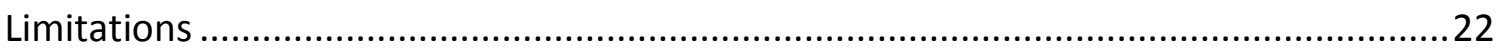

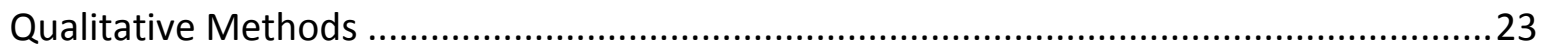

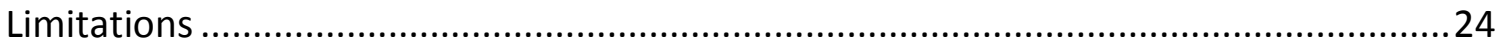




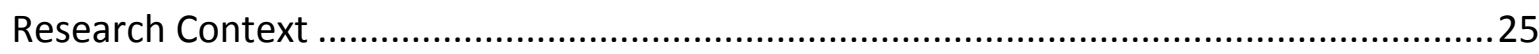

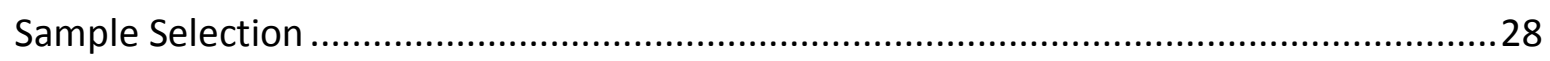

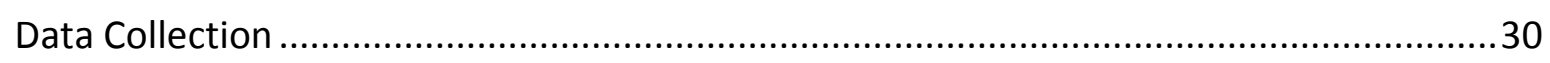

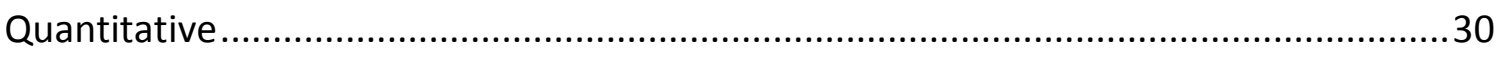

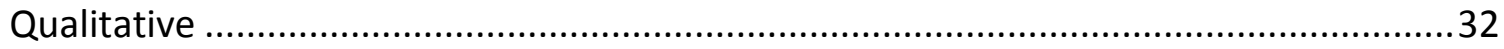

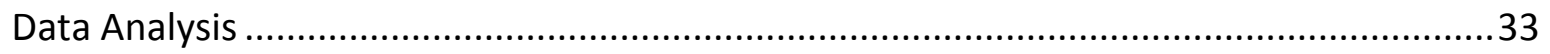

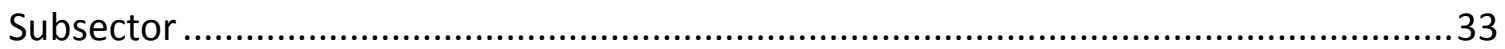

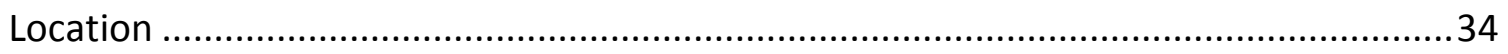

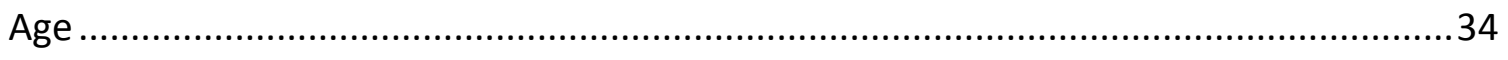

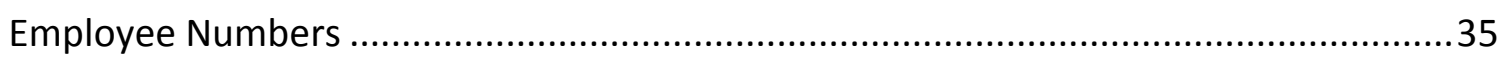

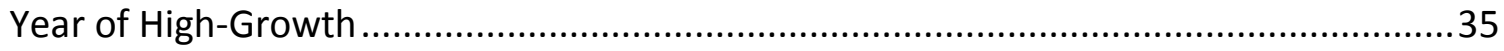

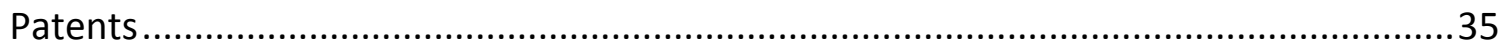

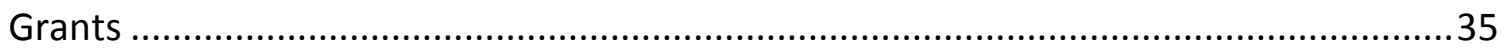

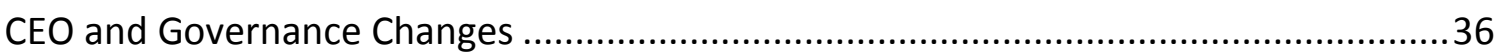

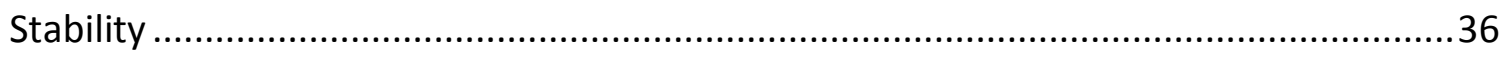

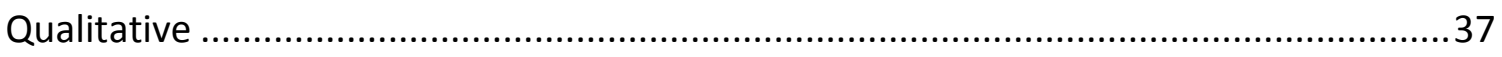

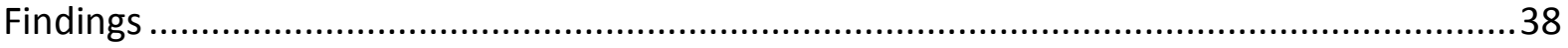

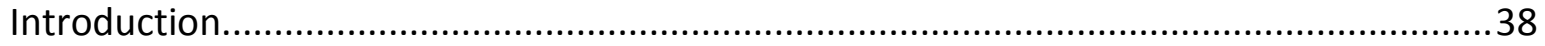

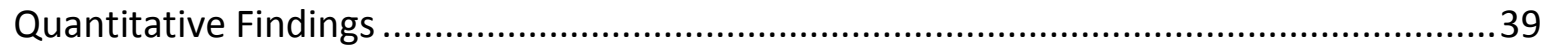

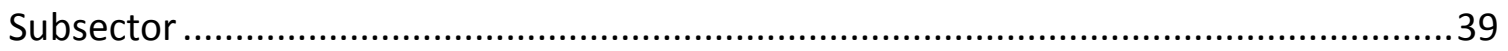

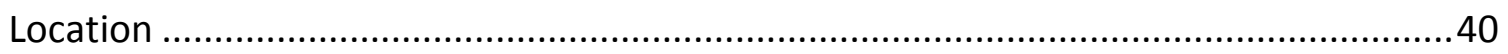

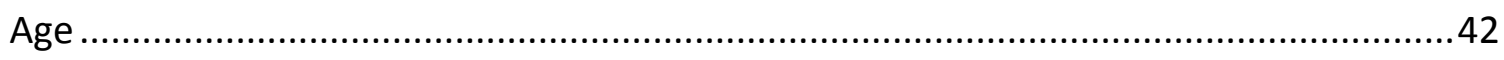

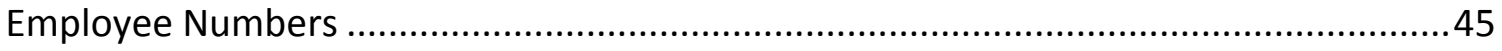

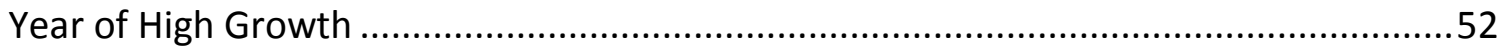

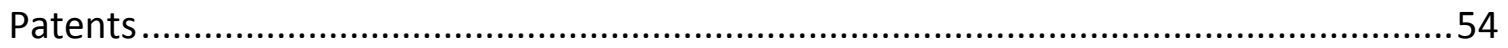

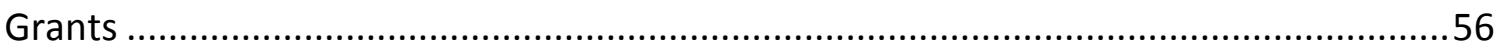

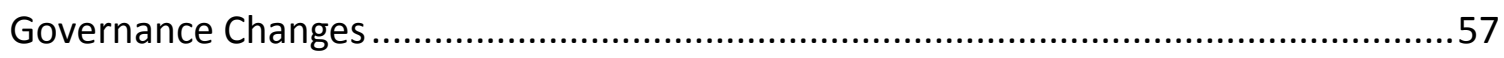

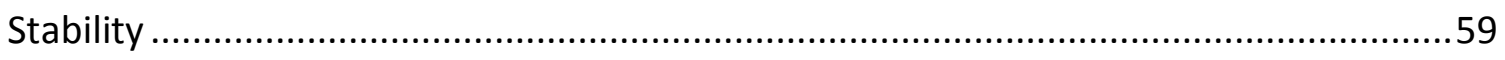

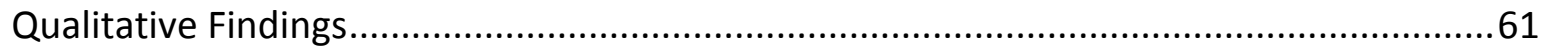

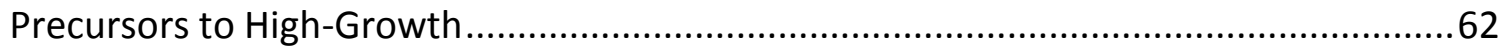

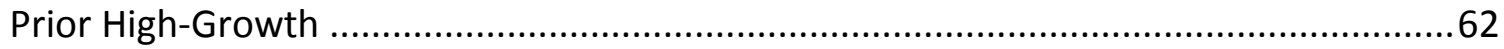

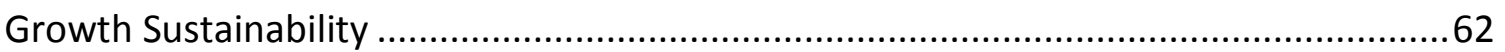

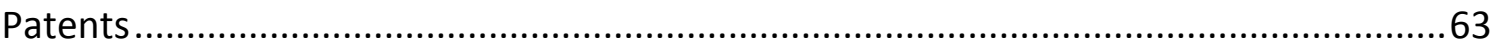


Grants

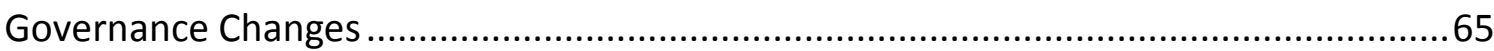

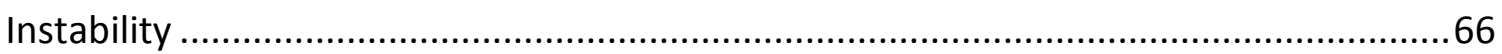

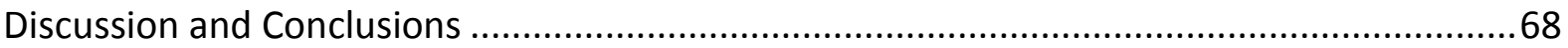

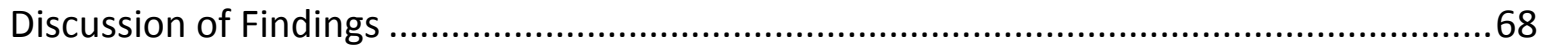

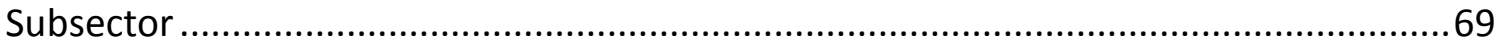

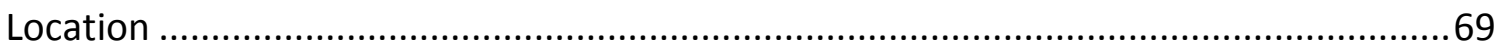

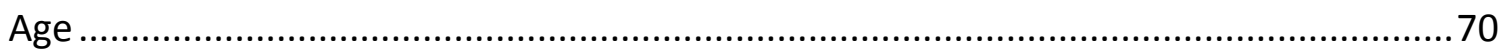

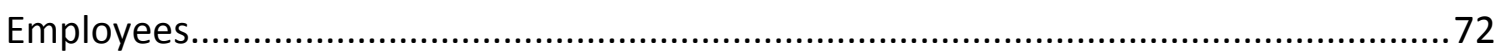

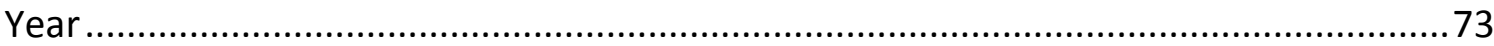

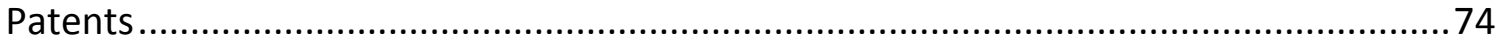

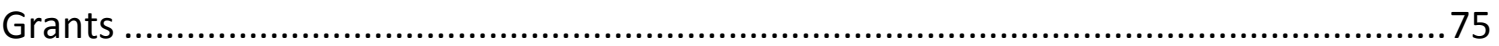

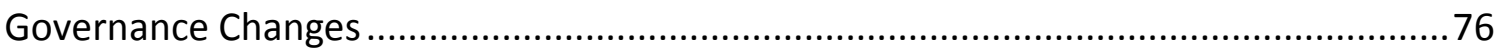

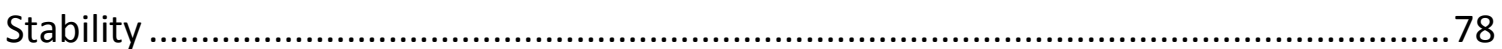

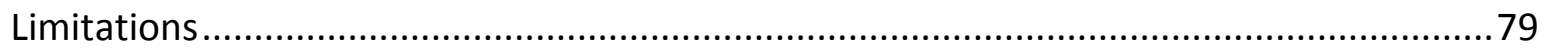

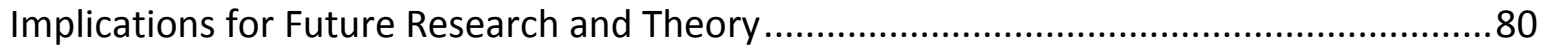

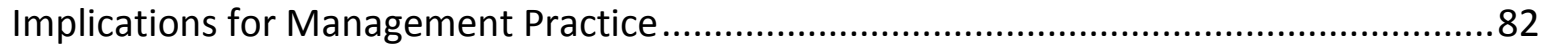

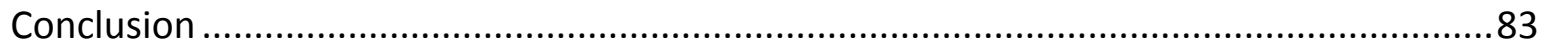

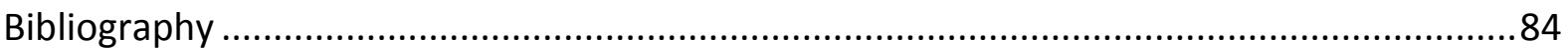

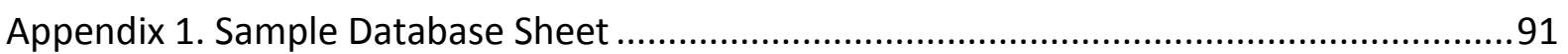

Appendix 2. List of TIN100 Companies and Years of Inclusion .............................................92

Appendix 3. List of Companies in Each Definition of High Growth ......................................96

Appendix 4. Company Interview Selection Matrix / Template ...........................................99

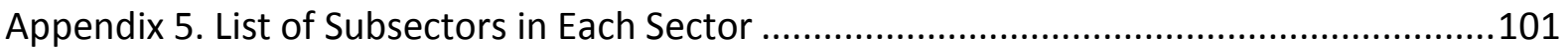

Appendix 6. Growth Percentages Database ..................................................................102

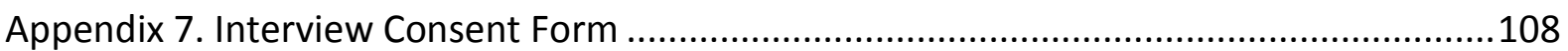

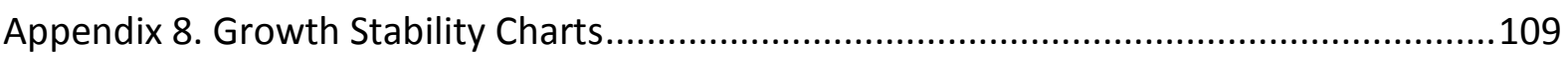




\section{Introduction}

\section{Personal Motivation}

The motivation to study the management issue of high-growth, particularly in the context of New Zealand firms, was largely driven by a personal interest in the work of Sir Paul Callaghan. While Sir Paul's academic career was firmly rooted in science, he passionately pursued the idea of increasing the wealth and competitive advantage of New Zealand and its firms (Callaghan, 2009). One way to do this, he suggested, was to move away from slowgrowth industries such as agriculture and forestry, and instead focus on innovative technology firms. However, the lack of understanding surrounding how and why some firms reach substantial revenue growth deemed to be high-growth, while others do not inspired a desire to investigate further. I was motivated to uncover common characteristics of highgrowth firms (HGFs), and contribute to the ever-growing knowledge around HGFs.

\section{Understanding and Defining High Growth}

Examinations of growth within firms through a management lens have their origins in the seminal work of Edith Penrose (1959), The Theory of the Growth of the Firm. This work provided the foundations for analysing how a variety of factors within organisations contribute to their growth, and ultimately, their success or failure. The pursuit of understanding how and why firms grow, and why some grow quicker than others has not slowed, and a focus of many management academics is the examination of HGFs (Henrekson \& Johansson, 2010; Lopez-Garcia \& Puente, 2012; St-Jean, Julien, \& Audet, 2008). These firms are referred to as gazelles because of their rapid growth rates (Acs \& Mueller, 2008), and are particularly interesting because of the relatively disproportionate amount of job creation and wealth they contribute to the economies that they are involved in (Coad, Daunfeldt, Holzl, Johansson \& Nightingale, 2014).

Despite the ongoing interest in HGFs, the factors that lead to them, and the effects they have on economies, there is still a relative lack of understanding of what contributes to 
high-growth (Delmar, Davidsson, \& Gartner, 2003), and whether it can be predicted (Reichstein \& Dahl, 2004). Some suggest that high-growth periods for firms could simply be the result of a random and unpredictable array of factors (Davenport, Daellenbach, Greig, Bibby \& Leitch, 2014; Geroski, 1999) that cannot be controlled for by firms. This may be the result of a focus on resource-based approaches to analysing precursors to high-growth in many studies. This emphasis means they largely ignore or downplay the effects of governance and managerial decision making, external funding and grants, and firm stability on high-growth. Therefore, they end up taking a narrow perspective of the causes of highgrowth periods, and eliminating factors that may indeed play a vital role.

Another reason for this ongoing disagreement among management academics, may be the lack of a single, common definition of high growth. This in itself should not be a barrier to understanding how high-growth occurs in firms, however many studies generally use a single measure of high-growth. This means factors that cause growth may be eliminated as they do not fit the definition being tested. This may have lead to many factors being overlooked as precursors to high-growth. Delmar et al (2003) have attempted to synthesise the many definitions and classifications of high-growth, into seven clusters of high-growth types. This allows for the examination of different types of growth, and the different factors that may lead to each type. However, studies considering multiple measures of high-growth are still in the minority. Therefore, there does not appear to be any consensus as to what leads to high-growth for organisations. This may be due to the fact that no study has investigated a wide range of factors simultaneously. It may also be that no definitive cause of high-growth exists, and that it is a some combination of effective management, sufficient support and funding, and favourable market conditions, location, and trends. However, further study is required to determine which of these may be the case. The motivation of this thesis is to contribute to the relatively sparse understanding of whether such conditions may lead to high-growth, and to work towards a better understanding of the characteristics shared by high-growth technology firms in New Zealand. 


\section{Why Technology Firms?}

In his 2009 book Wool to Weta, Sir Paul Callaghan argues, that if New Zealand wants to be truly competitive in the international economy, we must refocus our investment and attention away from the traditionally slow and lumbering primary industries of agriculture and forestry, and toward faster growing and more agile technology fields (Callaghan, 2009). He argued that this created more long-term value for the economy and culture of New Zealand. While he was speaking from a uniquely New Zealand perspective, these statements represent a growing focus of the wider management literature into the growth and development patterns of smaller firms, particularly in the up-and-coming science, technology, and engineering (STEM) sectors (Coad et al., 2014; Davenport et al., 2014). The interest in this field is largely driven by growing awareness of the contributions these sectors make to national economies (Henrekson \& Johansson, 2010).

A report released by the Australian Government in early 2015 identified STEM fields as contributing 11\% of national GDP (Australian Academy of Science, 2015). In 2012, the Ministry of Business Innovation and Employment reported that employment in technologyrelated fields was $22.7 \%$ of total employment (Ministry of Business Innovation and Employment, 2014). A report released in 2012 indicated that employment in the hi-tech sector in the United States was growing at a rate four times the private sector as a whole (Rushe, 2012). The US Bureau of Economic Analysis has published data that indicates that technology and information fields contributed approximately $13.3 \%$ of national GDP in 2014 (Bureau of Economic Analysis, 2015). Closer to home, New Zealand government science and innovation has increased by more than $70 \%$ in the past eight years (Ministry of Business, Innovation and Employment, 2015). However, it is not simply a case of short-term economic impacts that make STEM industries particularly appealing. It is also the potential they hold for innovation and discovery, the long-term legacies they have. If New Zealand is to maintain its clean, green image, it will be through knowledge-intensive organisations that are working towards less resource-intensive, and more efficient and clean ways of growing, the organisations who aim to discover new and better ways of doing things. Coincidentally, these also tend to be the organisations that use little land, and pollute very little (Callaghan, 
2009). Therefore, the global momentum of science and technology related industries is prompting a rapid rise in management interest in how organisations within these industries operate and grow, and how they may differ from other industries.

\section{Contributions of This Research}

Previous studies have identified a number of factors that appear to be shared by HGFs (Coad et al, 2014; Delmar et al, 2003). This research aims to build on the findings of these studies and contribute to the management literature of HGFs. This will be achieved through the use of mulitple measures of growth, in order to ensure that factors unrelated to one classification will not be automatically eliminated as being precursors to high-growth. This research also analyses a number of resource-, and non-resource-based factors of growth, in order to gain a more complete picture of the characteristics of the HGF. In order to do this, a mixed-methods approach is adopted. Quantitative analysis of each firm's revenue data, patents, grant and investment data, age, employee numbers, sector, governance changes, and revenue stability allows for the empirical examination of factors that occur in the leadup to high-growth periods. This provides the information required to draw conclusions regarding which factors are relevant precursors to high-growth. Qualitative interviews with management within HGFs were also used to provide context for some of the changes that may have occurred within firms preceding high-growth periods. In addition, this allows for managerial decision-making and conscious planning on the part of management and firm directors to be considered as potential precursor factors to high-growth. This will add a new dimension to management study of HGFs, as previous studies have primarily relied on quantitative analysis of predominantly firm revenue data (Davenport et al., 2015; Garnsey \& Mohr, 2011; Mohr, Garnsey, \& Theyel, 2014). The context in which this research is being conducted is relatively novel in the field of HGF analysis, as there is extremely little research involving New Zealand firms. Therefore, by deepening the understanding of how highgrowth occurs among New Zealand firms, this thesis will contribute to a greater global understanding of HGFs, and will contribute knowledge of how findings of management research conducted elsewhere may or may not apply to New Zealand firms. 
The thesis aims to identify characteristics shared by HGFs in the New Zealand technology sector, and will provide explanation as to why these characteristics may lead to high-growth periods for firms. Therefore, the main research question being examined in this thesis is What are the characteristics of high growth technology firms in New Zealand, and how do factors interact to cause high growth in these firms? Answering these questions will require the analysis of a number of different factors, from a longitudinal perspective, using multiple definitions or measures of high-growth. Contributing to a greater understanding of highgrowth in firms will assist in working towards agreement over the factors that lead to highgrowth, and better ability for firms to plan for and work towards sustained high-growth. Conducting this research in a New Zealand context allows for a better understanding of how New Zealand firms grow. It may also shed light on whether there are unique factors present in New Zealand that cannot be accounted for by management research conducted in other nations. Finally, analysing the growth of technology firms is extremely important, as their centrality to economic, societal, and environmental development becomes more and more apparent.

\section{Thesis Outline}

The research and findings of this thesis will be presented in four chapters.

Chapter One is a review of relevant literature surrounding the topics of firm growth and high-growth, the conditions specific to technology firms, and how technology firms grow in relation to other industries or firm types. A discussion regarding the limitations of current literature and the possible contributions of this research will also be conducted in this chapter.

Chapter Two will describe the methodology used in the current research, as well as outlining data collection and analysis methods.

Chapter Three presents the results of this research, through both quantitative outcomes of analysis conducted, and through the inclusion of comments obtained in interviews to provide context and potential explanation of quantitative findings. 
Chapter Four is a discussion of the findings from the research, and conclusions that can be drawn from these findings. These conclusions will be discussed in the context of previous literature, and contributions that this research makes. This chapter will also outline how the findings answer the key research question, and why these findings are relevant to both academic, and non-academic audiences. 


\section{Literature Review}

This research works towards a deeper understanding of the characteristics and conditions of high-growth technology firms in a New Zealand context. By considering a range of factors, firm-sizes, and measures, this research aims to build a more robust definition and categorisation of the HGF, and contribute to a better understanding how high-growth occurs, and whether firms can deliberately plan for it.

This chapter of the thesis is concerned with outlining and examining existing literature on the topics of firm-growth and high-growth, innovation (particularly as it applies to technology firms), and the various factors that should be considered when investigating the precursors to high-growth. Examination of this literature provides the foundation for the current research project, as well as future research, as it introduces many of the concepts and ideas that are of importance. As well as this, analysing previous literature reveals what may have been overlooked or underplayed in previous studies, and therefore provides the opening for the current research to contribute to management knowledge about highgrowth in technology firms.

\section{Origins of Growth Research}

"The problem (of predicting firm growth in a particular instance) is not unlike the problem of diagnosing the prospects of growth of, say, a tree. Upon examination, one can say that the tree will not grow unless certain environmental conditions are satisfied - but one can never certify in advance whether the tree will or will not survive all possible vicissitudes and how they will affect its growth." (Penrose, 1959, p. 8)

The conditions, characteristics, and decision-making processes that influence the growth of firms has been of significant interest to management researchers since Edith Penrose published her seminal work on the subject The Theory of the Growth of the Firm in 1959. Penrose was concerned with the frameworks on which examinations of firm growth had been previously conducted. She proposed new ways of looking at firms to examine their 
growth patterns. This allowed her to analyse whether firm growth was internally or externally-driven, how resources should be managed and allocated to maximise growth, how acquisitions and mergers affected firm growth, and how management can play a role in firm growth, but can also act as a barrier towards growth (Penrose, 1959). Since her research was published, many researchers have taken the foundations laid by Penrose, and built on them, focussing on the growth of different types of firms (Garnsey, 1998), the growth of firms in specific geographical regions (Garnsey \& Mohr, 2011), or the effects that firm growth has on other industry factors, such as employment (Acs \& Mueller, 2008; Birch, 1981). However, one field of particular interest within firm-growth research, is that of the HGF. Much work has been conducted in attempting to understand the factors and characteristics of HGFs (Coad et al, 2014; Davenport, Daellenbach, Greig, \& Leitch, 2015), and whether or not high-growth can be predicted and planned for (Delmar et al, 2003; Reichstein \& Dahl, 2004), or whether it is random and unpredictable (Davenport et al, 2014; Geroski, 1999) as well as whether or not high-growth can be sustained (Daunfeldt \& Halvarsson, 2015). Examining HGFs has been, and continues to be, of marked interest to management theorists. One could surmise that this is likely the result of their disproportionately large contribution to their economies (Henrekson \& Johansson, 2010), especially considering how few there are among all organsiations (Delmar et al, 2003). However, it could also be argued that it is actually the fact that relatively little is understood about the precurors to high-growth, which motivates ongoing research in this area.

\section{Defining High-Growth}

As mentioned, part of the difficulty in analysing and comparing HGFs is that it must first be determined what high-growth is, how it is measured, and where the line between 'normal' growth and high-growth sits. This is not a new phenomenon, and it does not only apply to high-growth. In her foundational work, Penrose herself discussed the difficulty in constructing a general theory for the growth of firms. She stated, "The term growth is used in ordinary discourse with two different connotations. It sometimes denotes merely increase in amount... At other times, however, it is used in its primary meaning implying an increase in size or an improvement in quality..." (Penrose, 1959, p. 1). Therefore, before one 
can begin to analyse high-growth, one must first determine what is meant by high-growth in the context of any given high-growth research.

\section{Measuring Firm Growth}

Coad et al (2014) offers that the two main ways to measure firm growth, and thereby highgrowth, is using employee or revenue data. They do suggest, however, that, in research at least, which measure is used is unlikely to make a significant difference to the results obtained. However, what does make a significant different to results, they propose, is whether absolute or relative growth is being measured (Coad et al, 2014). Delmar and Davidsson (1998) assert that four factors must be considered when defining or analysing high-growth in firms,

1) The variable by which the growth is being measured (sales, revenue, employee numbers)

2) Whether the growth is absolute or relative

3) The period of time over which the growth is measured

4) The 'process' of growth - i.e. whether the growth is organic, or the result of other activity such as mergers or acquisitions. (Delmar \& Davidsson, 1998)

In an attempt to consider and incorporate all of these factors in their research, a number of researchers have employed a coherent, single definition of high growth. For example, Garnsey and Mohr (2011) employ the OECD definition of HGFs, which holds that HGFs are those that have an average growth of at least $20 \%$ per annum over a three-year period, which can be measured by the number of employees, or by turnover (Eurostat-OECD, 2007).

\section{Single-Definition Approaches}

However, whether or not a single, or at least, a narrow definition of high-growth is necessary has been debated (Delmar et al, 2003). Some argue that a narrow definition of high-growth would only provide insight into one type of firm growth, and would ignore the many other types of growth that are present in firms. Therefore, in opposition to the studies that employ a single definition of growth, others have taken a multiple factor approach to studying high-growth, using multiple definitions of growth. (Daunfeldt, Elert, \& Johansson, 2010; Delmar et al, 2003). As Penrose (1959) discussed, much of the issue in trying to define 
growth stems from the variability in what is used to measure said growth. Throughout previous literature there appears to be two main approaches to defining growth. The first is to build on single definitions, by using employee and/or revenue data, and using the multiple definitions of growth to explore how these variables interact, for example, and why. Contrary to Coad et al. (2014)'s findings, increases in one measure, may not necessarily reflect the same or similar increases in the others. Delmar et al (2003) describe this first approach. They proposed seven 'clusters', or definitions of high-growth, that organisations could be classified by. They all use revenue and employment as their base variables: Super Absolute Growers - firms with high-absolute growth in both employment and sales, Steady Sales Growers - firms with strong increase in sales, but negative employment growth, Acquisition Growers - strong increase in sales and employment, but with the majority of the increase coming from acquisitions rather than organic growth, Super Relative Growers firms with a high relative growth in any measure, Erratic One-Shot Growers - firms that demonstrate high average growth, but the erratic nature of this growth begs the question of whether this growth is the result of measurement, rather than actual increases, Employment Growers - firms which had positive growth in the number of employees, but negative sales growth, and Steady Overall Growers - firms with high absolute sales and employment growth, but lower relative growth (Delmar et al, 2003).

\section{Multiple-Definition Approaches}

The second approach to multiple definitions of growth interprets growth in its "primary meaning" (Penrose, 1959, p. 1). This means that growth is not only measured or defined based on revenue and employment, but entirely new factors, such as value or process improvements are considered when defining high-growth. A key example of this approach is the 2010 study by Daunfeldt et al, in which they employed a 'multiple-definitions of growth' model; however they separated employment and revenue as two types of growth, and also added productivity and value as additional measures of growth. This led them to incorporating nine definitions of growth into their study: 
1. Absolute employment growth

2. Relative employment growth

3. Composite employment growth ${ }^{1}$

4. Absolute sales growth

5. Relative sales growth

6. Absolute productivity growth ${ }^{2}$

7. Relative productivity growth

8. Absolute value-added growth ${ }^{3}$

9. Relative value-added growth (Daunfeldt et al, 2010)

\section{Strengths and Weaknesses}

There appears to be a number of strengths and weaknesses to each of these approaches. By using the OECD definition of high-growth, Garnsey and Mohr (2011) adhere to the first three of Delmar \& Davidsson's (1998) factors when considering high-growth. It determines the variable being measured, it confirms that the growth being assessed is relative growth, and the definition gives a period over which growth is measured. However, it does not take into account whether the growth is organic, or the result of other processes, such as mergers or acquisitions, thereby ignoring Delmar \& Davidsson's fourth 'process' factor. In contrast, Delmar et al (2003) consider the variable, whether or not growth is relative or absolute, and the processes that result in the growth. However, they do not acknowledge a period within their definitions of high-growth. Daunfeldt et al (2010) do not consider the third or fourth factors put forward by Delmar \& Davidsson, however they do acknowledge Penrose's assertion that growth can be measured using more variables than simply revenue and employees.

Based on this diversity of approaches, it may not be necessary to work towards a single coherent definition of high-growth. Rather the strengths will lie in using robust multiple definitions that are well-clarified, with boundaries that are clear and well-considered, that

\footnotetext{
${ }^{1}$ This definition measured high-growth using a combination of relative growth and absolute growth measures.

${ }^{2}$ Absolute and relative productivity growth measures examined the value added per employee.

${ }^{3}$ Daunfeldt et al (2010) define value added as the value of a firm's production, minus the value of the inputs used in production.
} 
allow for the examination of multiple types of high-growth across a number of different contexts.

\section{Resource Theories of Growth}

Another set of factors to consider when examining high-growth, particularly early in a firm's life, is the resources that firms have access to that allow them to grow. Garnsey \& Mohr (2011) take a particularly resource-based approach to examining HGFs. However the approach has also appeared in the work of Penrose (1995), Barney (1991), Geroski, Mata, and Portugal (2010), and Garnsey (1998). In the latter of these studies, Garnsey (1998) found that only a small proportion of firms achieve what could be defined as 'high-growth', but those that do tend to do so early in their lifespans, and contribute a disproportionate amount towards employment. This reinforces the theory of gazelles introduced earlier in this chapter (Garnsey, 1998; Kirchoff, 1994). However, in taking a more resource-based approach to explaining why these high-growth periods may occur, and why they may not be sustained for great lengths of time Garnsey $(1998$, p.535) found that firms that arise out of incubators or partnerships may be more likely to survive and experience high-growth in the early years, as "they may already be generating revenue by the time they are incorporated", meaning they are more able to generate and mobilise resources to their advantage early in their life, giving them a competitive advantage over other firms in the industry, and allowing them to grow faster. Garnsey also considers injections of capital from outside of the firm, such as venture capital investment, and the effects that this may have on the growth of gazelle-type firms, suggesting that rapid growth may be the result of sudden increases in capital obtained by the firm, by methods other than increasing sales.

\section{Managerial Resources}

One of the key findings of most resource-based theories of growth is that having the resources to grow does not necessarily result in rapid growth for a firm. Rather, the management, allocation, and preservation of those resources is essential (Garnsey, 1998; Penrose, 1959). Effective management is considered a resource in itself and this, at least partially according to Garnsey (1998), explains the variation in growth patterns of firms in 
the same industry, and of the same age. She posits that, for unexpected or chance events to have a long-term effect on the growth of an organisation, they must prompt organisational change, which requires leadership able to conduct and maintain these changes. Garnsey also suggests that, especially in the early life of a firm, it is important to have a manager that has experience running a larger firm and managing greater resources, otherwise growth itself can become a barrier to future growth, as the sudden increase in funds and resources can become overwhelming and not be managed effectively (Garnsey, 1998). This was echoed by Chetty and Campbell-Hunt (2003), who found that similar issues can arise in small firms who rapidly internationalise, without sufficient support. Therefore, firms who have experienced individuals in positions of leadership and governance, or who have access to supportive business networks that can perhaps provide governance and managerial mentorship or experience externally, are more likely to grow faster, and longer-term, than young firms that do not.

In employing a more resource-based approach to high-growth, Garnsey and others demonstrate how the factors that are analysed when examining HGFs make a significant difference to the depth and generalisability of findings from such analyses. By providing a focus on external factors rather than simply the organic growth of sales or employees, Barney (1991) Garnsey (1998), and others, suggest that high-growth does not exist in a vacuum, and must be considered with a regard to wider economic conditions if it is to be properly understood.

\section{Growth Stability of Firms}

Much research has attempted to understand how high-growth in firms occurs, and why some firms seem to be able to overcome challenges and unfavourable economic conditions to become successful, when others fail at the first hurdle (Garnsey, 1998; Geroski, 1999; Greiner, 1972). At its roots, this pursuit is largely that of trying to decipher the effects that instability has on firm growth, and whether or not stability is an ideal, or even realistic goal for firms to pursue. 


\section{Stage Theories of Growth}

One of the ways theorists have attempted to address this question is by designing stage theories of growth (Geroski, 1999; Greiner, 1972), in which firm growth is modelled as going through a number of predictable stages, that are punctuated by what Greiner (1972) refers to as "crises". Greiner's five stages of growth are creativity, direction, delegation, coordination, and collaboration, and in between each stage is the crisis that the firm must overcome to progress to the next stage of growth. It is these crises that attempt to capture firm instability, although they still do not provide the entire picture of how firms can sustain positive growth, in the face of economic instability. Greiner's model is based on analyses of previous research, and he argues that five key dimensions of firm growth stages emerge. They are: firm age, size, stages of evolution and revolution, and the growth rate of the industry. It is the stages of evolution and revolution that are particularly interesting in the context of growth stability and high growth. Greiner describes the stages of evolution as the periods where firms enjoy continuous growth with only 'modest' adjustments needed to sustain the growth, and states that these periods usually develop after the firm has survived a 'crisis' (Greiner, 1972). In contrast, revolution periods are those that involve major disruptions to management practices, perhaps because the practices that were appropriate for a smaller or less-successful organisation are now no longer appropriate. This results in instability and uncertainty for the firm, and Greiner argues that the organisations who are unable to adapt their management practices and put in place organisational changes, are those that will experience reduced growth rates, or fold altogether. Therefore, those firms that are able to make the changes necessary to overcome the unstable periods of revolution, are those that are more likely to experience high-growth.

Garnsey (1998) also proposes a theory of growth that attempts to take into account the instability that firms may face. Her theory is premised by the statement that "a large proportion of firms do not survive as identifiable units beyond their first few years, and only a small proportion achieve significant growth" (Garnsey, 1998, p. 6). Where Greiner's model of firm growth was largely based on management practices and structures, Garnsey's is based on the mobilisation and utilisation of resources. While neither appears more valid 
than the other, some of the explanation for the difference may be drawn from the fact that Garnsey's paper is primarily focussed on the early growth of firms (Garnsey, 1998), whereas Greiner was considering later stages of firm growth (Greiner, 1972). Garnsey's model demonstrates that firms' growth roughly adheres to the following pattern: access resources, mobilise resources, generate resources, growth reinforcement, growth reversal (Garnsey, 1998). However, the model also considers the results for firms if they are unable to meet each of these stages, arguing that firms who are not able to mobilise resources tend to fail, and some firms may experience a growth plateau for a number of reasons after reaching the 'generate resources' stage (Garnsey, 1998). While this may sound like a largely stable position for many firms, in reality, Garnsey's model shows that while the firms on this plateau are unlikely to experience any major growth swings, instability in the form of small changes that occur often are likely (Garnsey, 1998). The model also shows that even firms who experience high-growth after generating resources, are able to experience significant instability, in the form of "growth reinforcement" and "growth reversal" (Garnsey, 1998, p. 530). This occurs when firms are able to generate capital that they can reinvest in future growth (growth reinforcement). However, much like Greiner (1972), and Penrose (1959), Garnsey found that this growth can be a problem in itself, as complexity of decision-making and managerial practices increases with growth, this can be a cause of instability and growth can act as a barrier to itself (Garnsey, 1998).

\section{The Argument for Instability}

At first, instability may appear to be a barrier to significant firm growth. However, a growing number of studies are arguing that instability does not necessarily result in poorer results for firms, and should not always be avoided at all costs (Davenport et al, 2014; Feeser \& Willard, 1990; Geroski, 1999). Geroski (1999) and Davenport et al (2014) both conclude that the growth patterns of firms often follow a "random walk" (Geroski, 1999, p. 169) and therefore defining a universal pattern of growth should not be expected. Rather, they argue, models of firm success should be adapted to incorporate firms who appear to succeed out of instability (Davenport et al, 2014), as these firms do exist, and comprise some of the highest-growers in some industries (Davenport et al, 2014). It is even argued that instability may be sustainable, as long as there is an overall trend towards growth (even if it is only 
slight), and none of the downward swings are too significant to overcome. Therefore, there is little evidence that instability should be discounted as being damaging to a firm's growth potential (Davenport et al, 2014). The supports and earlier proposition from Feeser and Willard (1990), who argue that instability is only as damaging as firms allow it to be (within reason). They suggest HGFs may benefit from greater export revenues than slower-growing firms, which may mitigate the effects of unstable domestic economic conditions, and vice versa (Feeser \& Willard, 1990). Therefore, they imply that one of the characteristics of HGFs may be that they are able to anticipate instability in advance, and prepare controls against it. This suggests that it is not instability that results in poorer firm performace, rather a lack of preparation for potential instability.

\section{The Theory of Gazelles}

As previously mentioned, there has not been consensus as to how firms actually grow. Alternatives include whether achieving high growth is a matter of careful resource management, planning, and innovation (Reichstein \& Dahl, 2004), or instead, if it is the random and unpredictable result of a combination of factors outside a firm's control or knowledge (Geroski, 1999). However, an important qualifier that Geroski adds to this view of the growth of firms is that "This is not quite the same as saying that growth is driven by 'mere chance' or 'good luck'." (Geroski, 1999, p. 4). He goes on to say that unexpected does not necessarily mean that the event or factor cannot be seen coming, but rather, may mean that it is known that it will happen, it is just not known when (Geroski, 1999).

As the high-growth literature has developed, a number of HGFs have come to be known as 'gazelles', a term coined by Birch (1987) to differentiate these companies from what he referred to as mice (small firms with slow or stagnating growth), or elephants (large enterprises) (Birch, 1987). Gazelles are defined as small and often young firms that have rapid growth rates, beyond what would be expected of a firm of that size (Acs \& Mueller, 2008; Birch, 1981). These firms have since become of intense interest to management theorists and academics, largely because of the disproportionate effect they have on job creation and wealth for the economies they are in, relative to their age and size (Henrekson \& Johansson, 2010; Lopez-Garcia \& Puente, 2012; St-Jean et al, 2008). 


\section{Measuring High Growth in Gazelles}

Despite their relative importance, identifying gazelles as HGFs is heavily dependent on how high-growth is defined and measured (Davenport et al, 2015), which means that they may end up being ignored in examinations of HGFs if the definitions employed are not favourable. For example, the OECD definition of high-growth discussed previously in this chapter holds that a HGF is one that achieves $20 \%$ employee growth per annum over three years (Eurostat-OECD, 2007), and another definition of high-growth defines the category as those firms who achieve $50 \%$ revenue growth each year over a three year period (Coad et al, 2014). However, some argue that these definitions of high-growth eliminate the majority of high-growth gazelle firms, which tend to experience short-term growth bursts, lasting only a single year (Holzl, 2009; Daunfeldt \& Halvarsson, 2015). Also of importance is whether the growth being considered is absolute or relative growth. When absolute measures of growth are employed, the findings tend to be more skewed towards larger enterprises, as they are more likely to experience high absolute growth. In opposition to this, relative measures may be more favourable towards smaller, gazelle-type, firms as these may have smaller levels of revenue or employees to begin with, and therefore higher relative growth (Davenport et al, 2015). Due to these variations, many high-growth studies have not been able to construct an accurate picture of how high-growth gazelles may or may not compare to other HGFs, and how prevalent gazelles are in the category of HGFs.

\section{Stage Theories Applied to Gazelles}

A number of key findings regarding the influences on the growth of gazelles, and the effects that have on their economies, have arisen. Firstly, firm age, rather than size, is said to be a more important factor when considering business dynamics (Acs \& Mueller, 2008; Davenport et al, 2015), and gazelles are more likely to have an impact on relative job creation in the first few years of existence, with the effect decreasing over time (Acs \& Mueller, 2008). The second is that nearly all organisations seem to go through similar stages of growth (Geroski, 1999; Greiner, 1972). In his analysis of early firm growth, Greiner (1972) proposes a five-stage model for firm growth, suggesting that firms undergo these five steps, following their inception: 1. Creativity. 2. Direction. 3. Delegation. 4. Coordination. 5. Collaboration. He states that between each stage firms must overcome new challenges in 
order to further grow and develop, a process he refers to as evolution and revolution (Greiner, 1972). The findings of Geroski (1999) echo this, asserting that firms progress through stages of growth at different rates, and experience different rates of growth within each stage. Therefore, it may be the case that gazelles are the firms that are able to progress more quickly through the stages of growth, and/or experience significantly higher growth rates within each stage.

Garnsey (1998) reinforces these findings, stating that firms must overcome a series of problems in order to generate growth, and those firms that are more able to overcome these challenges early in their lifespans are more likely to generate a dispoportionately high amount of employment, ie. gazelles. In her model, the majority of firms plateau after reaching the resource generation stage, as this is a sustainable point in a firm's growth, where they are able to sustain their operations, without the risk of reinvesting earned capital for future growth (Garnsey, 1998). However, Garnsey's model suggests that those companies who are able to raise "development capital" (Garnsey, 1998, p. 538), by being able to quickly mobilise or generate resources, and reinvest in future growth are likely to go through "growth reinforcement" (Garnsey, 1998, p. 530). In these cases, excess capacity creates the opportunity for further growth, which in turn generates the resources, capital, and confidence necessary to generate future excess capacity, and so on (Garnsey, 1998). These findings build on the growth theories of Penrose (1959), and Arthur (1990). Therefore, the firms that are able to enter the 'growth reinforcement' phase, are those that are most likely to be considered HGFs, or gazelles.

Corbett and Campbell-Hunt (2002) also considered how firms grow, examining the strategies that firms employ to sustain growth after experiencing a high-growth period. They described two main patterns of firm evolution, "going global" and "the gusher" (Corbett \& Campbell-Hunt, 2002, p. 513), with both exemplifying characteristics and factors found in the gazelles of other research. As with much previous research into the stages of firm growth (Garnsey, 1998; Greiner, 1972), Corbett \& Campbell-Hunt found that the firms most likely to succeed and sustain high-growth and competitive advantage were those who were able to adapt their operations and strategy to fit their rapid growth, and develop 
competitive capabilities that are important in their particular market. For example, customer service, manufacturing lead times, or quality control (Corbett \& Campbell-Hunt, 2002).

\section{Innovation}

Much like adopting a resource-based (Garnsey \& Mohr, 2011), age-based (Davenport et al, 2014), or location-based (Reichstein \& Dahl, 2004) analysis of growth patterns, examining growth within the context of technology-based firms has allowed management theorists to experiment with other factors that may have influence over the growth patterns of firms. One of the most significant of these factors is the set of behaviours that firms may undertake, that fall under the umbrella of 'innovation'.

The link between innovation and growth has been examined by a number of studies (Aghion \& Howitt, 1992; Geroski, 2005; Kenney, 1986), and is of great interest to real-world management practitioners (Carden, 2005; Hay \& Kamshad, 1994). However the strength of the relationship between the two has been much debated (Coad \& Rao, 2008; Garnsey, Galloway, \& Mathieson, 1994). Coad and Rao (2008) suggest that this debate may stem from differences in how innovation is defined in various studies, and the difficulty that arises from attempting to separate it from other variables and examine innovation as its own construct (Coad \& Rao, 2008). They also suggest that innovation varies across different industries, so measuring innovation and making comparisons across industries would be difficult. For example, in their study, Coad and Rao (2008) use patents and amount spent on research and development to quantify innovation in technology firms. Whereas Kenney (1986) takes a less quantitative approach to innovation, instead defining it a a process of "combining production factors in novel ways to produce old products more efficiently or to create entirely new products" (Kenney, 1986, p. 22). Much like other factors of growth discussed in this chapter, innovation may be only a small part of the high-growth picture, and it is possible that high-growth is the result of a complex interaction of variables, that may or may not be predictable and within a firm's control. 


\section{Summary and Research Aims}

While there is significant literature covering a multitude of growth, high-growth, and innovation factors, there has been relatively few attempts to synthesise all of these areas into a coherent picture of the precursors to high-growth across firms. Many of the studies discussed in this review employ only one definition of growth when measuring high-growth, and therefore consider relatively few factors as relevant potential precursors to said growth. There is also a lack of understanding of the interactions between management practices and high-growth when measured as revenue or employee growth. Many studies rely predominantly on theories of growth patterns and the effects that management practices have.

This research aims to contribute findings that may begin to fill some of the gaps in the literature around high-growth. Ultimately, this research seeks to build a more complete picture of the factors that lead to high-growth, particularly in high-tech firms, using the context of New Zealand technology firms, and in doing so, attempts to contribute to a better understanding of high-growth patterns of firms, and how firms may be better able to predict and control high-growth. In order to make these contributions, the research will investigate the following issues:

1. How do high-growth periods fit within the overall growth patterns of firms?

2. What are the characteristics of firms that appear to lead to high-growth periods?

3. How closely are management decisions and practices directly related to highgrowth? 


\section{Methodology}

This research aims to build on previous literature regarding the patterns and factors of highgrowth, and contribute to the field by attempting to address the gaps that remain around how external and internal factors may interact to result in high-growth for firms. In order to do this, the research takes a multiple-methodologies approach to examining HGFs, which allows for a broader understanding of the characteristics of HGFs.

Prior high-growth research has predominantly examined objective measures of growth, using quantifiable variables. Because this thesis aims to build on high-growth research traditions, this too will be seated firmly in a positivist research philosophy.

\section{Quantitative Methods}

Because high-growth is primarily considered to be based on revenue or employee growth (Coad et al, 2014; Garnsey \& Mohr, 2011), both of which are easily and accurately quantifiable variables, it is appropriate to employ quantitative methods to research highgrowth phenomena. Therefore, the primary part of this study will align with prior research into high-growth, by using similar quantitative methods to obtain and analyse data.

The main advantage of the quantitative methods employed in positivist research, over other research methodologies is the implied objectivism of the researcher, and the fact that quantitative methods allow for the discovery of an objective truth as the result of careful experimentation and hypothesis testing (Easterby-Smith, Thorpe, \& Jackson, 2012). While this research is exploratory in nature, and not seeking to answer or test a specific hypothesis, it does seek to uncover underlying relationships using concrete financial data that is not usually open to interpretation, and therefore adheres to elements of positivist research and employs quantitative methods. In the first instance, six quantitative definitions of high-growth are given, against which the remainder of the research will be conducted. These allow the research to definitively state which firms fall into high-growth categories, and which do not. For example, one of the definitions of high-growth used in this study is 
adapted from the OECD defintion of high-growth, which states that HGFs are those that have a growth rate of at least $20 \%$ per annum over a three-year period, which can be measured by the number of employees, or by turnover (Eurostat-OECD, 2007). This definition of high-growth either definitively rules firms in or out, based on quantitative data, and thereby, a clear conclusion of the extent of the growth can be drawn. This is in contrast to other research, which may employ more qualitative methods, and therefore asks firms to determine whether they considered themselves to be growing at a high-growth rate, and how they may justify this. Because qualitative methods allow more room for interpretation and bias on both the part of the researcher, and the participant, having a quantitative basis for the definitions and measurements of growth gives this research a more certain foundation on which to base the high-growth findings, and brings this research more in line with previous high-growth literature.

\section{Limitations}

Despite these advantages, positivist research employing quantitative methods has limitations that may play a role in preventing a fuller understanding of high-growth in firms. A large amount of the previous high-growth literature is rooted in positivist traditions, using quantitative methods; the research is conducted by measuring data against set definitions of growth in order to test a hypothesis of how factors affect growth. This means there has only been a small amount of discussion about the validity of these high-growth definitions, or the validity of measuring using high-growth as a measure of a firm's success in the first place. This is because quantitative methods do not generally provide us with the tools to analyse the validity of constructed definitions of firm success (although some have tried (Geroski, 1999)). Quantitative methods also do not provide the tools that allow firms to contribute their own comments or suggestions as to why the relationships between variables of high-growth may occur. Because a firm's comments cannot be quantified easily and analysed against a hypothesis without some level of interpretation on the part of the researcher, and they largely rely on the validity of the definitions of high-growth or firm success, these extra elements are often ignored in high-growth research. 


\section{Qualitative Methods}

While quantitative methods and a positivist research approach define the primary focus of this research, the limitations to quantitative methods are such that this research also employs elements of qualitative research. One of the significant gaps in the current highgrowth literature, as identified in the previous chapter of this thesis, is that most highgrowth research focuses on quantifiable measures such as revenue or employee changes (Delmar et al, 2003; Garnsey \& Mohr, 2011), and factors such as number of patents or monetary value of grants received (Coad \& Rao, 2008). However, relatively little attention is paid to the potential interactions between these factors, and the decision-making and management practices within organisations, that allow firms to capitalise on these factors, which in turn may lead to high-growth. Therefore, relationships may be found between easily quantifiable variables, but explanations for the relationships between the variables and high-growth may not be obtained. In order to attempt to fill this gap in the previous literature, and contribute to a better overall understanding of HGFs, this research thus employs qualitative methods to add an extra dimension to the research, and possibly uncover some explanations for the observed relationships in the quantitative findings.

The primary qualitative tool employed in this study is interviews, conducted with representatives of firms that are included in the dataset. These interviews are intended to probe respondents for explanations for the phenomena measured in the quantitative part of the research. In order to provide a more rounded and holistic picture of how a number of factors interact to affect the growth patterns of firms. Because these interviews are relatively structured, and the questions based on quantitative findings, this method may be considered less qualitative, or relatively more positivist than other survey methods. However, as O'Leary (2004) suggests, research is not always clearly defined between quantitative and qualitative, and perhaps the dichotomy itself is irrelevant; rather employing varying methodologies within the same research may contribute to more comprehensive, and well-rounded results (O'Leary, 2004), which, it could be argued, is particularly relevant to exploratory research such as this. 


\section{Limitations}

The most commonly raised limitations of qualitative methods are the potential subjectivity of interpretation and the lack of 'scientific' rigor or credibility (O'Leary, 2004; Sandelowski, 1986). However, this research attempts to overcome these limitations by removing as much subjectivity from the interview process as possible. By structuring interviews around the findings of the quantitative analyses conducted in the first part of the research, interviewees are not being asked to give their opinion, or comment on the validity of the findings. Rather they are simply asked to provide their explanation for the findings, and suggest a timeline of management decisions, changes or practices that preceded - and may have resulted in - the high-growth phenomena observed through quantitative methods. Despite this, the current research is conducted under the acknowledgement that this does not remove all subjectivity from the interview process. It relies on the organisation's representative considering a factor important enough to mention, and assumes that they have been involved in, or know about, potential decisions that could have led to some of the patterns observed in the initial findings.

This research also acknowledges the possible biases that may arise as a result of experimenter effects, which influence qualitative methods. As this research is primarily concerned with growth, and by extension, success of firms, organisations may be reluctant to discuss any negative trends, or factors that they consider may have affected their growth in negative ways. This may be because they are attempting to 'impress' the researcher, preferring only to talk about factors in which they could be considered to have succeeded. Similarly, driven by the motivation to say the right thing, or what psychologists have referred to as "demand characteristics" (Orne, 1962), which arise when participants are aware of what the researcher is looking at or for, participants may self-edit their answers to questions. For example, they may try to provide an explanation for a high-growth period or interaction between factors, when in fact one does not exist, at least from an organisational or management perspective. This is a limitation that can often be controlled in qualitative research by not telling the participants exactly what is being measured or observed. However it would not be possible to employ that control in this research, and still obtain the data needed from the interviews. Therefore, this limitation to the research is acknowledged. 
Overall, the mixed methodology approach chosen for this study allows this thesis to benefit from the advantages of both quantitative and qualitative methodologies, while overcoming some of the more significant limitations from both. By structuring interviews around existing quantitative findings, it reduces the potential for interview subjects to talk entirely to their own subjective experience, rather than the objective findings. Asking questions based on known objective findings may also help to reduce bias in responses, as interviewees cannot interpret or invent phenomena to suit their biases. Combining qualitative and quantitative methods may also provide some explanations for the quantitative findings, from the people who actually experienced the effects in their workplace. Therefore, adding another layer of depth and understanding to the high-growth findings in this thesis.

\section{Research Context}

While designing this research, much consideration was given to how the research database would be constructed, and which firms would be included in the sample. The conditions of this research are such that there needed to be sufficient firms included to provide a large enough sample to conduct proper exploration into how a range of factors influence highgrowth periods. There also needed to be a large enough number in the initial dataset that it would provide enough firms that fell within one of the definitions of high-growth used in the research, in order to properly conduct the analysis. Ultimately, it was decided that the initial database of firms could be derived, rather than constructed; therefore, this research is conducted using the firms included in the TIN100 database (Technology Investment Network, 2015). This research drew on reports published annually that rank and analyse the top performing (based on financial measures) technology companies in New Zealand each year. By basing the research in the context of New Zealand, it allows for a relative control over the factors that affect the firms within the database, and contributes findings from a context that has not often been explored in the growth literature. The criteria for inclusion in the TIN100, or the TIN100+ (the next 100 best performing technology companies) are as follows: 
1. The firm must have originated in New Zealand.

2. If the firm is no longer headquartered in New Zealand, or New Zealand owned, it must retain a meaningful presence in New Zealand.

3. The firm must operate in the high-tech manufacturing, ICT, or biotechnology sectors (excluding food technology and health supplements)

4. The firm must have developed their own technology-based intellectual property

5. The firm must generate at least $10 \%$ of their revenue offshore. (Technology Investment Network Ltd, 2014)

In addition to these criteria, firms usually self-nominate, and provide the information required for analyses by the Technology Investment Network, in order to be included in the TIN100 database. This database was chosen for the advantages it would provide for this research, although it was decided that not all of the information included in the TIN100 database was relevant to the current research. Therefore, a separate database was constructed with two intentions. The first was to condense the information to only what was relevant to the research, and eliminate any information that was irrelevant, and therefore clutter, such as website and contact details for each organisation. The second intention of the database was to collate all of the information from each separate TIN100 report, and present it in a way that was conducive to the analysis methods used in this research. For an example of a page from the research database, please refer to appendix 1.

Using an existing database, which already contained revenue, industry, location, product, and age information for each of the firms included, was a much more convenient way of obtaining a sample of firms, than having to build a database using information obtained from a wide range and number of different sources. Because of its nature as a selfnominating database, the firms had already given consent for the information in the database to be in the public domain. Therefore there are no ethical quandaries involved in using or publishing any of the information derived from the database.

The TIN100 reports have been published annually since 2005. Therefore, the entire database has been built up around data and information collected over a 10-year period. 
The longitudinal nature of this database is considered advantageous in high-growth research, as it enables observation of long-term growth patterns of firms, and allows the researcher to compare years in which firms had high-growth periods with years where they did not, and analyse the factors that may have led to this being the case. Employing a longitudinal database in this research aligns it with previous high-growth research (Delmar et al, 2003; Garnsey \& Mohr, 2011), as well as providing sufficient data to conduct an indepth exploration of how a number of factors may influence high-growth in firms over a period of time. Longitudinal datasets also allow for the examination of possible lag effects that may influence whether or not a factor is associated with high-growth. Datasets based on shorter periods may be less likely to produce results indicating that a factor has an influence on high-growth if that factor or influence is subject to lag effects, such as employee changes or patent approval.

By its very definition, the TIN100 database contains the best-performing technology firms in New Zealand (albeit with some possible inaccuracies due to the self-nomination aspect). Therefore, the firms included in the database are already considered 'successful' organisations by most definitions (for a full list of firms included in the database and their years of inclusion, please refer to appendix 2.). One would expect that, because these companies have indicated they are high performing across a range of metrics, there is a greater chance of HGFs being included in the database. Therefore, the TIN100 database is likely to provide sufficient firms that adhere to one or more of the definitions of highgrowth employed in this study, to allow the building of a secondary database to be used for further analysis - that of HGFs that conform to each definition of high-growth. In addition, because these firms, despite all being considered successful, come from a wide range of subsectors and locations, and cover a broad range of ages and sizes, it allows for further analysis of how these characteristics may influence high-growth.

While it is evident that setting this research in the context of New Zealand high-performing technology firms has significant advantages, it must also be acknowledged that this setting has some limitations. First and arguably most obviously, setting the research in a New Zealand context means the findings may or may not be applicable to other settings, 
particularly as New Zealand tends to have a much smaller population, economy, and GDP than other settings for high-growth research. These are all factors that could play a role in the growth patterns of a firm, and therefore the findings may be specific to this particular research setting. Similarly, by situating the research entirely within the context of technology firms, some of the factors considered for influencing high-growth, such as patents, may be more applicable to firms within this dataset, and may not be as relevant to other types of firms, and vice versa. This, once again, may limit the generalizability of the findings. Finally, the total size of the TIN100 database, including both TIN100 and TIN100+ companies, is 296 firms. Therefore, the sample of firms adhering to one or more of the definitions of high-growth used in this research is smaller. While this is still an acceptable sample size, a larger sample would likely result in more comprehensive and generalizable results.

\section{Sample Selection}

Because of the multiple methodologies employed in this research, there were two stages to sample selection. The first stage was simply to derive the sample of high-growth companies that would be examined, from the TIN100 database. In order to do this, six definitions, or criteria, of high-growth were chosen to provide a wide snapshot of the different ways in which high-growth is considered and measured. All of the definitions were based on revenue measures, primarily because this is one of the most commonly used measures of high-growth. The first and second definitions of high-growth were simply the ten firms experiencing the highest relative growth in terms of revenue across their inclusion in the database, and the ten firms with the highest absolute growth in terms of revenue over their inclusion in the database. These definitions are adapted from the work of Delmar et al (2003), who argue that both relative and absolute measures of growth are useful, as relative growth tends to be biased towards smaller and newer firms who are more likely to generate higher revenue growth relative to their current earnings. Whereas, absolute measures tend to skew towards larger firms that are more likely to have higher turnover each year. The third definition of high-growth is the OECD definition (Eurostat-OECD, 2007), which includes companies that have growth of at least $20 \%$ per year, over three years. The fourth definition 
is taken from the work of Halabisky, Dressen \& Parsley (2006), who suggest that HGFs are those who sustain $50 \%$ revenue growth for each of three consecutive years. The final two definitions of growth were similar to this, but adapted to allow for shorter periods of highgrowth. Therefore, firms who fall under definition five are those who were only able to sustain $50 \%$ revenue growth for two consecutive years, and definition six holds that highgrowth can be a short, one-year revenue burst of at least $50 \%$. A list of the companies that adhere to the criteria for each definition of high-growth can be found in appendix 3 .

Revenue data for all of the firms in the TIN100 database, excluding firms only included in the database for one year was analysed, and a sample size of 103 firms out of a total 262 eligible firms was obtained. The excluded firms were those where growth could not be measured as there was only one year of revenue data. The dataset was comprised of; 10 firms in definitions 1 and 2 each, 11 firms in definition 3, 2 firms each in definitions 4 and 5, and 92 firms in definition 6 . Some firms fit the criteria to be included in more than one definition of high-growth group.

The second component of sample selection in this research was conducted to select the firms that would be interviewed for the qualitative aspect of the study. Where the sample for the quantitative element of the study was simply selected based on revenue data, the organisations selected for the qualitative sample needed to be able to provide sufficient information to answer the questions of this research, therefore the selection needed to be somewhat more deliberate than the first part of the study (Luborsky \& Rubinstein, 1995). Because the purpose of the qualitative element of this research was to attempt to explain the findings obtained in the quantitative stage, the sampling for the qualitative interviews could not be conducted until preliminary findings were analysed, to determine what information the firms could provide. Therefore, based on the preliminary quantitative findings, a matrix of issues related to each factor was constructed, and the firms that these issues were observed in, were added to the selection matrix. This provided a picture of which firms may be able to provide explanations for which issues. This allowed deliberate sampling of firms based on two criteria. The first was to select firms that may be able to provide explanations for as many phenomena as possible, the second was to select firms 
that may be able to provide explanations for particularly rare or perplexing issues related to their high-growth - i.e. they were the only firm where the particular phenomenon was observed. An example of the elements in the matrix is the issue "patents are more likely to occur after the high-growth period than before, why might this be?" Therefore, companies who indeed received patent approvals after their high-growth period may be approached to provide explanation as to why this may be, or firms who received a patent before highgrowth but not after may be able to provide explanation as to why this was the case for them, and why they may have deviated from the observed trend. For the full company selection matrix, please refer to appendix 4 . The organisations selected the person to be interviewed themselves, guided by the criteria that the representative would need to have relatively complete knowledge of management processes and decision-making, company history, and significant company events or decisions that may have led to changes in growth patterns, in order to be able to provide the information required by the research.

\section{Data Collection}

\section{Quantitative}

The data collection methods for this research differed based on the variable being measured. As outlined earlier in this chapter, this research measures a number of different factors and their potential influence on high-growth. These factors are as follows:

1. Subsector - The TIN100 includes firms from three sectors, Hi-Tech Manufacturing, $\mathrm{ICT}$, and Biotechnology; however it also breaks these down into subsectors, to allow for more specific analysis of industries within these sectors. For the list of subsectors in each sector, refer to appendix 5

2. Location - All of the firms included in the sample are New Zealand firms, however regional analysis was also conducted

3. Age

4. Number of employees

5. Year of high-growth

6. Patents 


\section{Grants}

8. CEO and governance changes

9. Revenue stability

Because of the wide range of variables considered in this research, a number of sources were needed to obtain the necessary data.

The data for a number of the variables could be obtained directly from the TIN100 database alongside the firms being included. Therefore, the data collection for revenue, subsector, location, age, number of employees, and CEO changes involved transferring this information from the overall TIN100 database into the corresponding sheet in the functional database being used in this research (appendix 1) for each firm. The database enabled the building of a clear picture of the characteristics of each firm, and allowed for comparisons between firms, high-growth and not.

As well as this, the percentage change between each year of revenue for each firm was collated into a separate database to allow for the objective examination of growth patterns and high-growth periods. A copy of this database is provided in appendix 6 . The data for the year of high growth variable was obtained from this database, as it illustrated in which year a firm met the conditions for one or more definitions of high-growth used in this research. For example, the database allows one to see any trend of three or more years with growth above $20 \%$ per year, which year the high-growth began, and which year it ended.

The data collection for the patents component of the analysis was conducted by searching the name of each firm in the Intellectual Property Office of New Zealand (IPONZ) online patent database. This online register of patents has records of all patents applied for and granted in New Zealand since 1979, and some patents that have been applied for and are still undergoing assessment (New Zealand Intellectual Property Office, 2015). While the timeframe of inclusion in the database may exclude some patents obtained by companies in the sample before 1979, it is unlikely that a patent granted before 1979 is having a direct effect on firm growth patterns after 2005. Therefore, this is not a significant limitation to 
the research. It was also decided that only patents applied for by the organisation would be included, and not those applied for by an individual working within the organisation. This is to ensure consistency across organisations, and attempt to minimise conflating variables, which may affect the results of this research. Therefore, while this may exclude some patents that are associated with particular organisations, it was decided that this was the most valid way to carry out the data collection.

Data collection for the grants component of this research was carried out using a database of business-led grants administered by the Ministry of Business Innovation and Employment, which was obtained through private communication with the Ministry. The database contains all grants awarded to New Zealand businesses by the Ministry between June 2008, and March 2014. It is recognised that this period will exclude some companies who experienced their high-growth period before 2008, and who may have received grants before or during this time, and therefore this database does have limitations as a data source. However, it is the largest single source of awarded-grants information, and does provide enough information to be considered a useful source in an exploratory study such as this.

Finally, data collection for any observed changes in governance was carried out by recording the current directors, and director history, obtained from the Companies Office online database (Ministry of Business Innovation and Employment, 2016). This database contains records for all New Zealand companies, and overseas companies registered in New Zealand, and each record contains information about when the company was incorporated, company status, addresses, annual reports (if relevant), and director history. The current and former director data for each firm was transferred into the functional database.

\section{Qualitative}

The data collection for the qualitative aspect of this research involved structured interviews conducted face-to-face or by email with participants. The face-to-face interviews lasted approximately thirty minutes, and were conducted at the offices of each firm, in order to 
make the process convenient for the participants. Conducting the interviews at the organisation also enabled the possibility of more comprehensive or in-depth responses being given, as a result of "context-dependent memory" (Smith \& Vela, 2001), which means that managers are more likely to remember details of managerial decision-making if they are in the place where those processes took place. An information sheet was provided to participants, and they were given the opportunity to raise any concerns or questions that were not covered by said sheet. They were ensured of confidentiality and anonymity in reporting, and signed a consent form before conducting the interview, which can be found in appendix 7.

A structured interview technique was employed because the interviews were intended to draw out responses pertaining to specific events or trends in the firm's history. Where a semi-structured interview may be used to gain "authentic accounts of subjective experience" (Miller \& Glassner, 2011, p. 131), the interviews in this research were structured to obtain explanations that were as objective as possible, for observed phenomena. Therefore, questions were based on observed findings from the quantitative aspect of the research, and tailored to how the findings related to each firm. The interview contained questions relating to each of the variables that were analysed in the quantitative stage of the research (appendix 4).

\section{Data Analysis}

Much of the analysis conducted in this research is based on descriptive statistics, as they are sufficient indicators of high-growth characteristics in an exploratory study such as this. However, more in-depth statistical testing was also employed in areas where it could demonstrate how HGFs differ from others. Because of the number of variables being analysed in this research, the data analysis is broken down by variable.

\section{Subsector}

All firms, regardless of their growth patterns, were categorised based on subsector, which indicates the overall subsector trends for firms included in the TIN100 database. HGFs were 
then grouped into subsectors, within each definition of high-growth in order to compare across types of high-growth, and between high-growth and non-high-growth. In order to do this, chi-square tests were conducted for each definition of high-growth against each other, and against non-HGFs. A chi-square test was also conducted to examine any statistical significance in the difference between subsectors of high-growth and non-HGFs. Chi-Square tests were chosen for this research because they allow us to investigate whether there is a significant difference between the distributions of populations across categorical variables (Upton \& Cook, 2014). This is the case in this research, which compares the distribution of firms in each subsector across different types of high-growth, and between high-growth and non-high-growth.

\section{Location}

The data analysis for the location variable in this study was much the same as the subsector analysis, in that all firms were grouped based on location, as well as categorising each definition of high-growth individually. Descriptive statistics for the number of firms in each definition of growth in each location were obtained, and chi-square tests conducted for differences between each definition of high-growth, each high-growth definition against non-HGFs, and overall high-growth vs. non-high-growth.

\section{Age}

The age variable was measured based on the age of a firm was at the beginning of their high-growth period, compared with the first year of a firm's life marked by the year they were registered with the New Zealand Companies Office. Therefore, the analysis conducted for this variable was to obtain the mean, median, and range of ages of HGFs at the beginning of their growth period, based on each definition of high-growth. The same descriptive statistics were obtained for HGFs overall in order to build a more complete picture of the characteristics of HGFs. 


\section{Employee Numbers}

The analysis for this variable mirrors that of the age variable. The employee numbers for each firm at the beginning of their high-growth period was analysed to give the mean, median, and range of employee numbers within each definition of high-growth, and within the high-growth sample as a whole.

\section{Year of High-Growth}

Firms were grouped within each definition of high-growth, as well as within high-growth as a whole, based on the year in which their high-growth period began. This data was simply analysed based on frequency to determine commonalities between HGFs of similar and different types.

\section{Patents}

For each firm included in the high-growth sample, the number of patents awarded, and the year in which they were awarded, was recorded. This data was then aggregated based on each definition of high-growth, and the total high-growth samples. A chi-square test was conducted to examine the difference in the number of firms receiving patents in the highgrowth and non-high-growth samples. This was followed by an independent samples t-test to analyse whether the number of patents granted to firms in the high-growth sample differed significantly from the number of patents awarded to non-HGFs. Descriptive statistics of when patents were granted, in relation to high-growth periods were analysed based on frequency, and the number of patents received. This was also cross-analysed against subsector to test for any relationships, again based on descriptive statistics.

\section{Grants}

Grants were analysed based on the quantity awarded, rather than the monetary value of the grants given. The number of high-growth and non-HGFs receiving grants was obtained and a chi-square test was conducted to assess differences. An independent samples t-test was also conducted to examine differences in the number of grants awarded to firms in the high-growth and non-high-growth samples. The number of grants awarded to firms was also 
examined based on type of high-growth, with chi-square tests examining differences in the number of firms receiving grants between each definition of high-growth, and the non-highgrowth sample. Descriptive statistics, particularly frequency, were also examined for when grants were awarded in relation to the corresponding high-growth periods in relevant firms.

\section{CEO and Governance Changes}

CEO and director changes were considered if they occurred within three years either side of the growth period. This period was determined to allow for any lag effects that a new CEO or director might have on the growth of a firm, but not including so many to create noise in the analysis. Changes after the high-growth period were included to allow for examination of an organisation's possible responses to a high-growth period - or the ceasing thereof. Therefore, CEO and director changes were recorded for each HGF, and differences between each definition of high-growth were observed based on frequencies.

\section{Stability}

In order to analyse the influence of revenue stability on high-growth. Firms were grouped into four stability categories, based on observations of a firm's revenue patterns across their inclusion in the TIN100 database. All of the firms in the database were included, with the exception of firms who had only been in the database for one or two years, as this would be too short a time period to determine the stability of the firm's revenue. This left a total of 232 companies who would be categorised based on stability, and 66 firms whose inclusion in the TIN100 database was too short to observe stability. The criteria for consideration as a 'stable' firm was revenue movement in the same direction over a number of years, or changes in direction of no more than $10 \%$. Unstable firms were those that had two or more direction changes in their revenue in a three-year period, or those who had more than three revenue direction changes of more than $10 \%$ during their inclusion in the TIN100 database. Further, stability was considered irrespective of whether the revenue trends were overall positive (good) or negative (bad). Therefore a firm may be unstable, but have a positive overall revenue trend, and vice versa. This resulted in the construction of four stability classifications: Stable Good, Unstable Good, Stable Bad, and Unstable Bad. 
After firms had been classified, chi-square tests were conducted to analyse the differences between stability classifications for the high-growth and non-HGFs.

\section{Qualitative}

In most cases, data analysis of qualitative methods involves constructing some form of code in order to analyse themes or patterns in responses (O'Leary, 2004). However, this research is more concerned with how the qualitative findings related to the quantitative findings than to each other. Therefore, a code was not developed to analyse the qualitative. Instead, comments based on each area of analysis, or variable, were aggregated across firms, and then provided as context or explanation to augment the quantitative data and findings. 


\section{Findings}

\section{Introduction}

This chapter of the thesis presents the findings of the study, with the intention of building a better understanding of high-growth technology firms in a New Zealand context. The first part of this chapter presents the findings of the quantitative analyses that were conducted, and the second part of this chapter presents the qualitative findings obtained in interviews with five of the firms included in the database. The findings in the first part of this chapter are organised by variable, although some cross-comparisons are made, where findings are relevant to more than one variable. For example, the age of firms is not only considered for overall high-growth, but also based on the subsectors that HGFs belong to. This is done in order to provide a more comprehensive picture of the characteristics of HGFs. In the second part of this chapter, findings are organised by common themes that arose based on responses to questions that were asked in each interview. These findings are then discussed in the context of the wider literature, with practical implications in the next chapter of the thesis.

It is important to note that while six definitions of high-growth were considered overall, only definitions 3-6 were used for further analysis. This is due to the nature of definitions one and two (top 10 relative and absolute growth during inclusion in the TIN100 and/or TIN100+). Because these definitions consider overall growth, rather than year-by-year highgrowth, it is difficult to analyse the characteristics involved in the growth of these firms, as the rate of their growth may vary over their inclusion period. In addition, over their duration in the database, a firm's growth may actually decline in one or more years, but they may still be included in the first or second definition of high-growth employed in this study. Therefore, although these definitions may contribute to our understanding of how highgrowth can be measured, and the rates of growth that may be considered high-growth, in a database such as the one employed in this research, they are not included in further analysis. As a result, the firms that fall into definitions one and two of high-growth are not 
included in the HGF total, unless they also fit the criteria for another definition of highgrowth.

It is also important to note that, while results are reported for definitions four and five of high-growth, these definitions each had only two firms in the dataset. The sample sizes in these criteria are too small for the results to be considered meaningful individually. Therefore, they are reported to contribute to a better understanding of high-growth firms, but they are not discussed further.

\section{Quantitative Findings}

\section{Subsector}

The subsector variable is of interest in this research, because it provides insight into whether certain industries are more likely to generate high-growth companies than others. This will contribute some knowledge as to if and how the industry that a firm is in affects its growth patterns. Table 1 shows the frequency of HGFs across all definitions in each subsector.

\begin{tabular}{l|c|c|l|c|c} 
Subsector & HGFs & Total & Subsector & HGFs & Total \\
\hline Appliances & 1 & 7 & Digital Media & 3 & 14 \\
Wireless Solutions & 3 & 6 & Healthcare & 7 & 25 \\
Navigation Products & 7 & 11 & Software Development & 18 & 72 \\
Primary Sector Technologies & 3 & 17 & IT Services \& Support & 7 & 16 \\
Telco Solutions & 5 & 17 & Transportation & 4 & 9 \\
Energy Solutions & 0 & 7 & Airport Solutions & 3 & 6 \\
Financial Services & 9 & 16 & Production Equipment & 8 & 13 \\
Electronics & 10 & 25 & Other/Industrial & 9 & 36
\end{tabular}

Table 1. Number of HGFs compared to total firms by subsector.

In order to provide a more coherent image of the effects of industry types, these subsectors are considered within their overarching sectors, resulting in 35 companies in the Hi-Tech Manufacturing sector, 52 companies in the ICT sector, and 10 companies in the Biotechnology sector. A chi-square test was conducted to test for significant differences between the distributions of high-growth companies across the subsectors, compared to 
'normal' or non-HGFs. The test found no significant differences between high-growth and non-HGFs, returning a result of $\chi^{2}(2, N=296)=1.74, p=.42$.

\section{Definition 3.}

When subsector is considered in relation to each type of high-growth being analysed in this research, it may provide insight into whether different types of high-growth are more prevalent in different sectors i.e. some sectors are more likely to generate sustained highgrowth, but at a lower rate, and some are more likely to produce short-term, very high growth in firms. The distribution of firms across overarching sectors in definition 3 is as follows: 4 firms in High Tech Manufacturing, 7 firms in ICT, and no firms in Biotechnology. When compared to the distribution of the overall dataset, this result was found to be nonsignificant, $\chi^{2}(2, N=211)=2.16, p=.34$.

\section{Definition 6.}

Being the definition with the largest sample size of HGFs, definition 6 provides the best opportunity for comparison with a broader population of firms. Of the 92 firms that fit the criteria for this definition of high-growth, 34 belonged to the Hi-Tech Manufacturing Sector, 48 to the ICT sector, and 10 companies were from the Biotechnology sector. A chi-square test was conducted to test this distribution against the distribution of firms across subsectors that would be expected based on the overall dataset. This result was found to be not significant $\chi^{2}(2, N=292)=1.37, p=.50$.

\section{Location}

The companies in the TIN100 database, and therefore in the high-growth sample, are drawn from all over New Zealand. However, for ease of analysis, and to allow for comparison, the TIN100 database groups the location of firms based on five regions. They are Auckland, Hamilton, Central, Wellington, and South Island. In keeping with this format, the locations of HGFs in this research have been grouped the same way.

The relationship between high-growth and location is of interest in this research largely because it is a mostly-unexplored topic within high-growth research. Uncovering any 
relationships between the two variables builds a better understanding of the complete characteristics of HGFs. Table 2 illustrates where the HGFs in this sample were located within New Zealand.

\begin{tabular}{l|c|c} 
Location & HGFs & Total \\
\hline Auckland & 61 & 172 \\
Hamilton & 2 & 13 \\
Central & 4 & 15 \\
Wellington & 10 & 38 \\
South Island & 19 & 58
\end{tabular}

Table 2. Number of HGFs compared to total firms in each region

A chi-square test was conducted to examine whether there is a significant difference between the regional distribution of HGFs in this sample, and the expected regional distribution based on the normal population of firms in the TIN100 database. The result of this test was found to be non-significant, $\chi^{2}(4, N=296)=3.25, p=.52$. Evidently, companies, both high-growth and not, tend to cluster in Auckland, and be far less concentrated in other areas of New Zealand, but these results show that on its own, location is unlikely to play a role in whether a firm experiences high-growth or not.

\section{Definition 3.}

When examined based on type of growth, the regional distribution pattern of firms follows much the same pattern as overall. Table 3 shows the regional distribution of firms in definition three of high-growth.

\begin{tabular}{l|l} 
Location & No. of Firms \\
\hline Auckland & 5 \\
Hamilton & 0 \\
Central & 0 \\
Wellington & 4 \\
South Island & 2
\end{tabular}

Table 3. Number of Definition 3 HGFs in each Region

As well as examining the relationship between location and high-growth, may also be useful in the pursuit of a better understanding of the characteristics of HGFs, to analyse any relationships between location and specific types or definitions of high-growth. In order to do this, a chi-square test was conducted to analyse whether the regional distribution of 
firms in definition 3 differed significantly from the normal population. The result of this test was non-significant $\chi^{2}(4, N=211)=4.80, p=.31$. This indicates that location is unlikely to have an effect, at least on its own, on whether a firm meets the criteria of $20 \%$ revenue growth per annum over three years, in order to fit definition 3 of high-growth.

\section{Definition 6.}

Being the largest, and by extension, the most varied group of HGFs in this research, definition 6 allows for more robust analysis of the relationship between location and a particular type of high-growth. The type of high-growth considered in this definition, is very short-term, but very high revenue growth (at least 50\%). Table 4 shows the distribution of definition 6 firms across locations.

\begin{tabular}{l|l} 
Location & No. of Firms \\
\hline Auckland & 60 \\
Hamilton & 2 \\
Central & 4 \\
Wellington & 7 \\
South Island & 19
\end{tabular}

Table 4. Number of Definition 6 HGFs in each Region.

As with the other examinations of location effects on high-growth, a chi-square test was conducted to analyse whether the regional distribution of firms in this definition of highgrowth is significantly different from what would be expected based on the regional distribution of the TIN100 database. The result of the chi-square test was found to be nonsignificant, $\chi^{2}(4, N=292)=4.87, p=.30$.

\section{Age}

The age at which a firm experiences a high-growth period is important to consider for a number of reasons, which have all been discussed in the literature review. Age is considered against a number of other variables in this research, including the type, or definition of highgrowth, the subsector that the firm belonged to, and the age that the firm was when they entered the TIN100 database. It is important to note that age was based on the year a firm was registered with the New Zealand Companies Office, it is possible that some firms will appear to be younger than they actually are, due to re-incorporation under a different 
name. Table 5 shows the age that each firm was when they experienced their high-growth period (AAG), and the age they were when they entered the TIN100 database (AAE). Some firms in definition 6 of high-growth experienced more than one year of $50 \%$ revenue growth, but not consecutively, these firms have two ages in the centre column, each corresponding to the age at each individual high-growth year.

Table 5 demonstrates the wide range of ages at which companies experience high-growth periods. The youngest organisation experiencing high-growth was two-years old, and the oldest 65 years old. Elaborating on this further, the mean age for an organisation to experience a high-growth period was 17 years, and the median age was 14, indicating that the typical time taken to experience high-growth is somewhere in between. Also of interest was the relationship between the age at which companies entered the TIN100 database, and the age at which they experienced a high-growth period. In only 36 out of a possible 106 cases, the high-growth period occurred more than two years after the firm's entry into the TIN100 database.

When considered in relation to the types of firms that are included in this sample, the age characteristics of HGFs are further understood. By dividing HGFs based on subsector, we are able to observe any differences in the age characteristics of different types of HGFs. The mean and median ages at the time of high-growth for firms that fall into the Hi-Tech Manufacturing sector are 28 and 21 years old respectively. The mean and median ages at point of high-growth for firms in the ICT sector are 17 and 14 years old respectively, and for firms that sit in the Biotechnology sector, the mean and median ages at the onset of highgrowth were both 15 years old. 


\begin{tabular}{|c|c|c|c|c|c|}
\hline Company Name & AAE & AAG & Company Name & AAE & AAG \\
\hline 4RF Communications & 6 & 9 & Mcom & 8 & 9 \\
\hline Actronic & 29 & 29 & MedTech Global & 17 & 17 \\
\hline Allied Telesis & 13 & 14 & Methven & 6 & 6 \\
\hline Animation Research & 17 & 20 & Mole Map & 12 & 13 \\
\hline ARANZ Geo & 8 & 13 & Nautech & 16 & 17 \\
\hline ARANZ Healthcare & 8 & 9 & Navman & 19 & 19 \\
\hline Argent Networks & 6 & 6 & Navman Wireless & 3 & 7 \\
\hline Atrax Group & 7 & 12 & Neuren Pharmaceuticals & 5 & 8 \\
\hline Aucom Electronics & 30 & 32 & Next Window & 8 & 8 \\
\hline Aura Information Security & 7 & 7 & Ninja Kiwi & 6 & 6 \\
\hline Author IT Software & 11 & $11,15,17$ & Open Cloud & 6 & 10 \\
\hline Bank Link & 22 & 22 & Optimation & 13 & 14,16 \\
\hline Berill Control Systems & 0 & 8 & Orion Health & 12 & 13 \\
\hline Blackbay & 15 & 18 & Pacific Aerospace & 23 & 24 \\
\hline Buckley Systems & 15 & 19 & Peace Software & 21 & 22 \\
\hline Cadmus & 19 & 19 & Pingar & 5 & 5 \\
\hline Commtest Instruments & 16 & 16 & PharmaZen & 5 & 5 \\
\hline Compac Sorting Equipment & 21 & 24 & Phitek & 2 & 3 \\
\hline Conexa & 9 & 10 & Prolificx & 5 & 7 \\
\hline Cubic Defense & 20 & 26 & Provenco & 23 & 23 \\
\hline CWF Hamilton & 60 & 65 & Rakon & 38 & 40 \\
\hline Data Torque & 18 & 18,19 & Raztec & 14 & 15 \\
\hline Debit Success & 17 & 20 & Schneider Electric & 48 & 52 \\
\hline Designline & 21 & 23 & Screening \& Crushing & 3 & 5 \\
\hline Diligent & 20 & 20 & Serko & 8 & 8 \\
\hline Electronic Navigation & 61 & 62 & Simpl & 25 & 33 \\
\hline Enatel & 4 & 7 & Skope Industries & 63 & 64 \\
\hline Endace & 4 & 5 & Small Worlds & 4 & 7 \\
\hline Environmental Decontamination & 11 & 12 & SMX Ltd & 5 & 5 \\
\hline Finzsoft Solutions & 21 & 28 & Syft Technology & 7 & 10,12 \\
\hline Flo-Dry & 19 & 19,23 & Sysmex Delphic & 20 & 20 \\
\hline Frame Cad & 22 & 22 & Tait Electronics & 43 & 47 \\
\hline Fronde & 13 & 18 & TalkingTech & 23 & 24 \\
\hline Fusion Electronics & 14 & 14 & Technopak & 9 & 9,11 \\
\hline Genesis Research & 11 & 12 & TracMap & 8 & 8 \\
\hline GFG & 14 & 16 & Trimble Navigation & 14 & 23 \\
\hline Glidepath & 33 & 35 & Unlimited Realities & 13 & 14 \\
\hline Hayes International & 27 & 27 & Vega Industries & 37 & 39 \\
\hline Howard Wright & 47 & 47 & Vend & 5 & 5 \\
\hline Howick & 7 & 7 & Vista Entertainment & 12 & 14,18 \\
\hline HSA Global & 2 & 2 & Waikato Milking & 7 & 10 \\
\hline Intergen & 5 & 9 & Wellington Drive & 21 & 21 \\
\hline Intrahealth & 9 & 10 & Wherescape & 9 & 9 \\
\hline Invenco & 5 & 5 & Winscribe & 9 & 9,12 \\
\hline IPFX & 10 & 10 & Wyma Engineering & 0 & 4 \\
\hline JMP Engineering & 20 & 25 & Xero & 4 & 4 \\
\hline Kea Campers & 10 & 10 & Xlerate Technologies & 8 & 9 \\
\hline Magritek & 5 & 7 & & & \\
\hline Maskell Productions & 42 & 43 & & & \\
\hline Mastip Technology & 9 & 9 & & & \\
\hline
\end{tabular}

Table 5. Company ages at time of entry and high-growth 
When separated by definition or type of high-growth, the relationship between age and the type of high-growth achieved can be seen more clearly.

\section{Definition 3}

The mean age at time of high-growth for firms that matched the criteria for definition 3 of high-growth was 12.6 years, however the median, which controls for the influence of high or low outliers, sat lower at 9 years old.

\section{Definition 4}

The mean and median ages at high-growth reported for definition 4 was 12 years old. In order to provide some context, the individual companies were 20 and 4 years old at the time of their high-growth periods.

\section{Definition 5}

The average age at high-growth for the companies in this definition was 32 years old, with the individual companies being 24 and 40 at the initiation of their high-growth periods.

\section{Definition 6}

The age findings for definition 6 of high-growth largely reflect those of the overall highgrowth companies, likely because it is the largest component of the sample, and as such, has the greatest variation in firms included. The mean age at initiation of the high-growth period for companies in definition 6 was 17.1 years, and the median was 14 years old.

\section{Employee Numbers}

Within the high-growth literature, employee numbers are often used as a measure of highgrowth. However, in this research, the employee numbers within high-growth companies is considered a characteristic of high-growth, rather than a measure. Much like the age variable, this research considered both the number of employees within a firm at the beginning of its high-growth period (EAG), and at the point of the firm's inclusion in the TIN100/TIN100+ database (EAE). However, the change in employee numbers during the high-growth period (one, two or three years depending on the definition), was also 
considered in order to allow for comparisons between employee growth and revenue growth during a high-growth period. Table 6 demonstrates the employee numbers of firms at their inclusion in the database, and at the onset of their high-growth period.

Table 6 illustrates the lack of uniformity in the employee numbers of HGFs in this research. While the mean number of employees within a firm at the onset of a high-growth period was 87.3 , and the median was 50 employees, it is obvious from the inclusion of firms such as Neuren Pharmaceuticals, which had 5 employees at the time of its high-growth, and Tait Electronics which had 650, in the same list, that there is unlikely to be a direct link between the number of employees within a firm, and its potential for a high-growth period. The complete findings for the range of firm sizes at time of high-growth is as follows: largest = 650 , upper quartile $=100$, edian $=50$, lower quartile $=30$, smallest $=5$.

It could be reasonably expected that the type of firm, or the industry they operate in, affect the size of the organisation. Within this high-growth sample, subsector appeared to play a limited role in the size of a firm. When taking the number of people employed by a firm at the onset of their high-growth period, the mean number of employees for firms in the HiTech Manufacturing sector was 85 employees, and the median was 60 . Whereas, the traditionally smaller ICT sector had a mean number of employees of 100 , and the median was also 60. The Biotechnology sector, which is the smallest sector represented in this highgrowth sample had a mean of 33 employees, and a median of 29.

Interestingly, in 22 of the 106 total high-growth events, the number of employees at the onset of the high-growth period was lower than the number of employees the firm had at the beginning of their inclusion in the database. Out of the total 106 high-growth periods, 43 occurred in firms whose employee numbers were the same as at their entry into the database, however 37 of these firms were those who experienced their high-growth period, beginning in the year they were first included. 


\begin{tabular}{|c|c|c|c|c|c|}
\hline Company Name & $\mathrm{EAE}$ & EAG & Company Name & $\mathrm{EAE}$ & EAG \\
\hline 4RF Communications & 70 & 70 & Mastip Technology & 60 & 60 \\
\hline Actronic & 50 & 50 & Mcom & 25 & 65 \\
\hline Allied Telesis & 240 & 170 & MedTech Global & 45 & 45 \\
\hline Animation Research & 40 & 17 & Methven & 216 & 216 \\
\hline ARANZ Geo & 30 & 50 & Mole Map & 25 & 40,45 \\
\hline ARANZ Healthcare & 15 & 18 & Nautech & 70 & 72 \\
\hline Argent Networks & 35 & 35 & Navman & 500 & 500 \\
\hline Atrax Group & 25 & 12 & Navman Wireless & 75 & 80 \\
\hline Aucom Electronics & 90 & 100 & Neuren Pharmaceuticals & 18 & 5 \\
\hline Aura Information Security & 17 & 17 & Next Window & 40 & 40 \\
\hline Author IT Software & 29 & $29,45,40$ & Ninja Kiwi & 14 & 14 \\
\hline Bank Link & 105 & 105 & Open Cloud & 30 & 45 \\
\hline Berill Control Systems & 100 & 306 & Optimation & 115 & 160,100 \\
\hline Blackbay & 50 & 60 & Orion Health & 150 & 166 \\
\hline Buckley & 150 & 100 & Pacific Aerospace & 180 & 135 \\
\hline Cadmus & 80 & 80 & Peace Software & 375 & 200 \\
\hline Commtest Instruments & 30 & 30 & Pingar & 45 & 45 \\
\hline Compac Sorting Equip. & 125 & 102 & PharmaZen & 45 & 45 \\
\hline Conexa & 40 & 50 & Phitek & 22 & 65 \\
\hline Cubic Defense & 180 & 150 & Prolificx & 41 & 65 \\
\hline CWF Hamilton & 226 & 180 & Provenco & 200 & 200 \\
\hline Data Torque & 30 & 30,32 & Rakon & 400 & 500 \\
\hline Debit Success & 137 & 244 & Raztec & 12 & 7 \\
\hline Designline & 170 & 135 & Schneider Electric & 450 & 300 \\
\hline Diligent & 14 & 14 & Screening \& Crushing & 29 & 30 \\
\hline Electronic Navigation & 45 & 30 & Serko & 34 & 80 \\
\hline Enatel & 40 & 70,120 & Simpl & 150 & 42 \\
\hline Endace & 35 & 75,94 & Skope Industries & 300 & 200 \\
\hline Environmental Decontamination & 10 & 10 & Small Worlds & 30 & 30 \\
\hline Finzsoft Solutions & 51 & 42 & SMX Ltd & 23 & 23 \\
\hline Flo-Dry & 10 & 10,10 & Syft Technology & 30 & 23,20 \\
\hline Frame Cad & 42 & 42 & Sysmex Delphic & 66 & 66 \\
\hline Fronde & 200 & 190 & Tait & 960 & 650 \\
\hline Fusion Electronics & 37 & 37 & TalkingTech & 55 & 50 \\
\hline Genesis Research & 81 & 81 & Technopak & 10 & 10,22 \\
\hline GFG & 42 & 65 & TracMap & 26 & 26 \\
\hline Glidepath & 175 & 200 & Trimble Navigation & 200 & 230 \\
\hline Hayes International & 60 & 60 & Unlimited Realities & 19 & 28 \\
\hline Howard Wright & 40 & 40 & Vega Industries & 25 & 25 \\
\hline Howick & 18 & 18 & Vend & 90 & 90 \\
\hline HSA Global & 16 & 16 & Vista Entertainment & 42 & 61,177 \\
\hline Intergen & 112 & 210 & Waikato Milking & 150 & 80 \\
\hline Intrahealth & 50 & 70 & Wellington Drive & 26 & 26,50 \\
\hline Invenco & 97 & 97 & Wherescape & 21 & 21 \\
\hline IPFX & 30 & 30 & Winscribe & 22 & 22,40 \\
\hline JMP Engineering & 60 & 100 & Wyma Engineering & 70 & 73 \\
\hline Kea Campers & 37 & 37 & Xero & 90 & 90 \\
\hline Magritek & 10 & 10 & Xlerate Technologies & 27 & 30 \\
\hline Maskell Productions & 40 & 40 & & & \\
\hline
\end{tabular}

Table 6. Employee numbers by firm at time of entry and time of high-growth 


\section{Definition 3}

Much like age, employee numbers within a firm must also be considered through the lens of each individual definition of high-growth. This is especially relevant when considering the change in employee numbers that occurs during a period of high-growth, as each of the criteria has different timeframes, and different revenue growth thresholds that must be achieved in order to be considered a HGF. Therefore, the employee change that occurs in a firm who is considered high-growth over a three-year period is unlikely to match that of a one-year HGF.

In definition three, the mean number of people employed by a firm at the beginning of their high-growth period was 77, and the median 65. However, as table 7 demonstrates, the range of firm sizes varied significantly, with employee numbers ranging from 10 to 210 . Table 7 also illustrates the employee change that occurred during each firm's high-growth period. Surprisingly, one firm's employee numbers decreased during their period of highgrowth. However, of the remaining 10 firms, 8 had employee growth rates that were higher than the $20 \%$ per annum over three years revenue growth required to be considered a HGF in this criterion ${ }^{4}$. Only two firms had employee growth rates that approximately matched their revenue growth rates.

\begin{tabular}{l|ll} 
Company Name & Employees at Start & Employee Change \\
\hline Buckley Systems & 100 & 170 \\
Data Torque & 30 & 17 \\
Diligent & 14 & 250 \\
Enatel & 71 & 129 \\
Endace & 41 & -9 \\
Fronde & 190 & 141 \\
Intergen & 210 & 210 \\
Mcom & 65 & 219 \\
Technopak & 10 & 13 \\
Wellington Drive Technology & 26 & 34 \\
Xero & 90 & 1071
\end{tabular}

Table 7. Employee change during high-growth for definition 3

\footnotetext{
${ }^{4}$ It is important to note that although Xero and Diligent both met the criteria for three-year revenue growth, both had high-growth periods that actually lasted five years, therefore the employee change for these two firms is measured over a five year period, not a three year period.
} 


\section{Definition 4}

The mean number of employees at the start of a firm's high-growth period for firms that met the definition 4 criteria for high-growth was 52. Table 8 demonstrates the employees at the beginning of high-growth periods, and the employee change that occurred during highgrowth, for firms in definition 4 of high-growth.

\begin{tabular}{l|ll} 
Company Name & Employees at Start & Employee Change \\
\hline Diligent & 14 & 250 \\
Xero & 90 & 1071
\end{tabular}

Table 8. Employee change during high-growth for definition 4

For the firms in definition 4, both had employee growth rates that far exceeded the $50 \%$ per annum over three years required to be considered a HGF in this definition ${ }^{5}$, however as previously mentioned, the significance of this finding is likely to be limited by the small sample size.

\section{Definition 5}

The average employee number at the beginning of the high-growth period for firms in definition 4 was 301. Table 9 illustrates the employee change that occurred during highgrowth for firms in definition 4.

\begin{tabular}{l|ll} 
Company Name & Employees at Start & Employee Change \\
\hline Compac Sorting Equipment & 102 & 159 \\
Rakon & 500 & 271
\end{tabular}

Table 9. Employee change during high-growth for definition 5

Unlike definition four, the employee growth for firms in definition five was mixed in its relationship to their revenue growth. One firm had employee growth during the period that far exceeded the $50 \%$ revenue growth per annum over two years required for this definition of high-growth. However, the other firm only experienced employee growth of approximately half this rate.

\footnotetext{
${ }^{5}$ See footnote 1.
} 


\section{Definition 6}

The size of firms at the onset of their high-growth period varies greatly in definition 6, particularly as compared to the other definitions of high-growth used in this study, the mean number of employees within definition 6 firms at the time of high-growth was 83.5 employees, and the median was 47.5 employees. Table 10 demonstrates the variation in the employee numbers at the beginning of high-growth periods for companies in definition 6, and the employee change that occurred during the high-growth periods. The table also shows which firms in definition six experienced multiple non-consecutive years in which revenue growth exceeded the criteria to be included in definition six of high-growth.

As evident from table 10, the change in employee numbers over the high-growth period for firms in definition 6 was much more variable than in any other definition of high-growth, with a larger proportion of firms (13 out of 104), actually experiencing negative employee change during their high revenue growth periods. The average change in employee numbers for firms in definition 6 was 34.5, and the median was 14 . The fact that these results are far lower than found in the other definitions is unsurprising, as the firms in definition six only needed to experience one year of high-growth. This is opposed to firms in the other definitions, which had to experience two or three years of sustained high-growth in order to meet the criteria for those definitions. However, of the firms in definition 6, 43 (41\%) had absolute increases in employee numbers that matched or exceeded the required revenue growth required to be considered a HGF. This finding is also much lower than the results obtained for firms in definition 3-5. 


\begin{tabular}{|c|c|c|c|c|c|}
\hline Company Name & $\begin{array}{l}\text { Employees } \\
\text { at Start }\end{array}$ & $\begin{array}{l}\text { Employee } \\
\text { Change }\end{array}$ & Company Name & $\begin{array}{l}\text { Employees } \\
\text { at Start }\end{array}$ & $\begin{array}{l}\text { Employee } \\
\text { Change }\end{array}$ \\
\hline 4RF Communications & 70 & 5 & MCom & 65 & 55 \\
\hline Actronic & 50 & 27 & MedTech Global & 45 & 35 \\
\hline Allied Telesis & 170 & -17 & Methven & 216 & 144 \\
\hline Animation Research & 17 & 8 & Mole Map & 40 & 20 \\
\hline ARANZ Geo & 50 & 47 & Mole Map & 45 & 5 \\
\hline ARANZ Healthcare & 18 & 13 & Nautech & 72 & 11 \\
\hline Argent Networks & 35 & 50 & Navman & 500 & 265 \\
\hline Atrax Group & 12 & -1 & Navman Wireless & 80 & 770 \\
\hline Aucom Electronics & 100 & 20 & Neuren Pharmaceuticals & 5 & 0 \\
\hline Aura Information Security & 17 & 16 & Next Window & 40 & 25 \\
\hline Author IT & 29 & 21 & Ninja Kiwi & 14 & 26 \\
\hline Author IT & 45 & 0 & Open Cloud & 45 & 25 \\
\hline Author IT & 40 & 30 & Optimation & 160 & 0 \\
\hline Bank Link & 105 & 12 & Optimation & 100 & 50 \\
\hline Berill Control Systems & 306 & 94 & Orion Health & 166 & 76 \\
\hline Blackbay & 60 & 23 & Pacific Aerospace & 135 & -20 \\
\hline Buckley Systems & 100 & 50 & Peace Software & 200 & -30 \\
\hline Cadmus Tech & 80 & 50 & Pingar & 45 & 7 \\
\hline Commtest Instruments & 30 & 10 & PharmaZen & 45 & -20 \\
\hline Conexa & 50 & 0 & Phitek & 65 & 11 \\
\hline Cubic Defense & 150 & -5 & Prolificx & 65 & -35 \\
\hline CWF Hamilton & 180 & 140 & Provenco & 200 & 150 \\
\hline Data Torque & 32 & 3 & Raztec & 7 & 6 \\
\hline Debit Success & 244 & 106 & Schneider Electric & 300 & 40 \\
\hline Designline & 135 & 45 & Screening \& Crushing & 30 & 0 \\
\hline Electronic Navigation & 30 & 15 & Serko & 80 & 53 \\
\hline Enatel & 40 & 30 & Simpl & 42 & -7 \\
\hline Enatel & 120 & 80 & Skope Industries & 300 & 60 \\
\hline Endace & 75 & 25 & Small Worlds & 30 & 5 \\
\hline Endace & 94 & 27 & SMX & 23 & 2 \\
\hline Environmental Decontamination & 10 & 5 & Syft Technology & 23 & 2 \\
\hline Finzsoft Solutions & 42 & 48 & Syft Technology & 20 & 5 \\
\hline Flo-Dry & 10 & 0 & Sysmex Delphic & 66 & -2 \\
\hline Flo-Dry & 10 & 5 & Tait Electronics & 650 & 0 \\
\hline Frame Cad & 42 & 33 & TalkingTech & 50 & 4 \\
\hline Fusion Electronics & 37 & 19 & Technopak & 10 & 5 \\
\hline Genesis Research & 81 & -45 & Technopak & 22 & 1 \\
\hline GFG & 65 & -3 & TracMap & 26 & 2 \\
\hline Glidepath & 200 & -8 & Trimble Navigation & 230 & 60 \\
\hline Hayes International & 60 & 40 & Unlimited Realities & 28 & 14 \\
\hline Howard Wright & 40 & 5 & Vega Industries & 25 & 9 \\
\hline Howick Ltd & 18 & 2 & Vend & 90 & 133 \\
\hline HSA Global & 16 & 2 & Vista Entertainment & 61 & 23 \\
\hline Intrahealth & 70 & 14 & Vista Entertainment & 177 & 137 \\
\hline Intergen & 112 & 38 & Waikato Milking Systems & 80 & 45 \\
\hline Invenco & 97 & 4 & Wellington Drive & 26 & 44 \\
\hline IPFX & 30 & 40 & Wellington Drive & 50 & 103 \\
\hline JMP Engineering & 100 & 10 & Wherescape & 21 & 0 \\
\hline Kea Campers & 37 & -7 & Winscribe & 22 & 18 \\
\hline Magritek & 10 & 9 & Winscribe & 40 & 48 \\
\hline Maskell Productions & 40 & 35 & Wyma Engineering & 73 & 22 \\
\hline Mastip Technology & 60 & 5 & Xlerate Technologies & 30 & 11 \\
\hline
\end{tabular}

Table 10. Table 4. Employee change during high-growth for definition 6 


\section{Year of High Growth}

The year in which a company begins their high-growth period - or indeed experiences the whole thing if it is only a single year of high-growth, is important as it may provide insights into the external economic factors that enable some firms to grow at a rate far exceeding 'normal'. Even for companies with large annual revenue, a revenue spike in a certain year or years may be indicative of strong economic conditions in that particular industry, a favourable exchange rate, or a decrease in competition in target export markets.

The TIN100 database began in 2005, meaning the first measurable year was 2005-2006. The year in which the high-growth occurred or began is particularly important to consider in relation to different types of high-growth, as the changes in economic conditions from year to year may play a role in determining whether a company is able to sustain high-growth for a number of successive years, or only for a one-year period. Overall, it was found that $21 \%$ of all high-growth periods in the sample began in 2006, a further $18 \%$ began in 2010 , and 14\% originated in 2009 and 2014. The rest of the high-growth periods were distributed relatively evenly across the remaining years.

\section{Definition 3.}

To belong to this group of HGFs, a company must sustain at least $20 \%$ revenue growth per annum over a period of three years. Table 11 shows the frequency of high-growth periods in the group that began in each year.

\begin{tabular}{l|l} 
Year & Frequency \\
\hline $\mathbf{2 0 0 5}$ & 0 \\
$\mathbf{2 0 0 6}$ & 1 \\
$\mathbf{2 0 0 7}$ & 1 \\
$\mathbf{2 0 0 8}$ & 0 \\
$\mathbf{2 0 0 9}$ & 3 \\
$\mathbf{2 0 1 0}$ & 5 \\
$\mathbf{2 0 1 1}$ & 0 \\
$\mathbf{2 0 1 2}$ & 1 \\
$\mathbf{2 0 1 3}$ & 0 \\
$\mathbf{2 0 1 4}$ & 0
\end{tabular}

Table 11. Distribution of starting years for high-growth for firms in definition 3 
While the sample size in this group is relatively small, it is still possible to see that the overwhelming majority of three-year high-growth periods began in 2009 or 2010, among firms that fit the criteria for definition 3 of high-growth.

\section{Definition 4.}

The criteria for definition 4 of high-growth also requires a three-year revenue growth period, however the revenue threshold is significantly higher, at 50\% per annum rather than $20 \%$. The number of firms that adhere to this criteria is very small (2), and therefore much too small a sample size to observe any meaningful patterns in the years that high-growth periods originated. Yet it is still important to note the years in order to draw overall conclusions about the phenomena and characteristics of high-growth. In this case, both of the firms in definition 4 began their high-growth periods in 2010.

\section{Definition 5.}

Compared to the previously discussed high-growth groups, the firms in definition 5 had high-growth periods that began some years earlier. Of the firms in this group, one highgrowth period began in 2006, and the other in 2007. It is important to note that the criteria for this definition and definition four is largely the same, with the only difference being that this definition only requires two years of $50 \%$ revenue growth, not three. These findings for this definition may be somewhat affected by the Global Financial Crisis (GFC) of 2007-2008, as it may be part of the reason that the high-growth was not sustained for longer than two years.

\section{Definition 6.}

Table 12 demonstrates the years in which high-growth periods for firms in definition 6 began. 


\begin{tabular}{l|l} 
Year & Frequency \\
\hline $\mathbf{2 0 0 5}$ & 3 \\
$\mathbf{2 0 0 6}$ & 22 \\
$\mathbf{2 0 0 7}$ & 6 \\
$\mathbf{2 0 0 8}$ & 9 \\
$\mathbf{2 0 0 9}$ & 13 \\
$\mathbf{2 0 1 0}$ & 15 \\
$\mathbf{2 0 1 1}$ & 11 \\
$\mathbf{2 0 1 2}$ & 5 \\
$\mathbf{2 0 1 3}$ & 6 \\
$\mathbf{2 0 1 4}$ & 15
\end{tabular}

Table 12. Distribution of starting years for high-growth for firms in definition 6

These frequencies are particularly interesting in this group. First, there were ten companies in this group that had two high-growth periods, however they were not in consecutive years therefore they did not meet the criteria for definition 5 . There was also one firm that had three separate one-year high-growth periods. Of these companies, five had their second high-growth period occur only one year after their first had ended, for example, the highgrowth periods that were in the years 2006-2007 and 2008-2009.

\section{Patents}

Patents are often considered in high-growth research to be a good measure of innovation in firms. Because the assumption is made that the majority of the firms in this database are considered innovative, patents are not strictly being used to measure this factor. However, they are considered important for the potential influence they may have over a firm's revenue growth patterns. It was found in this research that 29 out of 96 high-growth companies received at least one patent in their lifetime. This was compared to 38 out of 200 non-high-growth companies that received at least one patent. Evidently, this is a much higher proportion of HGFs receiving patents, and when a chi-square test was conducted to test the statistical significance of this difference, a significant result was obtained, $\chi^{2}(1, N=296)=4.2, p<.05$, confirming that high-growth companies are indeed more likely to receive patents that non-HGFs.

However, the number of firms receiving patents was not the only aspect of this variable that was of interest in this research. Also considered was the number of patents that firms 
received, and whether firms who received more patents were likely to experience highgrowth. The mean number of patents obtained by HGFs was 1.60 for all HGFs, however when only HGFs that received patents are considered, the mean number of patents is 5.4 . For non-HGFs the overall mean is 1.30 , and the mean for firms that received patents is 6.82 . An independent samples t-test was conducted to analyse whether the difference in the number of patents awarded to each group was statistically significant, and the result obtained was found to be non-significant, $t(67)=-.49, p=.62$. Therefore, there does not appear to be a conclusive relationship between the number of patents awarded to a firm, and the potential for that firm to achieve high-growth. Therefore, the finding from this research is that HGFs are more likely to receive patents that non-HGFs; however, there is no significant difference between HGFs and non-HGFs in the number of patents they do receive if they are awarded patents.

In relation to high-growth, the period in which the patent was granted was also of interest. Understanding when patents occur in relation to high-growth periods in the same firms is important for building a more complete picture of the characteristics of HGFs. Of the 152 patents that were awarded to HGFs, 108 were awarded before the corresponding firm highgrowth period and 44 were awarded after. In addition to this, of the 28 HGFs that received patents, 14 of them received patents only before their high-growth period, 11 were granted patents before and after their high-growth period, and 3 were only awarded patents after undergoing high-growth. Of the 14 who only received patents before growth, 13 firms belonged to definition 6 of high-growth.

What is interesting to note about patents, is that the subsector or industry that a firm operates in, appears to play a role in patents awarded. Although, in the HGFs the effect is much less dramatic, the Hi-Tech Manufacturing and Biotechnology sectors are comparatively much more likely to be awarded patents than the ICT sector. For non-HGFs, the Hi-Tech Manufacturing sector received 142 out of the 259 patents, the Biotechnology sector received 113, and the ICT sector received only 4. Among the HGFs, the results are more similar when considered on the sector level, with the High-Tech Manufacturing sector receiving 66 of the 152 patents awarded to HGFs, ICT receiving 35, and the Biotechnology 
sector receiving 51 high-growth patents. However, it is important to note that among both groups, the subsectors of digital media and IT services and support both received no patents, and in the high-growth group, the subsectors of energy solutions and airport services also received no patents (although it is important to note that there were no energy solutions firms that fit the criteria for any definition of high-growth). Therefore, it can be concluded that there is a likely relationship between subsector and patents.

\section{Grants}

The awarding of government grants is another variable that has often been used in highgrowth research to indicate innovation in firms. In this research, grants awarded by the Ministry of Business Innovation and Employment, and later, Callaghan Innovation, were examined for their relationship to high-growth. Out of a total 96 HGFs, 56 were awarded at least one grant between 2008 and 2014. In the same period, 95 out of 200 non-HGFs were awarded grants by the government. A chi-square test was conducted to examine the significance of the difference between the two groups, and the result was found to be nonsignificant $\chi^{2}(1, N=296)=3.05, p=.08$, indicating that the proportion of high-growth and non-HGFs receiving grants was relatively similar, and neither group is much more likely to be awarded grants than the other.

In terms of the number of grants awarded to firms, the mean number of grants awarded to HGFs was 2.54 overall and 4.36 when only firms who received grants were considered. For the non-high-growth group, the mean number of grants awarded overall was 1.61, and 3.39 when only grant-receiving firms were considered. However, despite the difference in these means, the results of a t-test conducted indicated that the difference between the two groups was not significant, $t(150)=.89, p=.38$. Therefore, it appears that grant-receiving HGFs are unlikely to receive significantly more grants than grant-receiving non-HGFs.

\section{Type of Growth}

When considered in relation to the different types of high-growth being examined in this research we are able to analyse further the characteristics of high-growth, and whether they may be shared across different types of high-growth. The findings of this study show that of 
the 11 firms in definition 3, 9 received 29 grants, which gives a mean of 3.22 grants per grant-receiving firm, and 2.64 grants for the group overall. Of the two firms in definition 4, one firm received one grant. In contrast to this, both firms in definition 5 received grants, being awarded 18 between them. For definition 6, 51 out of 92 firms in the group were awarded grants, and they received 198 between them. Therefore, the mean for grant receiving firms in this group is 3.88 , and the mean for the group overall is 2.15 . A chi-square test was conducted to determine whether the number of firms receiving grants in definition 3 varied significantly from the number of definition 6 firms who received grants. The results of this analysis were found to be non-significant, $\chi^{2}(1, N=103)=2.81, p=.09$. However, when each of these types of high-growth was analysed separately against the non-highgrowth sample, the results were found to be significant for definition $3, \chi^{2}(1, N=211)=$ $4.91, p<.05$, and non-significant for definition $6, \chi^{2}(1, N=292)=1.59, p=.21$. This indicates that although overall HGFs are no more likely to receive grants than non-HGFs, if a firm meets the criteria for definition 3 of high-growth, then it is statistically more likely to have received a grant at some point.

\section{Governance Changes}

Governance in the case of this research was viewed as the most senior leadership of an organisation. Therefore, this includes CEO changes, as well as changes in the board of directors of each firm. It was found that 16 out of the total 96 firms included in the highgrowth sample had CEO changes within three years before the high-growth period. In terms of director changes, 51 of the 96 HGFs were found to have had new directors join their boards within the three-year period before high-growth, and 49 firms had directors leave their board within the three years prior to the high-growth period. Interestingly, though, these director entries and exits occurred during the same time period in only 30 firms. Therefore, 21 firms had new directors join their boards, with none leaving, and 19 firms had directors leave who were not replaced within the three-year period prior to high-growth.

In terms of changes that occurred following growth periods, it was found that only 23 of the 96 HGFs had changes occur in the board of directors in the three years following the highgrowth period, and no firms had CEO changes in the three years following their high-growth. 


\section{Definition 3.}

Because some of the firms included in the high-growth sample meet the criteria for more than one definition of high-growth, it is also important to consider these changes in relation to each specific definition of high-growth. It was found that 8 of the 11 high-growth companies in definition 3 had new directors join their boards within the three years prior to the high-growth period. 7 out of the 11 firms had directors exit the board within three years before the high-growth, and one firm had a change in CEO within three years prior to the high-growth period. Of the 8 firms who had new directors, and 7 firms who had directors exit, 6 were the same firm.

In addition to these findings, 4 of the firms in this definition of high-growth had changes to their boards of directors in the three years following their high-growth period.

\section{Definition 4.}

For this definition of high-growth it was found that both of the firms included in this group had directors enter and exit their boards within the three years leading up to their respective high-growth periods. However, neither firm had a CEO change prior to their growth period. It was also found that neither firm had a change to their board of directors following their high-growth period.

\section{Definition 5.}

The findings for this group were the same as for firms in high-growth definition 4 . Both firms had directors enter and exit their boards within three years prior to their high-growth period, and neither firm had a CEO change prior to high-growth. In addition to this, neither of the two firms in this definition had any governance changes in the three years following their high-growth periods.

\section{Definition 6.}

15 of the 92 firms in this definition of high-growth had a change in CEO within the three years prior to their high-growth periods. In addition, the 92 companies in total met the criteria to be included in definition 6, 45 firms had new directors join their boards in the 
three years prior to their high-growth periods. Similarly, 44 firms had directors exit the boards in the three years before their high-growth periods. However, only 30 the firms who had directors join their boards in the three years prior to high-growth, also had directors exit in the same period. Therefore, there were 15 firms who had new directors join their boards without there being an outgoing director, and 14 firms who had directors exit that were not replaced during the same period.

Only 21 firms out of the 92 in this group had governance changes occur in the three years following their high-growth period.

\section{Stability}

It was found that 29 out of the total 96 HGFs fell into the 'stable good' stability classification. This was the second largest group, behind 'unstable good', which had a total of 47 HGFs. As could be reasonably expected, the negative or downwards trending measures of stability were significantly lower for the high-growth group than the positive trends. 'Stable bad' consisted of only four HGFs, and 'unstable bad' had 12 HGFs in the group. Table 13 shows which firms were classified into each category of stability. Appendix 8 shows exemplary revenue charts for each type of stability. In addition to the firms shown in the table, four firms were only included in the TIN100 database for two years, therefore, it is impossible to classify their stability based on the available revenue data. These firms were Argent Networks, Invenco, Vend, and TracMap.

A chi-square test was conducted to examine any differences in the distribution of HGFs over the stability categories, against the total TIN100 database firms. The result was found to be statistically significant, $\chi^{2}(3, N=229)=34.00, p<.001$, indicating that the proportion of firms in the positively trending stability categories was much higher for the HGFs than the non-HGFs. It is important to note that the 'too short to tell' stability category was omitted from this chi-square test, as it is not actually a measure of stability, and it is assumed that the longer a firm is included in the database, the more opportunity there is to observe a high-growth period, therefore one would expect differences in this particular category. 


\begin{tabular}{|c|c|c|c|}
\hline Stable Good & Stable Bad & Unstable Good & Unstable Bad \\
\hline ARANZ Geo & Navman & 4RF Communications & Animation Research \\
\hline ARANZ Healthcare & Pingar & Actronic & Atrax Group \\
\hline Aura Information Security & Simpl & Allied Telesis & Conexa \\
\hline Bank Link & Trimble Navigation & Aucom Electronics & Data Torque \\
\hline Buckley Systems & & Author IT Software & Designline \\
\hline Cadmus Tech & & Berill Control Systems & Glidepath \\
\hline Debit Success & & Blackbay & Hayes International \\
\hline Diligent Board Member Services & & Commtest Instruments & Methven \\
\hline Environmental Decontamination & & Compac Sorting Equipment & Nautech \\
\hline Frame Cad & & Cubic Defense & Phitek \\
\hline Howard Wright & & CWF Hamilton & Prolificx \\
\hline Howick Ltd & & Electronic Navigation & Small Worlds \\
\hline HSA Global & & Enatel & \\
\hline Intergen & & Endace & \\
\hline JMP Engineering & & Finzsoft Solutions & \\
\hline Magritek & & Flo-Dry Ltd & \\
\hline Maskell Productions & & Fronde & \\
\hline Mcom & & Fusion Electronics & \\
\hline Navman Wireless & & Genesis Research & \\
\hline Ninja Kiwi & & GFG & \\
\hline Optimation & & Intrahealth & \\
\hline Orion Health & & IPFX & \\
\hline Peace Software & & Kea Campers & \\
\hline Provenco & & Mastip Technology & \\
\hline Technopak & & MedTech Global & \\
\hline Vista Entertainment Solutions & & Mole Map & \\
\hline Wellington Drive Technology & & Neuren Pharmaceuticals & \\
\hline Wherescape & & Next Window & \\
\hline Winscribe & & Open Cloud & \\
\hline \multirow[t]{18}{*}{ Xero } & & Pacific Aerospace & \\
\hline & & PharmaZen & \\
\hline & & Rakon & \\
\hline & & Raztec & \\
\hline & & Schneider Electric & \\
\hline & & Screening \& Crushing & \\
\hline & & Serko & \\
\hline & & Skope Industries & \\
\hline & & SMX & \\
\hline & & Syft Technology & \\
\hline & & Sysmex Delphic & \\
\hline & & Tait Electronics & \\
\hline & & TalkingTech & \\
\hline & & Unlimited Realities & \\
\hline & & Vega Industries & \\
\hline & & Waikato Milking Systems & \\
\hline & & Wyma Engineering & \\
\hline & & Xlerate Technologies & \\
\hline
\end{tabular}

Table 13. HGFs by stability classification

Definition 3.

Of the 11 firms in high-growth definition 3, 7 of them were considered 'stable good' firms, and a further 3 were considered 'unstable good'. Therefore, only one firm was classified in a negative stability category. 


\section{Definition 4.}

Both of the firms in definition 4 of high-growth were classified in the 'stable good' category.

\section{Definition 5.}

Both of the firms in high-growth definition 5 were considered to have 'unstable good' revenue patterns.

\section{Definition 6.}

Of the definition 6 firms, 28 of them were classified as having 'stable good' revenue. A further 44 were considered to be 'unstable good' firms. Therefore, as with the other definitions of high-growth, the majority of the firms had positive overall revenue trends, whether stable or unstable, however, perhaps as expected based on the shorter time threshold required to meet the criteria for this definition of growth, there is more instability present in this definition of high-growth than 3,4 , and 5 . There were four firms in this definition that were classified as 'stable bad' and 12 firms that were considered 'unstable bad'. The remaining four firms could not have their revenue stability examined as they were only included in the database for two years, which means that the only measurable period of revenue growth during their inclusion was one of high-growth.

The qualitative findings that have been illustrated provided the foundation for the questions in the qualitative sections of this research, the findings of which are outlined below.

\section{Qualitative Findings}

The findings in this chapter were derived from interviews conducted with five high-growth firms from the sample, who were asked to provide background information or explanations for the observed quantitative findings. 


\section{Precursors to High-Growth}

Perhaps as a result of the range of firms included in both the high-growth database, and the TIN100 overall, there were a number of different responses when asked if the respondent could name any changes to internal strategy, products or management, or external market conditions that may have been a cause or precursor of high-growth. It was found that none of the companies interviewed described any external stimuli or changes. Rather all of the companies responded that significant changes within the firms were likely precursors to the high-growth. The predominant factors named in interviews with firms were strategic overhaul, new organisational partners, acquisitions made, new products launched, and entering into new international markets. Each of the firms interviewed pointed to a number of these factors as preceding their high-growth, indicating that growth is driven by multiple modes of innovation occurring at the same time, rather than a single mode.

\section{Prior High-Growth}

Based on the finding that the average age at which a HGF enters into the TIN100 database is 15.6 years old, firms were asked whether they were able to recall a period of similar highgrowth prior to their inclusion in the TIN100, which may not have been considered in this sample. All of the firms interviewed suggested that they had significant periods of growth early in their lifespans, but were unsure or did not have figures to determine whether those periods would meet the criteria for the definitions of high-growth used in this study.

\section{Growth Sustainability}

"So while our cloud business had been growing very strongly, the rest of the business had been growing as well. But that stopped..."

-Firm One

Where possible, firms were asked for their explanations or suggestions as to why their highgrowth was not sustainable beyond their observed growth period. For firms whose highgrowth periods were still occurring at the time of the 2015 TIN100 report, they were instead asked whether they were projected to report the same level of revenue growth if 2016, and 
possible reasons why they may not. The majority of firms interviewed referred to changes in external market conditions to explain why their growth was not, or may not be, sustainable. For example, one firm described how their core market demand comes from an industry that had relatively stagnant economic conditions and decreased international demand; therefore, they in turn had less demand for the interviewed firm's product, resulting in a decreased growth rate. Similarly, another firm interviewed described how a change in government policy affected their high-growth, due to the significance of the demand from government departments that subsequently dried up. However, in both of these cases, and others, firms were able to maintain positive growth, albeit at a much smaller rate that in the previous year(s). Only one firm interviewed suggested that internal factors were to be blamed for the unsustainability of the high-growth period. This firm used the increased revenue obtained during the high-growth period to reinvest and develop a new product, resulting in lower profits for the subsequent two years. However, this firm then experienced another high-growth period because of the uptake of that product.

\section{Patents}

"Patents shield future revenue rather than giving you current revenue" -Firm Two

In order to understand further the relationship between patents and high-growth, interviewed firms were asked whether they felt their patents had a direct influence on a subsequent high-growth period, or whether undergoing high-growth made them more likely to apply for future patents. Firms responded that the products they have patents for would have gone to market with or without the patent, and it is likely that the product launches are more influential over growth than the patents. However, the firms also stated that the patents reduced competition for the product. Thus, while it may not have created growth, it allowed higher revenue generation from the new product to be sustained. Summarising the overall firm perspective on patents, one firm responded that "patents shield future growth rather than giving you current revenue", indicating less competition as a result of the patent allowed for better revenue generation from products in the future. 
Considering whether firms were more likely to pursue patents following a high-growth period, the majority of the firms interviewed responded that the financial cost of pursuing a patent was only one of the factors they considered, and was probably not the major concern, instead they focussed on factors such as long-term payoff of the patent, and whether it would be worth defending if a patent dispute arose. Therefore, the high-growth was not necessarily the reason further patents were pursued.

\section{Grants}

"We wouldn't have been able to get the revenue we got without the funding". -Firm Two

Because of the use-specific nature of the grants administered by MBIE and Callaghan Innovation, firms were only able to answer about their experience with the types of grants they had received. In this case, they were the R\&D Grants, and the Project Grants. Firms were asked questions depending on when they received the grant, if it was prior to their high-growth period, did the grant have a direct effect on the subsequent growth, and if it was following, did having the high-growth make the firm more confident in applying for grants, and did it aid in their application. Firms who answered the first of these questions overwhelmingly said that the grant was related to their subsequent growth, although each of these firms had received the Project Grant, which they said allowed them to develop a specific product or technologies that they could then launch to market, which increased their revenue. It could not be determined in this research if a different type of grant would have had a different/negligible influence on high-growth.

Firms who answered the second question had all received the R\&D Grant, which they stated assisted with future revenue, as it allowed them to be more speculative and experimental with research and development than they otherwise might have been, as they were not as concerned with risk. However, this type of grant was less attributed to high-growth than the Project Grant by the firms who were interviewed. 


\section{Governance Changes}

"The business experience the new Director brought was immense. It kept the company focused on moving from a locally focused company, to one with global aspirations." - Firm Three

In accordance with the findings regarding governance changes and how they may relate to high-growth periods, relevant firms were asked whether the high-growth period(s) could be directly attributed to changes in CEOs or boards of directors, or whether simultaneous changes were nothing more than coincidence. Of the companies interviewed, two had CEO changes prior to or during the high-growth period. Both of these companies responded that the change in CEO was an intentional strategic decision designed to stimulate future growth and aligned with changes to company strategy. One of the firms reported that the new CEO brought a "much needed" change in strategy and direction, and therefore was a major factor in the subsequent high-growth. The other firm reported that, although the new CEO started with the firm after the high-growth period had already begun, the intention was for the new CEO to sustain the growth, and develop further high-growth in the future.

In relation to changes in boards of directors, all except one of the companies interviewed responded that new directors added to their boards were the result of seeking individuals with the desired experience, who would be able to stimulate change and growth within the respective firms. Each of the firms interviewed about this particular factor suggested that the changes to boards of directors, especially the addition of new directors, would definitely be considered a positive influence on the occurrence of high-growth. The final company responded that the director additions were part of a general expansion, as they were still in the start-up phase of their business, however in the years following their high-growth period, they did begin to seek out experienced directors who could bring expertise to the firm. 


\section{Instability}

"Instability tends to undermine support and focus on strategy. When you have consistency of results, it is much easier to maintain support for your strategy, both from the board, and management, and shareholders. With increased inconsistency, that becomes more problematic. So from that perspective, you also spend more time fixing problems than driving growth."

- Firm One

I don't think anyone here would say that high growth is plain sailing and doesn't come with significant challenges - some anticipated and some that come out of left field. But what you do need with instability is excellent processes and expertise in place to deal with it so that it doesn't overcome you."

\section{- Firm Four}

Firms were asked about their responses to instability, and its influence over the potential for high-growth, regardless of their stability classification, as outlined earlier in this chapter. The only firms who were not asked this particular question in their interviews were those who were not included in the TIN100 long enough to determine their stability, as there is no objective data to verify their statements on their stability. The firms who answered this question overwhelmingly responded that instability, to a certain extent, was inevitable, and a relatively difficult aspect of managing a firm with the intention of pursuing high-growth. The main negative effect of instability that arose in the interviews was that instability tends to "undermine support and focus on strategy", with firms stating that instability distracted from longer-term strategies and plans, and that if instability becomes overwhelming, it can lead to a firm "spending more time fixing problems than driving growth".

However, the firms interviewed also postulated that instability could sometimes have a positive effect on growth trends. One firm suggested, "There is nothing like a crisis to drive a business", and therefore instability can sometimes be the primer for strategic and managerial changes that are needed to promote new rapid revenue growth. Overall, three main themes arose from interviews with firms in relation to coping with instability and using it to promote future high-growth. The first was that instability must drive positive change 
within the organisation, rather than a focus on the negative or unpredictable. The second main trend found was that instability could be positive for future growth if you have the processes, strategies, and expertise in place to deal with it, and not let it get the better of you. Finally, the third major trend in response to instability is that it can be positive if you are able to maintain buy-in and support from your key stakeholders, as it is they who will assist in future growth. 


\section{Discussion and Conclusions}

This thesis is centred on building a more comprehensive and complete picture of highgrowth in firms, using technology firms in New Zealand as a contextual example, as well as a sample on which to base the research. Previous chapters of this thesis have discussed the importance of high-growth as an academic pursuit for management theorists, and outlined the shortcomings of existing research in this area. Using a mixed-methodologies approach to research, this thesis has identified a number of factors that may play a role in highgrowth, and thereby, provided the foundation for these factors to be discussed in relation to existing knowledge about firm growth and high-growth in this chapter.

This chapter of the thesis will compare and contrast the findings of this research, with that of previous high-growth literature, and in doing so, will explore how a wide range of factors interact to result in high-growth periods for firms. In the interest of understanding and clarity, the discussion of findings will be presented by factor, and interactions between factors will be discussed where relevant. The qualitative findings will be discussed in relation to their corresponding quantitative variable. This chapter will also discuss the implications of these findings for previous, and future research, and how this research contributes overall to management knowledge and theory. In addition, limitations to this current research will be acknowledged and discussed, thereby providing scope for potential future research. Finally, practical implications of the findings of this thesis will be discussed in relation to management practices, and how these findings may be used by firms to evaluate and pursue high-growth.

\section{Discussion of Findings}

For this research, nine factors were considered in relation to high-growth, and the role that they may have played in causing a firm to undergo one or more high-growth periods. In order to determine what would be considered high-growth, this research utilised six definitions of high-growth, each with different criteria, and many of which were drawn from the work of previous high-growth theorists (Daunfeldt et al, 2010; Delmar et al, 2003; Garnsey \& Mohr, 2011). Therefore, each factor was not simply considered against high- 
growth as a whole, but also against different types, or criteria, of high-growth, therefore building a more complete picture of how high-growth develops.

\section{Subsector}

The findings of this thesis indicated no significant results in the relationship between subsector and high-growth, both when considered overall, and by individual definition of growth. Therefore, the initial suggestion from this finding would be that subsector, at least on its own, plays no meaningful role in whether a company experiences a high-growth period at some point. This is a finding which has been debated a number of times (Daunfeldt et al, 2015), with the unique characteristics of subsectors, rather than the subsectors themselves, the focus of high-growth research. For example, in the aforementioned paper, Daunfeldt et al found that contrary to previous belief, sectors with high R\&D focus had a lower proportion of HGFs than low R\&D focus industries, and in contrast, HGFs were more prevalent in knowledge-intensive service sectors. Similarly, Adriana Di Liberto argued in her 2013 paper that lower-skilled sectors might be excluded from much high-growth research or observations because the relative price dynamics are not considered, and that, if this were rectified, sectors such as tourism may feature a much higher proportion of HGFs (Di Liberto, 2013; Lanza \& Pigliaru, 1994). Part of the reason that no significant effect of subsector on high-growth was observed may be that the characteristics of the subsectors included in this research were too similar, and that it is these characteristics that make the difference when analysing HGFs, rather than the subsectors themselves. While the subsectors included in this research could be considered largely dissimilar, they do all belong to the larger category of high-earning technology firms. In saying this, while no significant findings were obtained for the direct effect of subsector on high-growth, subsector did appear to play a role in the granting of patents to firms, which may have in turn generated high-growth. This relationship will be discussed later in this chapter.

\section{Location}

In much of the previous high-growth literature, location factors were of interest not because of the effects that location may have on high-growth, but rather the effects that high- 
growth companies have on their local and national economies (Acs \& Varga, 2005; Coad et al., 2014). This research looked at possible relationships in the opposite direction, instead investigating what effects location may have on the occurrence of high-growth in the first place. While this is a much less-frequently discussed relationship in the high-growth literature, Li et al (2016) have argued for its relevance to the field, as understanding where high-growth firms base themselves, and why, may help with understanding the factors that lead to their high-growth.

As with the subsector variable, this research found no significant difference in the distribution of HGFs across regions, compared to the normal population of the TIN100 database. This was the case for overall HGFs, and when analysed by type or definition of high-growth. This finding suggests that on its own, location plays very little or no role in the occurrence of high-growth in firms. However, the finding that the majority of firms in the sample, high-growth or not, were based in Auckland may provide some reinforcement for previous theories of firm growth. Previous literature on firm growth patterns and highgrowth have suggested that HGFs tend to cluster together (Acs \& Varga, 2005; Frederick, 2004; Garnsey \& Mohr, 2011; Stam, 2005). While it is true that the vast majority of HGFs in this sample were based in Auckland, a non-significant result was obtained because the vast majority of non-HGFs were also based in Auckland. Therefore, based on this research, and previous, it may be possible to draw the conclusion that the defining feature of location that may have an impact on the occurrence of high-growth, is the presence of other high-growth or successful firms in the same area or region.

\section{Age}

Gazelle theory states that the firms who are most prone to rapid revenue and employee growth are typically small and young (Acs \& Mueller, 2008; Birch, 1987). Therefore, one would assume that the findings of this research would indicate that high-growth periods occurred relatively early in a firm's lifespan. Interestingly, this was not the case, rather the mean and median ages at which firms experienced their high-growth periods put them welloutside the 'young' firms usually considered to be gazelles, especially when it is considered that the average age of contemporary firms has found to be only 15 years, compared to 67 
years in the 1920s (Lam, 2015). However, it is important to note that when interviewed, all of the firms responded that they felt they had achieved similar levels of high-growth prior to their inclusion in the TIN100 database, although only one firm answered that they were certain their early growth would have met the criteria for at least one definition of highgrowth. Therefore, it may be possible that a number of older firms, who experienced highgrowth periods in this sample, also experienced high-growth earlier in their lifespans, which was not captured or analysed by this particular research. A number of theorists have argued that high-growth is unlikely to be sustainable, and the growth patterns of HGFs are likely to decline at the end of the high-growth period (Coad et al, 2014; Coad \& Holzl, 2009; Daunfeldt \& Halvarsson, 2015). Although Coad \& Holzl (2009) do add the caveat that this is the case for small firms only, and larger HGFs do not seem to adhere to the same pattern. However, in this research, the firms interviewed ranged in size between 20 and 300 employees, and the overall high-growth sample had a much wider age range. Therefore, it may be possible that the findings of previous high-growth research, which holds that HGFs "are essentially one-hit wonders" (Daunfeldt \& Halvarsson, 2015, p. 361), may not be true in a New Zealand context.

Another phenomena that arose serendipitously while analysing the age data, was the fact that the vast majority of high-growth periods in this sample occurred no more than two years following the firm's inclusion in the TIN100 database. Keeping in mind that the TIN100 uses a self-nominate model to obtain firm data, it begs the question of firms being are able to predict growth in the near future, which motivates them to self-nominate for inclusion perhaps when they would not have previously. This may be because knowing that relatively high-growth is predicted increases feelings of legitimacy within the company's management, or because firms feel they will be represented better in the database if they know their growth trends are going to be disproportionately positive. Therefore, firms are encouraged by this increased feeling of success or legitimacy. Conversely, it may also be possible that inclusion in the TIN100 database, known as an aggregation of New Zealand's most successful technology firms, increases outside perceptions of firm legitimacy. Previous research has suggested that perceptions of legitimacy can act as a resource that in turn generates and attracts more resources (Zimmerman \& Zeitz, 2002). Therefore, adopting the 
behaviours of other successful organisations in the industry can have positive effects on growth (Khaire, 2010; Schuman, 1995). As a result, it may be inclusion in the TIN100 that is one underlying cause of the high-growth period.

\section{Employees}

Employee numbers were of interest in this research due to two main concerns. The first was the size of firms by employee numbers at the onset of their high-growth periods. The second concern was the change in employee numbers during the high-growth period.

The number of employees at the onset of high-growth periods was especially of interest in this research because of the evolving picture of HGFs, or gazelles, and their defining characteristics. Initially gazelles were described as being predominantly small firms (Acs \& Mueller, 2008; Birch, 1987), however as research in this area has progressed, it has now become common theory that HGFs may not necessarily be small, and that age rather than size is the defining factor (Coad et al, 2014). The findings of this research indicate that the majority of firms who fit the criteria for at least one definition of high-growth could be considered medium to large employers. Particularly in the context of New Zealand, in which the threshold for small firms is typically considered to be less than 20 employees (Ministry of Economic Development, 2011). This fits with the current theories of high-growth, being that size is not the most important factor in determining whether a firm will have a highgrowth period, but it is still much less likely in larger firms.

The second concern regarding employee numbers in this research was the degree to which they changed as firms underwent a high-growth period. This particular analysis was informed by the research of Coad et al. (2014), who stated that whether employee numbers or revenue was used as a measure of high-growth was relatively inconsequential to the results obtained. A number of other theorists have echoed the sentiment that employee and revenue growth can be used interchangeably (Daunfeldt et al, 2010), despite the fact that correlations between the two have been found to be only moderate (Shepherd \& Wiklund, 2009). Interestingly, this research found that when changes in employee numbers 
were compared to the changes in revenue for each firm across the different criteria for each definition of growth, only definition 6 had fewer than half of its firms whose employee change would still qualify them as a HGF if used instead of their revenue growth. The remaining three definitions of high-growth analysed indicated that, if employee growth were used instead of revenue growth, all but one of the firms in definition 3 and 5 , and all of the firms in definition 4, would still meet the criteria. This provides further evidence for Coad et al (2014), and the finding that employee change and revenue change can be used relatively interchangeably to measure high-growth. This may be because firms are not only hiring new employees as they grow, but are also required to take on different types of employees as they grow, in order to deal with issues that arise with scaling up, and increased resource flow. This may contribute to employee growth as revenue increases, making them relatively interchangeable as measures of high-growth.

\section{Year}

The year in which a firm's high-growth period began was of interest to this research, largely because the TIN100 database, which the sample was drawn from, covers 10 years of reporting, between 2005 and 2015. Having a longitudinal database to draw from allowed this research to analyse trends in growth patterns over time, and observe any clustering effects of high-growth in the sample firms. Analysing the years in which high-growth tends to occur allows for examination of the external or market factors that may be at play in prompting high-growth. For this reason, how high-growth was affected by the Global Financial Crisis of 2007-2008 was particularly of interest in this research. In finding that greater than $20 \%$ of the high-growth periods began in 2008 or 2009 in this sample, this research indicates that some firms may be able to avoid or overcome the negative effects of even a global economic downturn to maintain growth, or even high-growth.

One possible reason for this was highlighted in the firm interviews, with one firm responding that they had a strategy during that period to form partnerships with internationally recognised brands in order to build a competitive advantage over their rivals, and for increased financial and strategic support during the period. This was also raised when discussing the stability variable during firm interviews. Nearly all of the firms spoken 
to conceded that instability was somewhat inevitable due to external market changes, however it does not necessarily need to have a negative impact on firm growth, if the firm has the resources and strategy to modify behaviour during difficult economic periods. This finding largely echoes that of Moore and Mirzaei (2016), who found that the global economic crisis had varying effects on industry, and not all firms and industries were as affected as others, depending on a number of controllable conditions such as reliance on external finance and trade-credit (Moore \& Mirzaei, 2016).

\section{Patents}

Central to this research and others in the high-growth literature is the idea of innovation (Aghion \& Howitt, 1992; Coad \& Rao, 2008; Davenport et al, 2014). Because of the nature of the database that the firms in this study were derived from, being a database of highearning technology firms, the assumption was made that all of these firms were at least to some degree, innovative. Therefore, rather than use patents as a measure of innovation by which we could classify firms, as other studies have done (Coad \& Rao, 2008; Cohen, Nelson, \& Walsh, 2000; Griliches, 1990), this research explored the influence of patents as a precursor factor to growth, and how one may influence the other and vice versa. The quantitative findings of this study indicated that HGFs were more likely than those who did not experience high-growth to receive at least one patent since their inception. However, there was no relationship between the number of patents received and the occurrence of high-growth. In order to attempt to explain this relationship further, relevant companies were interviewed about patents they received and whether they thought there was a direct relationship between being granted the patents and high-growth. The majority opinion of interviewed firms was that their high-growth was the result of new products being launched, which lead to new demand and increases in existing demand. However most of the firms stated that the products would have been launched with or without the patents. Therefore, it is unlikely that patents themselves are a direct driver of high-growth. However it is possible that they can make high-growth more sustainable, as many firms pointed out that while new products do not rely on patents, they do protect against competition and replication of successful products. 
Comments were also made that the financial cost of patents is not the only factor considered when deciding whether to apply for patents, and therefore not all new technologies or products that enter the market will be patented, as it may not be worth it to the firm in the long run. This is an issue that Coad and Rao (2008) touch on in their article, stating that one of the downsides to research involving patents is that they are not a direct measure of innovative product development. While that is not the focus of this research, it does call into question the causality of the relationship between patents and high-growth that seemingly appears in the quantitative findings, only to be challenged by the qualitative interviews, and previous literature on the subject.

\section{Grants}

This research found that there was no significant quantitative difference between the numbers of grants received by HGFs when compared to non-HGFs. This may be because all of the firms in the database are considered innovative technology firms, and therefore are more likely to be awarded grants, regardless of their growth patterns. It was also found that there was no significant difference in the proportion of HGFs receiving grants compared to non-HGFs but grants are still an area of interest in the examination of firm growth patterns (Davenport et al, 2015). Interestingly, while no significant quantitative findings were obtained, firms that were interviewed saw grants as being more directly related to growth than the awarding of patents. This may be particularly the case in a New Zealand context, because of the way grants are awarded. Callaghan Innovation, the science and technology funding and support body in New Zealand, awards four types of grants, Getting Started Grants, Growth Grants, Student Grants, and Project Grants (Callaghan Innovation, 2015). It is the latter of these that was particularly cited as being a leading driver of high-growth among firms in this research, as it provides funding for specific projects, which allows for the development of specific products or technologies that can then be taken to market. This finding reinforces that of Adam Jaffe and Trinh Le (2015), who also found that the most significant outcome of grants is the introduction of new goods and services to the market (Jaffe \& Le, 2015). 
The way in which grants are awarded to firms was also of interest in this research. Whether grants were awarded to HGFs before or after their high-growth period was analysed, in order to attempt to answer some of the questions raised by previous discussions about grants and growth (Davenport et al, 2015; Jaffe \& Le, 2015). This research found that grants were more likely to be awarded to high-growth companies after their high-growth period, suggesting that grants are a response to positive revenue growth, rather than a cause. This may be because firms feel more confident in applying for grants if they have experienced positive revenue growth, or it may be a result of funding bodies taking more notice of firms who have undergone high-growth. However, despite the prevalence of grants awarded after high-growth periods, the interviews indicated that those that do get awarded prior to highgrowth are a significant driver of the subsequent growth. This may be a symptom of the different funding structures and conditions present in each type of grant awarded by Callaghan Innovation, with some being particularly useful for driving growth, and other types being more useful in sustaining performance and future innovation without rapid revenue growth.

\section{Governance Changes}

While the relationship between management and the growth of firms has been explored a great deal, largely spurred by Edith Penrose's seminal work The Theory of the Growth of the Firm (Penrose, 1959), contemporary management growth research tends to focus narrowly on the entrepreneur, and early start-up firm growth (Audretsch, Keilbach, \& Lehmann, 2006; Garnsey, 1998). This research, in an attempt to contribute new knowledge to this field, examined how the management and governance changes within more established firms may influence the occurrence of high-growth periods. Only a small number of firms had CEO changes in the years prior to their high-growth periods, indicating that perhaps a certain level of management stability is needed in order for the momentum towards highgrowth to build. If this is the case, it would reinforce the theories of Garnsey (1998) and Chetty \& Campbell Hunt (2003), who state that growing firms require experienced and stable managers that are able to contend with changes in revenue and other resources. Certainly, the evidence from this research suggests that HGFs are more likely to be those that have few management changes, and a stable CEO. However, when companies whose 
CEO did change within the three years prior to their high-growth period were interviewed, they pinpointed the new CEO as one of the primary drivers of high-growth. The specific reasoning behind this varied for each firm, but responses were largely based around the theme of new CEOs introducing useful experience and new strategic directions to the firm, that allowed them to grow at a faster rate than previously achieved. This finding also reinforces previous work of Garnsey (1998), in that she also argued for the event of highgrowth being prompted by much-needed organisational change, especially when conducted under experienced management. Therefore, it may not be a simple case of one is more likely to lead to high-growth than the other, rather a firm's individual needs dictate whether they are more likely to benefit from stable, unchanging management who understand the firm, or a managerial overhaul lead by a CEO with new experience and direction.

The relationship between governance and high-growth is a much more underexplored area than that of CEOs and their role in growth. While some management literature has approached the subject of governance and growth, it is usually either a broad approach to all firms (OECD, 2012), or an exploration of changes to board structures or dynamics (Nelson \& Levesque, 2007). This research instead intended to broadly examine the role that directors may play in the potential for high-growth periods in firms, and found that more than half of the HGFs had directors join and exit their boards in the three years prior to their high-growth periods. The qualitative findings can provide some evidence as to why this may be the case. Each of the firms interviewed, to whom this finding was relevant, answered that the changes in directors were intended to bring new ideas and directions to the board, and were largely driven by previous issues. One firm interviewed even stated that the chair had lead a board review due to dissatisfaction with prior performance, and they believed that this was a very large part of the reason they subsequently underwent a high-growth period. Therefore, it is likely that changes in boards of directors are deliberate decisions made to try to prompt high-growth where it has not been occurring previously. It follows, then, that the finding of this research that a minority of HGFs had changes to their boards after their high-growth period, is common sense. After undergoing strategic governance changes intended to spur high-growth, firms will be unwilling to change a winning formula after that high-growth period has ended. 
In relation to the different types of growth examined in this study, definition 6 was found to be the only type of high-growth in which fewer than half of the HGFs had director changes prior to their high-growth periods. This may be an indication that the longer high-growth periods described in the other definitions of high-growth are the result of deliberate strategic decisions, such as governance changes, whereas the one-year growth spike described by definition 6 may be the result of less controlled factors, such as market conditions, or chance rather than just skilful decision-making. This may also explain why the growth periods in this definition are less sustainable, because good management and governance do not lead them.

\section{Stability}

In 1999, Geroski claimed that the financial performance of firms was "erratic" (Geroski, 1999), and while this does not mean that firms cannot have sustained periods of highgrowth, in Geroski's mind, firm growth rates were largely random - and thereby unstable. In contrast to this, a number of papers in the high-growth literature have put forward stagetheories of growth, which assume that firm growth follows a relatively predictable growth models that include different stages of resource and revenue generation (Garnsey, 1998; Greiner, 1972). Evidently, the stability of firm growth is something that is of great interest, particularly when attempting to understand the evolution of HGFs. This study found that 76 out of the total 96 high-growth companies analysed were classified as having 'positive' revenue growth trends, although perhaps the more interesting finding was that 20 of the firms had 'negative' revenue growth trends, despite having at least one high-growth period during their inclusion in the database. However, of the firms that had positive revenue trends, there were only 29 that could be considered stable, the remaining 47 had unstable revenue growth. Further, only two of the unstable firms were able to sustain their highgrowth revenue periods for longer than one year, although some did have more than one single-year high-growth period during their inclusion. Therefore, while instability does not appear to prevent high-growth, it may act as a barrier to sustained high-growth, which lasts longer than one financial year. The qualitative findings were able to provide some explanation as to why this may be the case. The theme that arose while interviewing firms was that some degree of instability is inevitable, due to outside factors that have influence 
over the market conditions. However this instability is not always detrimental, and sometimes may work to a firm's advantage.

The main disadvantage of instability raised by firms is that it makes it more difficult to get buy-in from stakeholders and build external confidence in the firm. However, the firms also responded that instability could be the driver of much-needed managerial and strategic change that can lead to subsequent growth. This was the case in a number of the firms interviewed in this research, where management within the firm had the expertise and processes in place to ensure this change is well executed and long lasting. This finding reinforces arguments that have been made by a number of others in the management literature (Garnsey, 1998; Chetty \& Campbell-Hunt, 2003), and provides further evidence for Garnsey's view, that management itself can be a resource for high-growth. These findings also provide strong evidence for the notion raised by Davenport et al (2014), that instability does not always have negative outcomes for firms.

\section{Limitations}

While every effort was taken to ensure the findings of this research and the way they were obtained were robust, there are a number of limitations that must be taken into account when considering the outcomes of this research. First, the nature of the database used in this research was largely self-nominating. Therefore the sample of firms was biased towards those that would put themselves forward for inclusion. While it is difficult to tell whether this has any impact on the findings, it should be taken into consideration. It also became apparent over the course of the research that much of the data that is self-reported and/or estimated in the TIN100 might not always be entirely accurate. It is not clear how prevalent this issue in within the database, but should be considered for future research that makes use of the same dataset.

Other limitations of the database used to form the sample for this research were that it included no data prior to 2005 , and that it includes only firms that are 'successful' by most indicators. Therefore the sample was skewed towards firms with higher revenues. It is likely 
that this led to a skewed representation of the prevalence of HGFs in New Zealand, as 32\% of the sample was considered high-growth by at least one definition, which is a larger than expected proportion of high-growth firms in the normal firm population.

Another limitation that arose in this research, and indeed much of the other high-growth literature (Delmar et al, 2003), is that the definitions of high-growth employed may limit the number of firms that are considered high-growth. This research attempted to mitigate this issue by including multiple definitions and criteria of high-growth that could be analysed. However, all of the definitions used in this research examined relatively short periods of extremely high revenue growth; therefore, firms who had sustained growth over long periods may have been excluded from this research.

Finally, it must also be considered that qualitative results may have been influenced by who was interviewed. In the case of all firms, the person interviewed was someone in a senior management position, either during or immediately following the high-growth period in question. Therefore, it is likely that they had some vested interest in accentuating the effect that management skill and expertise had on high-growth. While this is not to say that the interviewed subjects were exaggerating or inflating their role, it is important to consider that the qualitative findings were not drawn from objective sources.

\section{Implications for Future Research and Theory}

This research was positioned to fill some of the gaps that exist in the high-growth management literature, between empirical research and practical explanations for observed phenomena. It achieved this outcome by including qualitative interviews with the firms that had observed quantitative high-growth characteristics, in order to provide explanations for relationships between variables. However, it is also apparent that the experiences of those working within, and managing, the HGFs that are being analysed are invaluable resources for those trying to understand how high-growth occurs, and how it may be sustained. Previous high-growth research has been primarily focussed on empirical outcomes, and observed trends based on large samples of data, and has largely ignored the experiences 
and thoughts of those actually involved in the industries being explored. The qualitative interviews were a data rich source for this mixed-methodologies research, and should be pursued further in order to build a more complete picture of the precursors, characteristics, and outcomes of high-growth.

As discussed earlier in this thesis, much of the existing high-growth literature focusses only on one factor, or one set of factors and the role they play in the occurrence of high-growth. This research goes some way to exploring a multitude of factors that all interrelate to 'create' a HGF. However, it is still should still be an aim for future research, to investigate the relationships between factors that may not necessarily appear related on the surface, such as stability and governance changes, and the role that these may play in high-growth.

Current growth research focusses largely on a narrow scope of high-growth, and the related growth patterns of firms (Geroski, 1999; Greiner, 1972). In most cases, this focus is centred on relatively consistent upward growth, even though, as indicated by this research, many firms who experience high-growth have revenue which is prone to fluctuation. As alluded to by a number of firms interviewed in this study, crises or instability can provide opportunities for growth, if the firm is able to manage their way through. This has been suggested previously, with Feeser \& Willard (1990) arguing that instability is only as damaging as firms allow it to be. A number of studies have considered entrepreneurial locus of control (Monsen \& Urbig, 2009; Mueller \& Thomas, 2001; Wijbenga \& van Witteloostujin, 2007), the concept that entrepreneurs tend to be more likely to believe that outcomes are within their control and determination (internal locus of control), rather than being determined by factors outside their control (external locus of control) (Mueller \& Thomas, 2001). However, these theories have been overlooked for inclusion in high-growth research. The findings of this research show that firms who are able to overcome instability and achieve high-growth, are likely to do so because there is a strong perception of internal locus of control within the organsiation, thus management within the organisation actively controls which factors it can, and uses this control to mitigate negative environmental effects, or exploit opportunities. 
It is also possible that an internal locus of control plays a role itself in creating instability. A number of firms in this research stated strategic overhaul as one of the defining factors that led to their high-growth period, and this overahul caused some instability. Yet, it was also this overhaul, undertaken by the firms because of a dissatisfaction with previous performance and a belief that they had control over positive outcomes, that led to subsequent high-growth. Therefore, there is an obvious opportunity for future research to expand the breadth and depth of understanding of high-growth, by including locus of control theories and analyses when considering what leads to high-growth in firms. Future research could also benefit from reconsidering instability as a negative outcome for firms, and repositioning instability as a driver of positive change and growth in firms with a strong perception of internal locus of control and managerial expertise.

\section{Implications for Management Practice}

The findings of this research have led to the synthesis of three major implications for management, particularly in the context of New Zealand technology firms, although it is likely that these implications can be more broadly applied. The first is that high-growth predominantly appears to follow the launch of new products or services to the market. Therefore, strategies need to extend past this point, and plans need to be made for how to sustain the subsequent revenue influx as a result of the launch. High-growth companies in this research were those that were able to capitalise on revenue from new products, and reinvest for future growth, or create increases in existing demand, as well as demand from new consumers.

The second implication for managerial practice is that crises and instability do not always have negative outcomes for firms, and should not be treated as such. All of the HGFs interviewed over the course of this research commented that instability could be the driver or major managerial or strategic change that is necessary, not only to abate the crisis, but also build towards high-growth. This implication was also raised by Garnsey (1998), who stated changes within organisations, whether resource-based, managerial, or strategic, can 
be the causes of high-growth, if the management of the organisation is able to enact these changes and sustain their positive effects.

Finally, the third implication follows logically on from the second, and is the major implication to arise from the current research. Managerial expertise appeared to be the common thread linking all of the HGFs that were interviewed in this study. In all situations, from financial crises, product development, decisions to pursue funding, and organisational expansion, it was apt decision making from both managers and directors that lead to these opportunities being utilised and exploited for subsequent high-growth. Therefore, a major implication for firms is to ensure managers and directors have relevant experience and expertise, especially in relation to strong guidance and strategic planning through crises, and if this is not present in the firm, to actively seek it out.

\section{Conclusion}

This research was intended to be an exploration of the precursors to high-growth, and the characteristics of HGFs, using the New Zealand technology industry as a contextual setting. In conclusion, this study has contributed to the building of a more comprehensive picture of what a HGF is, how it behaves, and how the high-growth occurs in the first place. Highgrowth is of ever-growing interest in the management literature. However, there is ongoing conflict over how high-growth is defined, which factors are considered as precursors, and how high-growth should be measured. The findings of this research indicate that there are a number of factors that interact with each other to create the conditions under which a firm experiences high-growth, with managerial expertise and experience being the factor that appears to unite others and provide the most direct foundation for high-growth. This thesis

represents the some of the first steps in the direction of more complete high-growth research, using multiple measures of high-growth, and multiple methodologies. This research also lays the foundations and opens opportunities for future research in this area, ultimately working towards building a deeper and more comprehensive understanding of HGFs. 


\section{Bibliography}

Acs, Z. J., \& Varga, A. (2005). Entrepreneurship, Agglomeration \& Technological Change. Small Business Economics, 323-334.

Acs, Z., \& Mueller, P. (2008). Employment Effects of Business Dynamics: Mice, Gazelles and Elephants. Small Business Economics, 85-100.

Aghion, P., \& Howitt, P. (1992). A Model of Growth Through Creative Destruction. Econometrica, 323-351.

Arthur, B. (1990, February). Positive Feedbacks in the Economy. Scientific American, pp. 8085.

Audretsch, D., Keilbach, M., \& Lehmann, E. (2006). Entrepreneurship and Economic Growth . New York: Oxford University Press.

Australian Academy of Science. (2015). The Importance of Advanced Physical and Mathematical Sciences to the Australian Economy. Canberra: Australian Academy of Science.

Barney, J. (1991). Firm Resources and Sustained Competitive Advantage . Journal of Management, 99-120.

Birch, D. (1981). Who Creates Jobs? The Public Interest, 3-14.

Birch, D. (1987). Job Creation in America. New York: Free Press.

Bureau of Economic Analysis. (2015, April 23). Interactive Data - GDP by Industry. Retrieved from US Department of Commerce Bureau of Economic Analysis: http://www.bea.gov/iTable/iTable.cfm?ReqID=51\&step=1\#reqid=51\&step=51\&isuri $=1 \& 5114=a \& 5102=1$ (accessed 11 December 2015)

Callaghan Innovation. (2015, December 3). R\&D Grants. Retrieved from Callaghan Innovation: http://www.callaghaninnovation.govt.nz/grants (accessed 8 March 2016)

Callaghan, P. (2009). Wool to Weta: Transforming New Zealand's Culture and Economy. Auckland: Auckland University Press. 
Carden, S. (2005). What Global Executives Think About Growth and Risk. McKinsey Quarterly, 16-25.

Chetty, S., \& Campbell-Hunt, C. (2003). Explosive International Growth and Problems of Success of Small to Medium-Sized Firms. International Small Business Journal, 5-27.

Coad, A., \& Holzl, W. (2009). On the Autocorrelation of Growth Rates. Journal of Industry Competition and Trade, 139-166.

Coad, A., \& Rao, R. (2008). Innovation and Firm Growth in High-Tech Sectors: A Quartile Regression Approach. Research Policy, 633-648.

Coad, A., Daunfeldt, S.-O., Holzl, W., Johansson, D., \& Nightingale, P. (2014). High Growth Firms: Introduction to the Special Section. Industrial and Corporate Change, 91-112.

Cohen, W. M., Nelson, R. R., \& Walsh, J. P. (2000). Protecting their intellectual assets: appropriability conditions and why US manufacturing firms patent (or not). NBER Working Paper 7552.

Corbett, L., \& Campbell-Hunt, C. (2002). Grappling with a Gusher! Manufacturing's Response to Business Success in Small and Medium Enterprises. Journal of Operations Management, 495-517.

Daunfeldt, S.-O., \& Halvarsson, D. (2015). Are High-Growth Firms One-Hit Wonders? Evidence from Sweden. Small Business Economics, 361-383.

Daunfeldt, S.-O., Elert, N., \& Johansson, D. (2010). The Economic Contribution of HighGrowth Firms: Do Definitions Matter? Ratio Working Papers, 151.

Daunfeldt, S.-O., Elert, N., \& Johansson, D. (2015). Are High-Growth Firms Overrepresented in Hi-Tech Industries? IDEAS Working Paper Series from RePEc.

Davenport, S., Daellenbach, U., Greig, S., \& Leitch, S. (2015). Innovative Firm Growth and the Search for Elusive Gazelles. ISPIM: Shaping the Frontiers of Innovation Management. Budapest.

Davenport, S., Daellenbach, U., Greig, S., Bibby, D., \& Leitch, S. (2014). Patterns in Innovative Firm Growth: Instability is Not Always Bad. The Proceedings of the Asia-Pacific Innovation Forum. Singapore. 
Delmar, F., \& Davidsson, P. (1998). A Taxonomy of High Growth Firms. Frontiers of Entrepreneurship Research, 399-343.

Delmar, F., Davidsson, P., \& Gartner, W. (2003). Arriving at the High Growth Firm. Journal of Business Venturing, 189-216.

Di Liberto, A. (2013). High Skills, High Growth: Is Tourism an Exception? Journal of International Trade \& Economic Development, 749-785.

Easterby-Smith, M., Thorpe, R., \& Jackson, P. (2012). Management Research 4th Edition. London: Sage Publications.

Eurostat-OECD. (2007). Eurostat-OECD Manual on Business Demography Statistics. Paris: OECD.

Feeser, H., \& Willard, G. (1990). Founding Strategy and Performance: A Comparison of High and Low Growth Hi Tech Firms. Strategic Management Journal, 87-98.

Frederick, H. H. (2004). Towards High Growth Enterprise. Journal of Entrepreneurship and Small Business, 238-248.

Garnsey, E. (1998). A Theory of the Early Growth of the Firm. Industrial and Corporate Change, 556.

Garnsey, E. W., Galloway, S. C., \& Mathieson, S. H. (1994). Flexibility and Specialisation in Question: Birth, Growth and Death Rates of Cambridge New Technology-Based Firms 1988-1992. Entrepreneurship and Regional Development, 81-107.

Garnsey, E., \& Mohr, V. (2011). How do High Growth Firms Grow? Evidence from Cambridge, UK. Economics, Management and Financial Markets, 29-59.

Geroski, P. (1999). The Growth of Firms in Theory and in Practice. Discussion Paper 2092. Centre for Economic Policy Research.

Geroski, P. (2005). Understanding the Implications of Empricial Work on Corporate Growth Rates. Managerial and Decision Economics, 129-138.

Geroski, P., Mata, J., \& Portugal, P. (2010). Founding Conditions and the Survival of New Firms. Strategic Management Journal, 510-529.

Greiner, L. E. (1972, July-August). Evolution and Revolution as Organisations Grow. Harvard Business Review, pp. 37-46. 
Griliches, Z. (1990). Patent Statistics as Economic Indicators: A Survey. Journal of Economic Literature, 1661-1707.

Halabisky, D., Dressen, E., \& Parsley, C. (2006). Growth Firms in Canada, 1985-1999. Journal of Small Business and Entreprenurship, 255-268.

Hay, M., \& Kamshad, K. (1994). Small Firm Growth: Intentions Implementation and Impediments. Business Strategy Review, 49-68.

Henrekson, M., \& Johansson, D. (2010). Gazelles as Job Creators: A Survey and Interpretation of the Evidence. Small Business Economics, 227-244.

Holzl, W. (2009). Is the R\&D Behaviour of Fast Growing SMEs Different? Evidence from CIS III Data for 16 Countries. Small Business Economics, 59-75.

Jaffe, A., \& Le, T. (2015). The Impact of R\&D Subsidy on Innovation: A Study of New Zealand Firms. Wellington: Motu Economic \& Public Policy Research.

Kenney, M. (1986). Schumpterian Innovation \& Entrepreneurs in Capitalism: A Case Study of the US Biotech Industry. Research Policy, 21-31.

Khaire, M. (2010). Young and No Money? Never Mind: The Material Impact of Social Resources on New Venture Growth. Organization Science, 168-185.

Kirchoff, B. (1994). Entrepreneurship and Dynamic Capitalism: The Economics of Business Firm Formation and Growth. Westport, CT: Praeger.

Lam, B. (2015, April 12). Where Do Firms Go When They Die? Retrieved from The Atlantic: http://www.theatlantic.com/business/archive/2015/04/where-do-firms-go-whenthey-die/390249/ (accessed 1 March 2016)

Lanza, A., \& Pigliaru, F. (1994). The Tourism Sector in the Open Economy . Rivista Internazionale di Scienze Economiche e Commerciali, 15-28.

Lopez-Garcia, P., \& Puente, S. (2012). What Makes a High Growth Firm? A Dynamic Probit Analysis Using Spanish Firm-Level Data. Small Business Economics, 1029-1041.

Luborsky, M., \& Rubinstein, R. (1995). Sampling in Qualitative Research: Rationale, Issues and Methods. Research on Aging, 89-113. 
Miller, J., \& Glassner, B. (2011). The "Inside" and the "Outside": Finding Realities in Interviews. In D. Silverman, Qualitative Research (pp. 131-148). London: Sage Publications.

Ministry of Business Innovation and Employment . (2016). Companies Office Online Search. Retrieved from Companies Office Website:

https://www.business.govt.nz/companies/learn-about/searching/companies-search (accessed 6 November 2015)

Ministry of Business Innovation and Employment. (2014). The New Zealand Sectors Report 2014. Wellington: New Zealand Government.

Ministry of Business, Innovation and Employment. (2015). National Statemement of Science Investment. Wellington: Ministry of Business, Innovation and Employment.

Ministry of Economic Development. (2011). SMEs in New Zealand: Structure and Dynamics 2011. Wellington: Ministry of Economic Development.

Mohr, V., Garnsey, E., \& Theyel, G. (2014). The Role of Alliances in the Early Development of High-Growth Firms. Industrial and Corporate Change, 233-259.

Monsen, E., \& Urbig, D. (2009). Perceptions of Efficacy, Control, and Risk: A Theory of Mixed Control. In A. Carsrud, \& M. Brannback, Understanding the Entrepreneurial Mind (pp. 259-284). New York: Springer.

Moore, T., \& Mirzaei, A. (2016). The Impact of the Global Financil Crisis on Industry Growth. The Manchester School, 159-180.

Mueller, S., \& Thomas, A. (2001). Culture and Entrepreneurial Potential: A Nine Country Study of Locus of Control and Innovativeness. Journal of Business Venturing, 51-75.

Nelson, T., \& Levesque, L. (2007). The Role of Women in Corporate Governance in HighGrowth, High-Potential Firms. Entrepreneurship Theory and Practice, 209-232.

New Zealand Intellectual Property Office. (2015, May 7). Searchable New Zealand Patents. Retrieved from New Zealand Intellectual Property Office website: http://www.iponz.govt.nz/cms/patents/searching-for-existing-patents/guide-toonline-searching-of-the-patent-register/1.-searchable-new-zealand-patents (accessed 10 February 2016) 
OECD. (2012). Corporate Governance, Value Creation and Growth: The Bridge Between Finance and Enterprise. Paris: OECD Publishing.

O'Leary, Z. (2004). The Essential Guide to Doing Research. London: Sage Publications.

Orne, M. (1962). On the Social Psychology of the Psychological Experiment: With Particular Reference to Demand Characteristics and their Implications. American Psychologist, 776-783.

Penrose, E. (1959). The Theory of the Growth of The Firm. Oxford: Blackwell.

Reichstein, T., \& Dahl, M. (2004). Are Firm Growth Rates Random? Analysing Patterns and Dependencies. International Review of Applied Economics, 225-246.

Rushe, D. (2012, December 6). Technology Sector Found to be Growing Faster than the Rest of the US Economy. The Guardian.

Sandelowski, M. (1986). The Problem of Rigor in Qualitative Research. Advances in Nursing Science, 27-37.

Schuman, M. C. (1995). Managing Legitimacy: Strategic and Institutional Approaches. Academy of Management Review, 571-611.

Shepherd, D., \& Wiklund, J. (2009). Are We Comparing Apples with Apples or Apples with Oranges? Appropriateness of Knowledge Accumulation Across Growth Studies. Entrepreneurship Theory and Practice, 105-123.

Smith, S., \& Vela, E. (2001). Environmental Context-Dependent Memory: A Review and Meta-Analysis. Psychonomic Bulletin \& Review, 203-220.

Stam, E. (2005). The Geography of Gazelles in the Netherlands. Tijdschrift voor Economische en Sociale Geografie, 121-127.

St-Jean, E., Julien, P.-A., \& Audet, J. (2008). Factors Associated with Growth Changes in Gazelles. Journal of Enterprising Culture, 161-188.

Technology Investment Network. (2015). About TIN100 Reports. Retrieved from TIN100 Website: http://www.tin100.com/About+TIN100+Reports.html (accessed 5 November 2016)

Technology Investment Network Ltd. (2014). TIN100 Report 2014. Auckland: Technology Investment Network. 
Upton, G., \& Cook, I. (2014). A Dictionary of Statistics. Oxford: Oxford University Press.

Wagner, J. (1992). Firm Size, Firm Growth and Persistence of Chance. Testing Gibrat's Law with Establishment Data from Lower Saxony. Small Business Economics, 125-131.

Wijbenga, F., \& van Witteloostujin, A. (2007). Entrepreneurial Locus of Control and Competitive Strategies - The Moderating Effect of Environmental Dynamism. Journal of Economic Psychology, 566-589.

Zimmerman, M., \& Zeitz, G. (2002). Beyond Survival: Achieving New Venture Growth by Building Legitimacy. Academy of Management Review, 414-431. 
Appendix 1. Sample Database Sheet

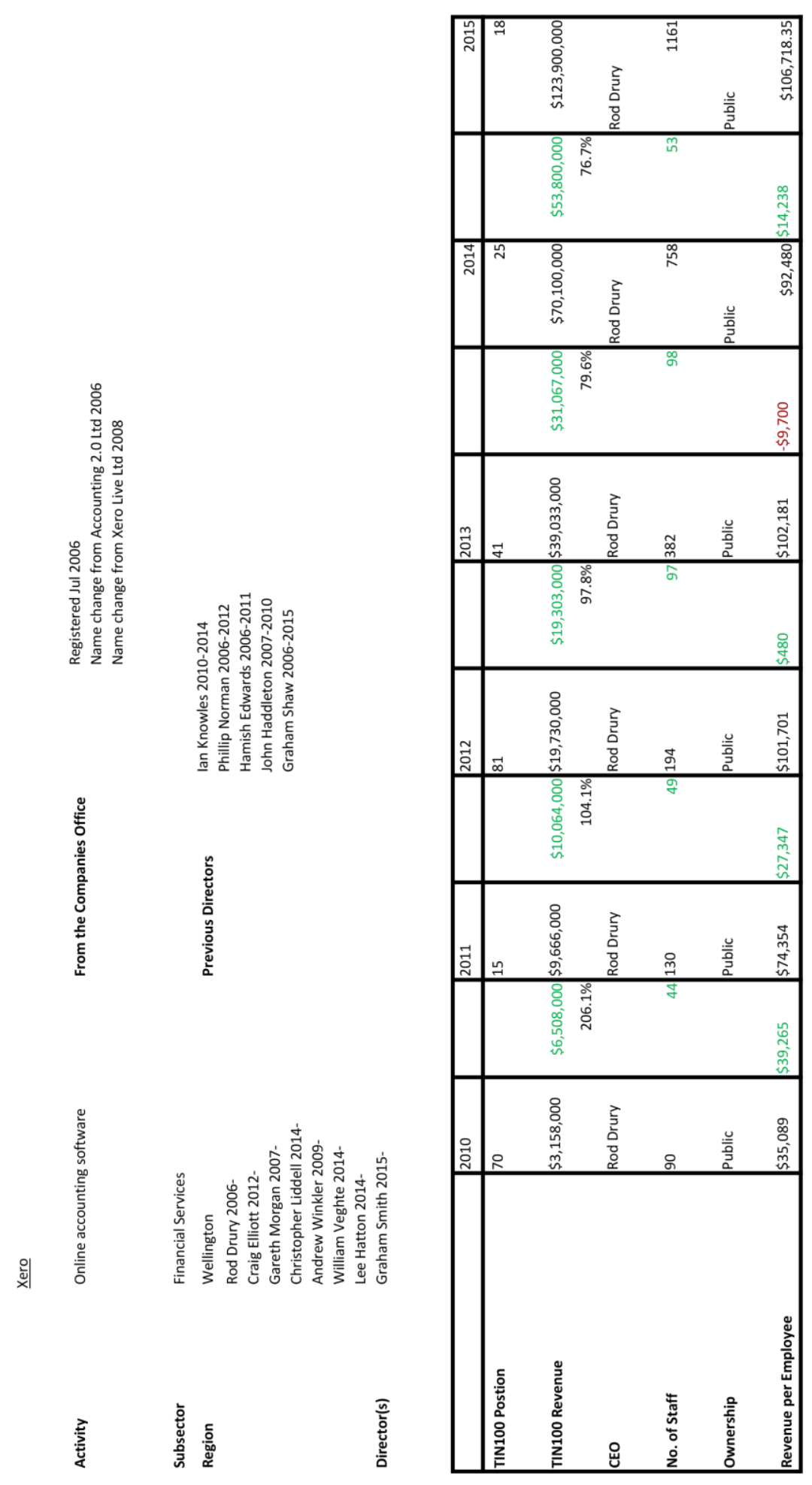




\section{Appendix 2. List of TIN100 Companies and Years of Inclusion}

\section{3}

4D Steel Detailing

4RF Communications

A

Acclipse

Actronic

ADInstruments

Aeroqual

AFT Pharmaceuticals

Aftermail

Agility CIS

Allied Telesis

Alpha Aviation

Ancare

Animation Research

Aptimize

ARANZ Geo

ARANZ Healthcare

Aerograph

Argent Networks

Argenta

Arrowhead Alarm Products

Arvus Group

Atlantis Healthcare

Atrax Group

Aucom Electronics

Augen

Aura Information Security

Author IT Software

B

Bank Link

Bay City Communications

BBC Technologies

BEP Marine

Berill Control Systems

Biomatters

Biostart

Blackbay

Black Coffee Software

Bomac

Buckley Systems

Business Intelligence Systems

C

Cabco Group

Cadimage

Cadmus Tech

Canterbury Scientific
2009

2005-2015

2012

2006-2015

2009-2015

2011-2015

2010-2015

2006-2007

2014-2015

2005-2015

2007

2005-2008

2006-2007, 2009-2015

2010-2011

2009-2015

2013-2015

2010

2006-2007

2010-2015

2010-2015

2010-2011

2011-2015

2005-2007, 2009-2015

2008-2015

2006, 2010-2015

2013-2015

2007-2015

2009-2012

2010-2012

2014-2015

2006-2015

2005-2015

2010-2015

2012

2005-2015

2006

2006-2011

2005-2015

2013

2007

2014-2015

2005-2007

2009-2012
N

Nautech

2005-2015

Navman

Navman Wireless

NDA

Net Value

Neuren Pharmaceuticals

NZ Pharmaceuticals

Next Window

Ninja Kiwi

o

Obsidium

Omni Solutions

Open Cloud

Optima

Optimation

Orion Health

Orthopaedic Synergy

Oscmar

Outpost Central

2005-2015

2010-2012, 2014-2015

200-2015

2012-2015

2006, 2009-2015

2005-2015

2008-2014

2012-2015

2007, 2009-2011

2012-2014

2006-2015

2009-2015

2005-2015

2005-2015

2009-2015

2005-2015

2010-2011

2005-2015

2015

2005-2014

2006-2007, 2009-2013

2005-2008

2010-2015

2006-2007, 2009-2015

2005-2015

2013

2012-2014

2013-2015

2010, 2013-2015

2009-2011, 2013-2015

2006-2011

2006-2015

2005-2007

2008-2009

2015-2015

2011-2013, 2015

2010-2015

2015

\section{Q}

Q4bis

2006-2007

Qbik

2006, 2010

Quick Circuit

2010-2015 


\begin{tabular}{|c|c|c|c|}
\hline Car Parking Technologies & 2012-2013, 2015 & $\mathbf{R}$ & \\
\hline Catalyst IT & 2012-2015 & Rakon & 2005-2015 \\
\hline Catapult Software & 2010-2011 & Raztec & 2010-2013 \\
\hline Ceiba Solutions & 2009-2015 & Revera & 2007-2012 \\
\hline Cerebral Fix & 2011-2015 & RGL Telecom & 2007-2015 \\
\hline Certus Solutions & 2013-2015 & Right Hemisphere & 2006-2012 \\
\hline Cervina & 2008-2011 & RML Engineering & 2010-2015 \\
\hline Clearpoint & 2015 & RMSD & 2010 \\
\hline Coherent Solutions & 2014-2015 & Rocklabs & 2006-2008 \\
\hline Comacc & 2006-2008 & Run The Red & 2010-2011, 2014 \\
\hline Commtest Instruments & 2008-2012 & & \\
\hline Compac Industries & 2009-2015 & $\mathbf{s}$ & \\
\hline Compac Sorting Equipment & $2005-2015$ & Schneider Electric & $2005-2015$ \\
\hline Compuspec Industries & 2006-2007, 2009-2015 & Scott Design \& Manufacture & 2010-2011 \\
\hline Comrad Medical Systems & 2008-2015 & Scott Technology & 2005-2015 \\
\hline Conexa & 2009-2014 & Screening \& Crushing Solutions & 2009-2015 \\
\hline Connexions & 2009-2011, 2013-2015 & Sentient Software & 2009-2015 \\
\hline Core Tech & 2009-2015 & Senztek Holdings & 2010-2011 \\
\hline Cortell & 2009 & Serato Audio Research & 2010-2015 \\
\hline Crossware & 2014 & Sidhe Interactive & 2009-2015 \\
\hline \multirow[t]{2}{*}{ CWF Hamilton } & 2005-2015 & Silver Stripe & 2012-2015 \\
\hline & & Simcrotech & 2008-2015 \\
\hline D & & Simpl & 2006-2015 \\
\hline Daestra & 2010-2011 & Simtics & 2010 \\
\hline Datacom & $2005-2015$ & Skope Industries & 2005-2015 \\
\hline Data South & 2009-2010 & SLI Systems & 2008-2015 \\
\hline Datasquirt & 2009-2011 & Small Worlds & 2009-2015 \\
\hline Data Torque & 2012-2015 & SmartPay & 2010-2015 \\
\hline DC Ross & 2009-2014 & SMX & 2010-2013 \\
\hline Debit Success & 2011-2015 & Snakk Media & 2014-2015 \\
\hline Derceto & 2010-2013 & Snap Comms & 2015 \\
\hline Designline & 2006-2012 & Soft Tech & 2005-2015 \\
\hline Digital Post & 2010-2013 & Software of Excellence & $2005-2008$ \\
\hline Diligent Board Member Services & 2010-2015 & Sonar 6 & 2009-2012 \\
\hline Direct Payment Solutions & 2010-2015 & South Pacific Sera & 2010-2015 \\
\hline Donovan Group & 2008-2015 & Spider Tracks & 2010-2015 \\
\hline Douglas Pharmaceuticals & 2005-2015 & Sprite Software & 2006 \\
\hline \multirow[t]{2}{*}{ Dynamic Controls } & 2005-2015 & Steelbro & $2009-2013$ \\
\hline & & Straker Translations & 2015 \\
\hline $\mathbf{E}$ & & Surveylab & 2010-2011 \\
\hline Eaton Power Quality & $2005-2015$ & Syft Technology & $2009-2010,2012-2015$ \\
\hline ECONZ & $2006-2007,2009-2015$ & Symantec NZ & $2005-2008$ \\
\hline Electronic Navigation & 2008-2015 & Synergy & 2005-2015 \\
\hline Electropar & 2011-2015 & Sysmex & 2006-2015 \\
\hline Emendo & 2010-2014 & System Controls & 2009-2015 \\
\hline EMS Cortex & 2006 & & \\
\hline Enatel & 2006-2015 & $\mathbf{T}$ & \\
\hline Endace & $2005-2015$ & Tacit Technologies & 2005 \\
\hline Energy Intellect & 2008-2013, 2015 & Tait Electronics & 2005-2015 \\
\hline Energy Mad & $2012-2015$ & TalkingTech & 2009-2015 \\
\hline
\end{tabular}




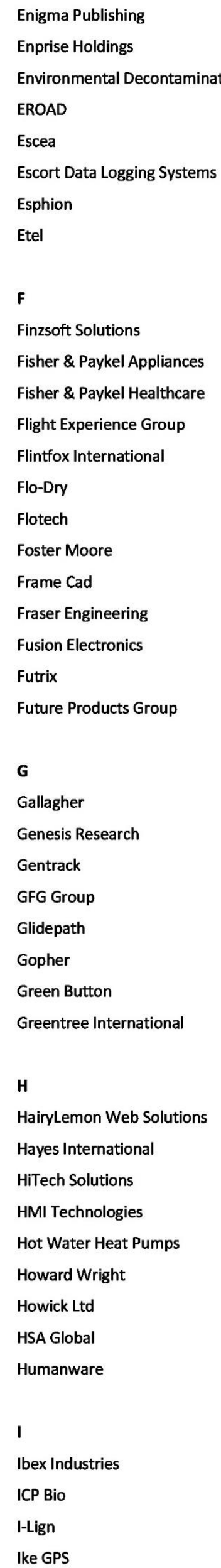




\begin{tabular}{|c|c|}
\hline Infinity Group & 2006-2008 \\
\hline Information Tools & $2008-2015$ \\
\hline Instrument Supplies & 2008-2015 \\
\hline Intergen & 2006-2015 \\
\hline Intrahealth & 2006-2015 \\
\hline Intuto & 2006-2011, 2013 \\
\hline Invenco & 2014-2015 \\
\hline IPFX & $2006-2015$ \\
\hline Irwin International & 2005-2009 \\
\hline \multicolumn{2}{|l|}{ J } \\
\hline Jackson Electrical Industries & 2015 \\
\hline Jade Corporation & $2005-2015$ \\
\hline JMP Engineering & 2009-2015 \\
\hline \multicolumn{2}{|l|}{ K } \\
\hline Kea Campers & $2008-2013$ \\
\hline Konnect Net & 2010-2015 \\
\hline \multicolumn{2}{|l|}{$\mathbf{L}$} \\
\hline \multicolumn{2}{|l|}{ M } \\
\hline Mactec Aerospace International & 2006 \\
\hline Magritek & 2009-2015 \\
\hline Mako Networks & $2006,2012-2015$ \\
\hline Maskell Productions & 2010-2015 \\
\hline Mastip Technology & 2006-2015 \\
\hline McKay Engineering & 2008-2015 \\
\hline MCom & $2009-2015$ \\
\hline MedTech Global & 2006-2015 \\
\hline Mercer Tech & 2008-2015 \\
\hline Merlot Aero & 2015 \\
\hline Metalform & 2011-2015 \\
\hline Methodware & 2006-2007 \\
\hline Methven & $2007-2015$ \\
\hline Modica Group & 2012-2015 \\
\hline Modtech Industries & 2010-2015 \\
\hline Moffat & $2009-2015$ \\
\hline MoleMap & 2009-2015 \\
\hline
\end{tabular}

$\mathbf{Y}$

Yike Bike 2013-2015

Z

Zeacom 2005-2012

Zeald 2010-2015

Zee Tags 2010-2015

Zelam 2009-2015

Zephyr Technology 201-2011

Zintel 2006-2012 


\section{Appendix 3. List of Companies in Each Definition of High Growth}

Definition 1: Top 10 firms by relative growth

Xero

Diligent Board Member Services

Mcom

Orion Health

PowerbyProxi

FrameCad

Enatel

Vista Entertainment Solutions

Wherescape

Magritek

Definition 2: Top 10 firms by absolute growth

Datacom

Fisher \& Paykel Healthcare

Fisher \& Paykel Appliances

Navman Wireless

Tait Electronics

Orion Health

Weta Digital

Xero

Diligent Board Member Services

Berill Control Systems 
Definition 3: 20\% Revenue Growth per year over 3 years

Buckley Systems

Fronde Group

Intergen

Enatel

Endace

Wellington Drive Technology

Mcom

Diligent Board Member Services

Xero

Technopak

Data Torque

Definition 4: 50\% revenue growth per year over three years

Diligent Board Member Services

Xero

Definition 5: 50\% revenue growth per year over two years

Rakon

Compac Sorting Equipment 
Definition 6: $50 \%$ revenue growth over one year

\begin{tabular}{|c|c|c|}
\hline Navman & MedTech Global & IPFX \\
\hline Tait Electronics & Intrahealth & Sysmex Delphic \\
\hline Schneider Electric & Phitek & Neuren Pharmaceuticals \\
\hline Provenco & Animation Research & Genesis Research \\
\hline Allied Telesis & Wherescape & Aucom Electronics \\
\hline CWF Hamilton & Methven & Electronic Navigation \\
\hline Trimble Navigation & Finzsoft Solutions & Bank Link \\
\hline Skope Industries & Wellington Drive- & FrameCad \\
\hline Buckley Systems & Technology & TalkingTech \\
\hline Glidepath & Author IT Software & Navman Wireless \\
\hline Oscmar & Waikato Milking Systems & Maskell Productions \\
\hline Desginline & Kea Campers & Debit Success \\
\hline Berill Control Systems & $\begin{array}{l}\text { Vista Entertainment- } \\
\text { Solutions }\end{array}$ & SMX Ltd \\
\hline Orion Health & Commtest Instruments & Dingar \\
\hline Peace Software & Next Window & Flo-Dry Ltd \\
\hline Fusion Electronics & JMP Engineering & Xlerate Technologies \\
\hline Cadmus Tech & Howard vvrignt & Unlimited Realities \\
\hline Prolificx & Winscribe Itd & Syft Technology \\
\hline Wyma Engineering & Ninia Kiwi & Technopak \\
\hline Optimation & Conexa & Magritek \\
\hline Intergen & ARAN7 GOO & Environmental- \\
\hline Hayes International & & Decontamination \\
\hline Actronic & Tivie iviap & Raztec \\
\hline Mastip Technology & Vega Industries & Data Torque \\
\hline 4RF Communications & $\begin{array}{l}\text { Screening \& Crushing- } \\
\text { Solutions }\end{array}$ & ARANZ Healthcare \\
\hline Enatel & Howick Ltd & Aura Information Security \\
\hline Pacific Aerospace & Argent Networks & Small Worlds \\
\hline Nautech & PharmaZen & Invenco \\
\hline Endace & Atrax Group & TracMap \\
\hline GFG & Open Cloud & Vend \\
\hline Blackbay & Interactive Technologies & \\
\hline
\end{tabular}




\section{Appendix 4. Company Interview Selection Matrix / Template}

\begin{tabular}{|c|c|}
\hline Area & Question \\
\hline Age & $\begin{array}{l}\text { Do you recall having a period of similar growth } \\
\text { before entering the TIN } 100 \text { ? }\end{array}$ \\
\hline Year & $\begin{array}{l}\text { Can you explain any possible effects of } \\
\text { orders/lag/management decisions/organisational } \\
\text { changes that may have affected the year the growth } \\
\text { started? (looking to explain growth starting in 2008) } \\
\text { Is there any explanation for why the growth was not } \\
\text { sustainable past the high-growth period? } \\
\text { Were there any similar factors that could have led to } \\
\text { growth in these two years, but not the years in } \\
\text { between? }\end{array}$ \\
\hline Patents & $\begin{array}{l}\text { Did having a high growth period make you more } \\
\text { likely to pursue patents afterwards? } \\
\text { Do you think that receiving the patent played a role } \\
\text { in high-growth, or was it unrelated to revenue? (For } \\
\text { companies with multiple patents, why did high- } \\
\text { growth follow some patents but not others?) }\end{array}$ \\
\hline Grants & $\begin{array}{l}\text { Do you think having a high-growth period made you } \\
\text { more confident in pursuing grants, or made grant } \\
\text { givers more confident in the business, or both? }\end{array}$ \\
\hline Governance & Directors were far more likely to change before high- \\
\hline
\end{tabular}




\begin{tabular}{|l|l|}
\hline $\begin{array}{l}\text { growth than after, is this a coincidence, or a } \\
\text { conscious decision not to change a winning formula? } \\
\text { Do you think the CEO change in the years preceding } \\
\text { the high-growth had an effect on spurring that } \\
\text { growth period? }\end{array}$ \\
\hline Stability & $\begin{array}{l}\text { Do you have any explanations for the instability in } \\
\text { revenue patterns? }\end{array}$ \\
& $\begin{array}{l}\text { Can you explain possible reasons for the high-growth } \\
\text { period, when the rest of the growth patterns have } \\
\text { been negative? }\end{array}$ \\
\hline
\end{tabular}




\section{Appendix 5. List of Subsectors in Each Sector}

\section{High-Tech Manufacturing}

Appliances

Production Equipment \& Materials Handling

Other/Industrial

Transportation

Electronics

Energy Solutions

Airport Solutions

ICT

Wireless Solutions

Navigation Products

Telco Solutions

Financial Services

Digital Media

Software Development

IT Services \& Support

Biotechnology

Healthcare

Primary Sector Technologies 


\section{Appendix 6. Growth Percentages Database}

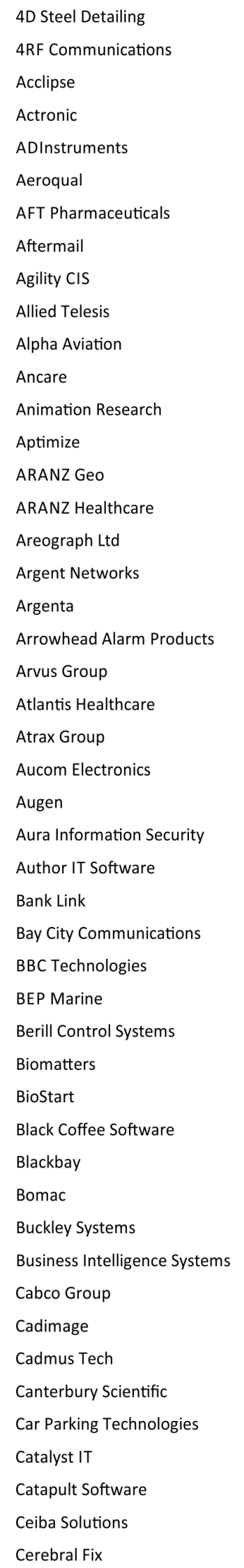




\begin{tabular}{|c|c|c|c|c|c|c|c|c|c|c|}
\hline Certus Solutions & $-2.7 \%$ & $-11 \%$ & & & & & & & & \\
\hline Cervina & $-64.0 \%$ & $-33.3 \%$ & $27.8 \%$ & & & & & & & \\
\hline \multicolumn{11}{|l|}{ Clearpoint } \\
\hline Coherent Solutions & $+5.8 \%$ & & & & & & & & & \\
\hline Comacc & $29.0 \%$ & $-0.5 \%$ & & & & & & & & \\
\hline Commtest Instruments & $100.0 \%$ & $-4.3 \%$ & $-5.2 \%$ & $-30.6 \%$ & & & & & & \\
\hline Compac Industries & $-13.5 \%$ & $27.1 \%$ & $-6.6 \%$ & $-4.4 \%$ & $12.6 \%$ & $-26.7 \%$ & & & & \\
\hline Compac Sorting Equipment & $+7.1 \%$ & $+74.1 \%$ & $+60.6 \%$ & $-18.5 \%$ & $+21.9 \%$ & $+10.7 \%$ & $-1.2 \%$ & $+4.9 \%$ & $+15.2 \%$ & \\
\hline Compuspec Industries & $-3.6 \%$ & $-21.2 \%$ & $-10.5 \%$ & $-1.2 \%$ & $-23.1 \%$ & $8.3 \%$ & $15.4 \%$ & $+36.3 \%$ & & \\
\hline Comrad Medical Systems & $-7.5 \%$ & $3.6 \%$ & $5.7 \%$ & $-7.5 \%$ & $14.0 \%$ & $-9.0 \%$ & $+9.9 \%$ & & & \\
\hline Conexa & $-26.0 \%$ & $85.0 \%$ & $-4.3 \%$ & $-29.9 \%$ & $-14.3 \%$ & $-14.3 \%$ & & & & \\
\hline Connexionz & $-0.4 \%$ & $+47.8 \%$ & & & & & & & & \\
\hline Core Tech & $2.0 \%$ & $0.1 \%$ & $26.5 \%$ & $-9.2 \%$ & $-5.7 \%$ & $+23.2 \%$ & & & & \\
\hline \multicolumn{11}{|l|}{ Cortell } \\
\hline \multicolumn{11}{|l|}{ Crossware } \\
\hline CWF Hamilton & $+29.2 \%$ & $+30.1 \%$ & $-45.5 \%$ & 0 & $+60.1 \%$ & $-3.9 \%$ & $+4.1 \%$ & 0 & $+0.1 \%$ & \\
\hline D C Ross & $-49.4 \%$ & $0.0 \%$ & $-29.4 \%$ & $31.6 \%$ & $-20.8 \%$ & $-20.8 \%$ & & & & \\
\hline Daestra & $+13.7 \%$ & & & & & & & & & \\
\hline Data South & 0 & & & & & & & & & \\
\hline Data Torque & $32.4 \%$ & $51.1 \%$ & $+42.6 \%$ & & & & & & & \\
\hline Datacom & $+17.2 \%$ & $+27.5 \%$ & $+15.4 \%$ & $+35.3 \%$ & $+9.5 \%$ & $+8.7 \%$ & $+8.5 \%$ & $+10.4 \%$ & $+1.1 \%$ & $+6.5 \%$ \\
\hline Datasquirt & $2.7 \%$ & $30.8 \%$ & & & & & & & & \\
\hline Debit Success & $15.4 \%$ & $10.6 \%$ & $11.5 \%$ & $+54.8 \%$ & & & & & & \\
\hline Derceto & $38.9 \%$ & $-2.7 \%$ & $-24.4 \%$ & & & & & & & \\
\hline Designline & $-18.6 \%$ & $+2.9 \%$ & $+75 \%$ & $-30.3 \%$ & $-50.4 \%$ & $-15.1 \%$ & & & & \\
\hline Digital Post & $-30.0 \%$ & $7.1 \%$ & $5.1 \%$ & & & & & & & \\
\hline Diligent Board Member Services & $66.0 \%$ & $168.2 \%$ & $+255.2 \%$ & $+42.7 \%$ & & & & & & \\
\hline Direct Payment Solutions & $23.8 \%$ & $45.9 \%$ & $-21.9 \%$ & $0.0 \%$ & $+2.2 \%$ & & & & & \\
\hline Donovan Group & $0.0 \%$ & $6.7 \%$ & $-11.9 \%$ & $1.3 \%$ & $-0.8 \%$ & $9.4 \%$ & $-26.3 \%$ & & & \\
\hline Douglas Pharmaceuticals & $-15.4 \%$ & $+12.1 \%$ & $+14.4 \%$ & $+2.9 \%$ & $-3.9 \%$ & $-8.3 \%$ & $+2.7 \%$ & $-0.8 \%$ & $+4.2 \%$ & \\
\hline Dynamic Controls & $-32.4 \%$ & $-6.3 \%$ & $+5.3 \%$ & 0 & 0 & $-8.0 \%$ & $-16.2 \%$ & $-31.9 \%$ & $+20.1 \%$ & \\
\hline Eaton Power Quality & $-31.5 \%$ & $+6.8 \%$ & 0 & $-23.1 \%$ & $+33.3 \%$ & $-5.6 \%$ & $-0.3 \%$ & $-3.2 \%$ & $-2.4 \%$ & \\
\hline ECONZ & $-59.3 \%$ & $-4.3 \%$ & $+5.9 \%$ & $+23.3 \%$ & $-35.1 \%$ & $+35.8 \%$ & $-31.3 \%$ & $+14.3 \%$ & & \\
\hline Electopar & $-15.1 \%$ & $0.0 \%$ & $-2.4 \%$ & $-11.4 \%$ & & & & & & \\
\hline Electronic Navigation & $-33.3 \%$ & $50.0 \%$ & $4.5 \%$ & $0.0 \%$ & $0.0 \%$ & $45.0 \%$ & $-2.3 \%$ & & & \\
\hline Emendo & $0.0 \%$ & $-33.7 \%$ & $12.2 \%$ & $0.0 \%$ & 0 & & & & & \\
\hline \multicolumn{10}{|l|}{ EMS Cortex } & \\
\hline Enatel & $+91.8 \%$ & $+14.7 \%$ & $-19.3 \%$ & $+26.8 \%$ & $+33.3 \%$ & $+152 \%$ & $+5 \%$ & $-28.6 \%$ & $+0.5 \%$ & \\
\hline Endace & $+180 \%$ & $+25.8 \%$ & $+55.8 \%$ & $-9.8 \%$ & $+13 \%$ & $-1.9 \%$ & $-6.7 \%$ & $-15.6 \%$ & $-9.2 \%$ & \\
\hline Energy Intellect & $-12.5 \%$ & $11.1 \%$ & $14.3 \%$ & $16.8 \%$ & $-60.8 \%$ & $+265.7 \%$ & & & & \\
\hline Energy Mad & $48.2 \%$ & $-18.8 \%$ & $-20.9 \%$ & & & & & & & \\
\hline \multicolumn{11}{|l|}{ Enigma Publishing } \\
\hline Enprise Holdings & $-30.7 \%$ & $-9.6 \%$ & $12.5 \%$ & $-31.9 \%$ & $-4.3 \%$ & $0.1 \%$ & $33.0 \%$ & $+6 \%$ & & \\
\hline Environmental Decontamination & $0.0 \%$ & $116.3 \%$ & $42.8 \%$ & $-5.7 \%$ & $0.0 \%$ & $-4.4 \%$ & & & & \\
\hline Eroad & $+76.1 \%$ & & & & & & & & & \\
\hline Escea Ltd & $6.4 \%$ & $1.4 \%$ & $20.7 \%$ & $28.3 \%$ & $+6.3 \%$ & & & & & \\
\hline \multicolumn{11}{|l|}{ Escort Data Logging Systems } \\
\hline \multicolumn{11}{|l|}{ Esphion } \\
\hline Etel Ld & $15.9 \%$ & $9.5 \%$ & $3.9 \%$ & $5.2 \%$ & $11.8 \%$ & $+8 \%$ & & & & \\
\hline Finzsoft Solutions & $8.6 \%$ & $-7.7 \%$ & $-0.1 \%$ & $-8.2 \%$ & $12.9 \%$ & $13.3 \%$ & $7.1 \%$ & $+108 \%$ & & \\
\hline
\end{tabular}




\begin{tabular}{|c|c|c|c|c|c|c|c|c|c|c|}
\hline Fisher \& Paykel Appliances & $+21.8 \%$ & $+35.9 \%$ & $-0.4 \%$ & $-2.4 \%$ & $-15.2 \%$ & $-3.7 \%$ & $-7.4 \%$ & $-1.7 \%$ & $+1.2 \%$ & $+9.2 \%$ \\
\hline Fisher \& Paykel Healthcare & $+11.9 \%$ & $+45.2 \%$ & $+2.5 \%$ & $+28.2 \%$ & $+9.7 \%$ & $+0.6 \%$ & $+2.1 \%$ & $+7.7 \%$ & $+12.1 \%$ & $+7.8 \%$ \\
\hline \multicolumn{11}{|l|}{ Flight Experience Group } \\
\hline Flintfox International & $31.1 \%$ & $-3.1 \%$ & $+6.2 \%$ & & & & & & & \\
\hline Flo-Dry Ltd & $167.9 \%$ & $0.0 \%$ & $0.0 \%$ & $-28.3 \%$ & $50.0 \%$ & 0 & & & & \\
\hline Flotech & $10.7 \%$ & $8.4 \%$ & $1.9 \%$ & $-27.5 \%$ & $0.3 \%$ & & & & & \\
\hline Foster Moore & $40.0 \%$ & $-24.0 \%$ & $-11.9 \%$ & $-55.7 \%$ & & & & & & \\
\hline Frame Cad & $376.2 \%$ & $20.0 \%$ & $0.0 \%$ & $3.2 \%$ & $-6.1 \%$ & $+3.3 \%$ & & & & \\
\hline Fraser Engineering & $-6.0 \%$ & $0.0 \%$ & $-1.9 \%$ & & & & & & & \\
\hline Fusion Electronics & $+62.5 \%$ & $-7.7 \%$ & $+16.7 \%$ & $-35.5 \%$ & $+15.1 \%$ & +19.2 & $+6.5 \%$ & $+15.2 \%$ & $+10.5 \%$ & \\
\hline Futrix & $0.0 \%$ & $4.5 \%$ & $-4.3 \%$ & $9.9 \%$ & & & & & & \\
\hline Future Products Group & $6.7 \%$ & $6.7 \%$ & $-19.5 \%$ & $+8.4 \%$ & & & & & & \\
\hline Gallagher & 0 & $+25 \%$ & $+6.7 \%$ & 0 & $+9.4 \%$ & $+6.9 \%$ & $-3.7 \%$ & $+1.1 \%$ & $+11.5 \%$ & \\
\hline Genesis Research & $-41.5 \%$ & $317.1 \%$ & & & & & & & & \\
\hline Gentrack & $0.0 \%$ & $15.8 \%$ & $33.3 \%$ & $2.5 \%$ & $+9 \%$ & & & & & \\
\hline GFG & $-23.8 \%$ & $+62.7 \%$ & $-1.8 \%$ & $-36 \%$ & $+41.9 \%$ & $+13.8 \%$ & $-13.6 \%$ & $+0.5 \%$ & $+23.6 \%$ & \\
\hline Glidepath & $+9.6 \%$ & $+82.5 \%$ & $+6 \%$ & 0 & $-15 \%$ & $-15 \%$ & $-49.9 \%$ & $-21.9 \%$ & $+12 \%$ & \\
\hline \multicolumn{11}{|l|}{ Gopher } \\
\hline Green Button & $+9.5 \%$ & & & & & & & & & \\
\hline Greentree International & $31.4 \%$ & $8.6 \%$ & $2.0 \%$ & $8.9 \%$ & $8.9 \%$ & $-0.8 \%$ & $-90.0 \%$ & $+8.3 \%$ & & \\
\hline HairyLemon Web Solutions & $15.4 \%$ & $13.3 \%$ & $-11.8 \%$ & $-3.3 \%$ & $+35.1 \%$ & & & & & \\
\hline Hayes International & $+82.7 \%$ & $+20 \%$ & $-30.2 \%$ & 0 & $-7.2 \%$ & 0 & $-12.9 \%$ & $-24.5 \%$ & $+7.1 \%$ & \\
\hline HiTech Solutions & $-25.1 \%$ & $21.8 \%$ & $-2.2 \%$ & & & & & & & \\
\hline HMI Technologies & $30.3 \%$ & $0.0 \%$ & $0.0 \%$ & $0.0 \%$ & $22.8 \%$ & $15.4 \%$ & $-3.7 \%$ & & & \\
\hline Hot Water Heat Pumps & $5.3 \%$ & $-10.7 \%$ & $-7.5 \%$ & $2.7 \%$ & $0.0 \%$ & $+22.4 \%$ & & & & \\
\hline Howard Wright & $88.3 \%$ & $6.1 \%$ & $0.0 \%$ & $-12.5 \%$ & $-10.2 \%$ & & & & & \\
\hline Howick Ltd & $123.2 \%$ & $22.0 \%$ & $-19.7 \%$ & $26.5 \%$ & $14.5 \%$ & $-1.4 \%$ & & & & \\
\hline HSA Global & $84.6 \%$ & $29.2 \%$ & $-3.2 \%$ & $33.3 \%$ & $-7.5 \%$ & & & & & \\
\hline Humanware & $+37 \%$ & 0 & & & & & & & & \\
\hline Ibex Industries & $27.9 \%$ & $-0.9 \%$ & $-60.0 \%$ & $-35.3 \%$ & $41.9 \%$ & $-5.1 \%$ & $26.5 \%$ & $+26.5 \%$ & & \\
\hline \multicolumn{11}{|l|}{ ICP Bio } \\
\hline \multicolumn{11}{|l|}{ Ike GPS } \\
\hline I-Lign & $21.4 \%$ & $-7.8 \%$ & & & & & & & & \\
\hline Infinity Group & $-6.7 \%$ & 0 & & & & & & & & \\
\hline Information Tools & $3.9 \%$ & $44.1 \%$ & $-0.9 \%$ & $-4.3 \%$ & $0.1 \%$ & $-17.2 \%$ & $+31.8 \%$ & & & \\
\hline Instrument Supplies & $30.7 \%$ & $7.5 \%$ & $-11.2 \%$ & $-5.5 \%$ & $9.3 \%$ & $-3.2 \%$ & $+6.8 \%$ & & & \\
\hline Interactive Technologies & $35.0 \%$ & $-7.4 \%$ & $0.0 \%$ & $11.0 \%$ & $-4.3 \%$ & $0.0 \%$ & $25.9 \%$ & $+76.2 \%$ & & \\
\hline Intergen & $+80 \%$ & $-22.9 \%$ & $+20.2 \%$ & $+9.6 \%$ & $+28.5 \%$ & $+21 \%$ & $+30.2 \%$ & $+5.6 \%$ & $-11.3 \%$ & \\
\hline Intrahealth & $-40.3 \%$ & $65.6 \%$ & $-10.1 \%$ & $27.0 \%$ & $3.8 \%$ & $0.0 \%$ & $12.6 \%$ & $0.0 \%$ & 0 & \\
\hline Intuto & $+8 \%$ & $-44.4 \%$ & $-16.7 \%$ & $-4.2 \%$ & $-38.9 \%$ & & & & & \\
\hline Invenco & $+102.1 \%$ & & & & & & & & & \\
\hline IPFX & $215.0 \%$ & $11.9 \%$ & $-4.1 \%$ & $12.5 \%$ & $0.0 \%$ & $11.4 \%$ & $-11.5 \%$ & $16.7 \%$ & $-3.2 \%$ & \\
\hline Irwin International & $+18.2 \%$ & $-.46 \%$ & $-76.3 \%$ & & & & & & & \\
\hline \multicolumn{10}{|l|}{ Jackson Electrical Industries } & \\
\hline Jade Corporation & $+11.1 \%$ & $+5 \%$ & $+19.2 \%$ & $-6.1 \%$ & $-4.3 \%$ & $-25 \%$ & $-2.2 \%$ & $-18.2 \%$ & $+11.1 \%$ & \\
\hline JMP Engineering & $33.3 \%$ & $-2.4 \%$ & $1.3 \%$ & $13.7 \%$ & $6.4 \%$ & $+63.1 \%$ & & & & \\
\hline Kea Campers & $110.2 \%$ & $14.3 \%$ & $12.5 \%$ & $0.0 \%$ & $-44.2 \%$ & & & & & \\
\hline Konnect Net & $20.5 \%$ & $15.4 \%$ & $19.7 \%$ & $40.4 \%$ & $-14.1 \%$ & & & & & \\
\hline \multicolumn{11}{|c|}{ Mactec Aerospace International } \\
\hline Magritek & $0.0 \%$ & $44.2 \%$ & $103.5 \%$ & $19.1 \%$ & $0.0 \%$ & $+27.4 \%$ & & & & \\
\hline
\end{tabular}




\begin{tabular}{|c|c|c|c|c|c|c|c|c|c|c|}
\hline Mako Networks & $-37.7 \%$ & 0 & & & & & & & & \\
\hline Maskell Productions & $5.6 \%$ & $106.7 \%$ & $6.4 \%$ & $-37.5 \%$ & $+40.6 \%$ & & & & & \\
\hline Mastip Technology & $+61.9 \%$ & $-30.4 \%$ & $+10.9 \%$ & 0 & $+16.4 \%$ & $-6.7 \%$ & $-0.9 \%$ & $-6.7 \%$ & $+25.2 \%$ & \\
\hline McKay Engineering & $6.8 \%$ & $20.0 \%$ & $-22.2 \%$ & $0.0 \%$ & $4.4 \%$ & $7.1 \%$ & $-14 \%$ & & & \\
\hline Mcom & $10.7 \%$ & $200.0 \%$ & $36.1 \%$ & $31.7 \%$ & $29.1 \%$ & $+1.9 \%$ & & & & \\
\hline MedTech Global & $80.0 \%$ & $-46.9 \%$ & $17.6 \%$ & $28.9 \%$ & $17.2 \%$ & $0.0 \%$ & $9.3 \%$ & $12.0 \%$ & $+32.3 \%$ & \\
\hline Mercer Tech & $-36.1 \%$ & $20.1 \%$ & $-24.0 \%$ & $9.6 \%$ & $35.1 \%$ & $-8.9 \%$ & $+9.5 \%$ & & & \\
\hline \multicolumn{11}{|l|}{ Merlot Aero } \\
\hline Metalform & $0.0 \%$ & $30.4 \%$ & $7.7 \%$ & 0 & & & & & & \\
\hline Methodware & $-24.5 \%$ & & & & & & & & & \\
\hline Methven & $63.0 \%$ & $19.6 \%$ & $-5.4 \%$ & $-6.0 \%$ & $-13.0 \%$ & $-7.3 \%$ & $-1.7 \%$ & $-0.4 \%$ & & \\
\hline Modica Group & $6.7 \%$ & $14.7 \%$ & $+2.6 \%$ & & & & & & & \\
\hline Modtech Industries & $5.6 \%$ & $12.2 \%$ & $-3.4 \%$ & $0.0 \%$ & $-21.1 \%$ & & & & & \\
\hline Moffat Ltd & $0.0 \%$ & $0.0 \%$ & $9.4 \%$ & $-5.6 \%$ & $0.0 \%$ & 0 & & & & \\
\hline Mole Map & $-24.0 \%$ & $50.0 \%$ & $-41.3 \%$ & $3.5 \%$ & $-9.9 \%$ & $+65.9 \%$ & & & & \\
\hline Nautech & $+139.4 \%$ & $-11.2 \%$ & $-0.9 \%$ & $+1.25 \%$ & $-43.2 \%$ & $-7.3 \%$ & $+12.6 \%$ & $+13 \%$ & $+28.3 \%$ & \\
\hline Navman & $+225.8 \%$ & $-6.9 \%$ & $-15.5 \%$ & $-78.1 \%$ & $-63.3 \%$ & $-24.1 \%$ & 0 & $+1.9 \%$ & $+21.9 \%$ & $-10.5 \%$ \\
\hline Navman Wireless & $0.0 \%$ & $0.0 \%$ & $10.7 \%$ & $+171.1 \%$ & & & & & & \\
\hline NDA & $10.4 \%$ & $-24.5 \%$ & $-20.0 \%$ & $3.1 \%$ & $-9.1 \%$ & $10.0 \%$ & 0 & & & \\
\hline Net Value & $-11.4 \%$ & $0.0 \%$ & $-11.5 \%$ & & & & & & & \\
\hline Neuren Pharmaceuticals & $115.9 \%$ & $-0.5 \%$ & $-30.0 \%$ & $29.2 \%$ & $5.2 \%$ & $+25.1 \%$ & & & & \\
\hline Next Window & $638.5 \%$ & $35.4 \%$ & $-4.6 \%$ & $0.0 \%$ & $-55.8 \%$ & $-1.1 \%$ & $-1.1 \%$ & & & \\
\hline Ninja Kiwi & $148.0 \%$ & $45.2 \%$ & $+6.1 \%$ & & & & & & & \\
\hline NZ Pharmaceuticals & $+6.7 \%$ & 0 & $+12.6 \%$ & 0 & 0 & $+33.2 \%$ & $+1.4 \%$ & 0 & $+19.9 \%$ & \\
\hline Obsidium & $-6.1 \%$ & $9.5 \%$ & $0.0 \%$ & & & & & & & \\
\hline Omni Solutions & $24.1 \%$ & $0.0 \%$ & 0 & & & & & & & \\
\hline Open Cloud & $31.3 \%$ & $20.6 \%$ & $-1.3 \%$ & $0.0 \%$ & $72.7 \%$ & $-4.3 \%$ & $7.2 \%$ & $46.9 \%$ & $-2.7 \%$ & \\
\hline Optima & $0.0 \%$ & $19.0 \%$ & $33.9 \%$ & $5.8 \%$ & $-18.9 \%$ & $-26.3 \%$ & & & & \\
\hline Optimation & $+71.4 \%$ & $-40.9 \%$ & $+96.8 \%$ & 0 & $+19.6 \%$ & $+20.8 \%$ & $-0.6 \%$ & $-13 \%$ & $+13.3 \%$ & \\
\hline Orion Systems & $+84.2 \%$ & $+38.3 \%$ & $+9.3 \%$ & $+8.9 \%$ & $+42.9 \%$ & $+9.9 \%$ & $+22 \%$ & $+33.6 \%$ & $+0.6 \%$ & \\
\hline Orthopaedic Synergy & $19.9 \%$ & $45.2 \%$ & $2.6 \%$ & $0.0 \%$ & $0.0 \%$ & $+16.1 \%$ & & & & \\
\hline Oscmar & $+9.6 \%$ & $-28.8 \%$ & 0 & $+15.4 \%$ & 0 & $+84.1 \%$ & $-19.6 \%$ & $-1.6 \%$ & $+31.8 \%$ & \\
\hline Outpost Central & $-40.9 \%$ & & & & & & & & & \\
\hline Pacific Aerospace & $+218.3 \%$ & $+28.5 \%$ & $-3.7 \%$ & $-23.1 \%$ & 0 & $+6.7 \%$ & $-10.7 \%$ & $-17.4 \%$ & $-40.7 \%$ & \\
\hline \multicolumn{11}{|l|}{ Pacific Edge } \\
\hline Panztel Ltd & $12.5 \%$ & $11.1 \%$ & $12.5 \%$ & $20.0 \%$ & $24.1 \%$ & $1.5 \%$ & & & & \\
\hline PayGlobal & $+48.6 \%$ & $-56.6 \%$ & $+49.6 \%$ & 0 & $+3 \%$ & $-4.3 \%$ & $+25.1 \%$ & $-14.2 \%$ & $-14.2 \%$ & \\
\hline Peace Software & $+51.6 \%$ & 0 & & & & & & & & \\
\hline Pertronic Industries & $-3.4 \%$ & $25.6 \%$ & $-16.0 \%$ & $4.3 \%$ & $-18.8 \%$ & & & & & \\
\hline PharmaZen & $74.7 \%$ & $-40.5 \%$ & $-10.2 \%$ & $20.6 \%$ & $5.1 \%$ & $1.3 \%$ & $4.5 \%$ & $-4 \%$ & & \\
\hline Phitek & $129.2 \%$ & $-3.8 \%$ & $-15.5 \%$ & $-0.1 \%$ & $-9.2 \%$ & $-32.2 \%$ & $18.8 \%$ & $35.8 \%$ & $+32.7 \%$ & \\
\hline \multicolumn{11}{|l|}{ Photonic Innovations } \\
\hline Pingar & $65.2 \%$ & $-54.6 \%$ & $-54.6 \%$ & & & & & & & \\
\hline Power Smart & $+18.2 \%$ & $-0.9 \%$ & & & & & & & & \\
\hline PowerbyProxi & $+44.7 \%$ & $-1.90 \%$ & & & & & & & & \\
\hline Precept Health & $0.0 \%$ & $13.2 \%$ & $87.1 \%$ & $4.4 \%$ & $+6.4 \%$ & & & & & \\
\hline Prism & $-18.4 \%$ & $+22.5 \%$ & $-20 \%$ & 0 & $+9.5 \%$ & & & & & \\
\hline Prolificx & $-69.6 \%$ & $+27.7 \%$ & $+185.7 \%$ & 0 & $-50 \%$ & 0 & $+23.5 \%$ & & & \\
\hline Provenco & $+57.3 \%$ & $+48.6 \%$ & & & & & & & & \\
\hline ProvencoCadmus Group & $-51.2 \%$ & & & & & & & & & \\
\hline
\end{tabular}


Provoke Solutions

PTL

Pultron Composites

PushPay

Q4bis

Qbik

Quick Circuit

Rakon

Raztec

Revera

RGL Telecom

Right Hemisphere

RML Engineering

RMSD

Rocklabs

Run the Red

Schneider Electric

Scott Design \& Manufacture

Scott Technology

Screening \& Crushing Solutions

Sentient Software

Senztek Holdings

Serato Audio Research

Sidhe Interactive

Silver Stripe

Simcrotech Ltd

Simpl

Simtics

Skope Industries

SLI Systems

Small Worlds

SmartPay

SMX Ltd

Snakk Media

SnapComms

Soft Tech

Software of Excellence

Sonar 6

South Pacific Sera

Spider Tracks

Sprite Software

Steelbro NZ

Straker Translations

Surveylab

Syft Technology

Symantec

Synergy

Sysmex Delphic

Systems Controls Ltd

Tacit Technologies

\begin{tabular}{|c|c|c|c|c|c|c|c|c|}
\hline \multicolumn{9}{|l|}{$+0.9 \%$} \\
\hline $20.5 \%$ & $-15.7 \%$ & $+3.2 \%$ & & & & & & \\
\hline $5.6 \%$ & $-17.6 \%$ & $28.3 \%$ & $-5.9 \%$ & $+8.3 \%$ & & & & \\
\hline \multicolumn{9}{|l|}{$-4.2 \%$} \\
\hline$-56.2 \%$ & $20.9 \%$ & $23.6 \%$ & $16.9 \%$ & $+5 \%$ & & & & \\
\hline$+77.1 \%$ & $+64.1 \%$ & $-19.9 \%$ & $+3.6 \%$ & $+31 \%$ & $-5.8 \%$ & $-1.1 \%$ & $-14.9 \%$ & $-12.4 \%$ \\
\hline$-41.8 \%$ & $123.4 \%$ & $15.4 \%$ & & & & & & \\
\hline $18.7 \%$ & $34.6 \%$ & $0.0 \%$ & $10.9 \%$ & $0.0 \%$ & & & & \\
\hline $17.6 \%$ & $-0.2 \%$ & $6.7 \%$ & $-3.8 \%$ & $-7.7 \%$ & $-8.3 \%$ & $2.7 \%$ & $+2.7 \%$ & \\
\hline$+23.8 \%$ & $-18.2 \%$ & $+35.8 \%$ & 0 & $-40.3 \%$ & $-3.4 \%$ & & & \\
\hline $13.2 \%$ & $0.0 \%$ & $33.4 \%$ & $-0.6 \%$ & $+11.8 \%$ & & & & \\
\hline $25.0 \%$ & $30.0 \%$ & & & & & & & \\
\hline$+33.3 \%$ & $+13.5 \%$ & & & & & & & \\
\hline$-8.6 \%$ & $-22.4 \%$ & $-11.8 \%$ & $+80 \%$ & 0 & 0 & $+3.3 \%$ & 0 & $-0.4 \%$ \\
\hline \multicolumn{9}{|l|}{$+46.5 \%$} \\
\hline$+12.3 \%$ & $-31.9 \%$ & $+6.2 \%$ & $-14.3 \%$ & $+25.2 \%$ & $+48.8 \%$ & $+15.1 \%$ & $+19.4 \%$ & $-6.3 \% 0$ \\
\hline $0.0 \%$ & $0.1 \%$ & $59.4 \%$ & $-12.2 \%$ & $0.0 \%$ & 0 & & & \\
\hline $0.0 \%$ & $4.5 \%$ & $-4.3 \%$ & $-25.4 \%$ & $40.9 \%$ & $+1.9 \%$ & & & \\
\hline \multicolumn{9}{|l|}{$-32.2 \%$} \\
\hline $33.2 \%$ & $40.2 \%$ & $0.0 \%$ & $0.0 \%$ & $+37.7 \%$ & & & & \\
\hline $0.0 \%$ & $-13.6 \%$ & $-32.4 \%$ & $13.8 \%$ & $-5.6 \%$ & $+3.8 \%$ & & & \\
\hline $19.5 \%$ & $6.1 \%$ & $+14 \%$ & & & & & & \\
\hline$-20.0 \%$ & $0.0 \%$ & $8.0 \%$ & $-0.9 \%$ & $0.0 \%$ & $7.5 \%$ & $-14.7 \%$ & & \\
\hline$+12.5 \%$ & $-18.5 \%$ & $-13.6 \%$ & $-30.3 \%$ & $-23.5 \%$ & $+22.1 \%$ & $-6.1 \%$ & $-73 \%$ & $+125.9 \%$ \\
\hline$+80 \%$ & $-11.1 \%$ & 0 & $+6.25 \%$ & $+9.4 \%$ & $+12.9 \%$ & $-20 \%$ & $-16.2 \%$ & $-0.6 \%$ \\
\hline $29.4 \%$ & $30.0 \%$ & $-14.6 \%$ & $31.0 \%$ & $18.5 \%$ & $17.1 \%$ & $+26.1 \%$ & & \\
\hline$-43.5 \%$ & $0.0 \%$ & $0.0 \%$ & $53.3 \%$ & $6.5 \%$ & $+6.1 \%$ & & & \\
\hline $20.2 \%$ & $-38.9 \%$ & $-42.4 \%$ & $37.3 \%$ & $-3 \%$ & & & & \\
\hline $70.2 \%$ & $-12.6 \%$ & $14.4 \%$ & & & & & & \\
\hline \multicolumn{9}{|l|}{$+40.3 \%$} \\
\hline $28.6 \%$ & $16.7 \%$ & $-35.6 \%$ & $0.0 \%$ & $-17.9 \%$ & $8.9 \%$ & $22.2 \%$ & $0.0 \%$ & $-1.2 \%$ \\
\hline$+20.2 \%$ & $+37 \%$ & $-1.7 \%$ & & & & & & \\
\hline $13.6 \%$ & $9.5 \%$ & $37.8 \%$ & & & & & & \\
\hline $12.5 \%$ & $-19.8 \%$ & $4.7 \%$ & $-8.3 \%$ & $+2.3 \%$ & & & & \\
\hline $1.5 \%$ & $30.0 \%$ & $24.2 \%$ & $16.1 \%$ & $+19.7 \%$ & & & & \\
\hline $0.0 \%$ & $-9.3 \%$ & $10.7 \%$ & $7.0 \%$ & & & & & \\
\hline \multicolumn{9}{|l|}{$+13.7 \%$} \\
\hline $0.0 \%$ & $16.4 \%$ & $59.6 \%$ & $-20.0 \%$ & $+64.1 \%$ & & & & \\
\hline$+9.6 \%$ & $+4.9 \%$ & & & & & & & \\
\hline$+0.9 \%$ & $+2.1 \%$ & $-5.4 \%$ & $-13.9 \%$ & $-9.3 \%$ & $+37.7 \%$ & $+39.1 \%$ & $+25.9 \%$ & $+4.7 \%-5 \%$ \\
\hline $188.0 \%$ & $-0.2 \%$ & $-8.9 \%$ & $0.2 \%$ & $-6.6 \%$ & $-37.0 \%$ & $5.3 \%$ & $-1.9 \%$ & $+28.6 \%$ \\
\hline $0.0 \%$ & $16.6 \%$ & $-5.4 \%$ & $33.3 \%$ & $-11.4 \%$ & & & & \\
\hline
\end{tabular}




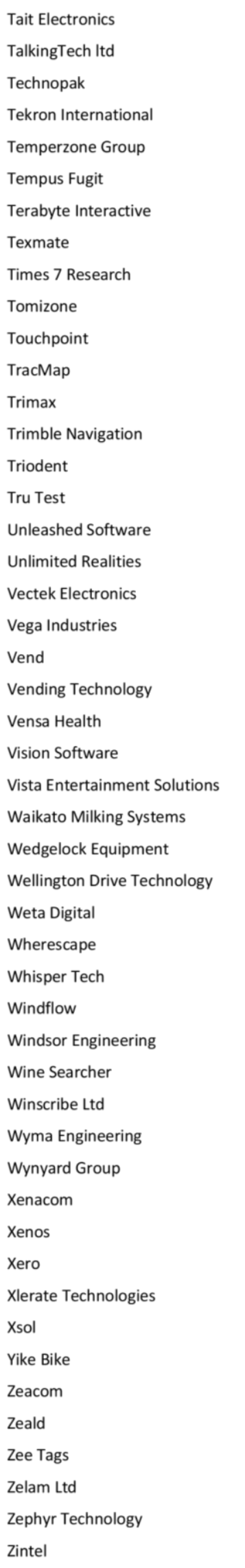

\begin{tabular}{|c|c|c|c|c|c|c|c|c|}
\hline$+12.8 \%$ & $-17.3 \%$ & $-7.7 \%$ & $+74.8 \%$ & 0 & 0 & $+7.0 \%$ & $-17.2 \%$ & $-1.6 \%$ \\
\hline$-9.1 \%$ & $53.8 \%$ & $11.7 \%$ & $-18.5 \%$ & $7.4 \%$ & $-12 \%$ & & & \\
\hline $50.0 \%$ & $39.6 \%$ & $91.8 \%$ & $11.1 \%$ & $-23.0 \%$ & $+16.9 \%$ & & & \\
\hline$-7.1 \%$ & $+1.8 \%$ & & & & & & & \\
\hline $15.6 \%$ & $9.2 \%$ & $1.7 \%$ & $-4.4 \%$ & $-0.6 \%$ & $+0.6 \%$ & & & \\
\hline \multicolumn{9}{|l|}{$+12.5 \%$} \\
\hline $5.4 \%$ & $-2.6 \%$ & $-15.8 \%$ & & & & & & \\
\hline $45.5 \%$ & $15.6 \%$ & $-7.7 \%$ & $16.0 \%$ & $+1 \%$ & & & & \\
\hline $10.0 \%$ & $-18.2 \%$ & $33.3 \%$ & $16.7 \%$ & 0 & & & & \\
\hline $1.1 \%$ & $-43.0 \%$ & $18.3 \%$ & $2.3 \%$ & $21.2 \%$ & $-21.4 \%$ & $+34 \%$ & & \\
\hline \multicolumn{9}{|l|}{$+55 \%$} \\
\hline$+9.6 \%$ & $+19.7 \%$ & $-14.6 \%$ & $-5.4 \%$ & $-24.5 \%$ & $+14 \%$ & $-2.4 \%$ & $+12.3 \%$ & $-20.2 \%$ \\
\hline$-28 \%$ & 0 & 0 & 0 & $-22.5 \%$ & 0 & $+2.2 \%$ & $-2.1 \%$ & $+72 \%$ \\
\hline $25.0 \%$ & $26.7 \%$ & $5.3 \%$ & $0.0 \%$ & $-14.1 \%$ & & & & \\
\hline 0 & $-10.8 \%$ & $-19.7 \%$ & $-17.8 \%$ & $+27.9 \%$ & $+14.5 \%$ & $+3.7 \%$ & $+26.8 \%$ & $+8.1 \%$ \\
\hline$-28.6 \%$ & $58.3 \%$ & & & & & & & \\
\hline \multicolumn{9}{|l|}{$-13.7 \%$} \\
\hline $0.0 \%$ & $-9.6 \%$ & $50.8 \%$ & $1.1 \%$ & $14.3 \%$ & $-11.8 \%$ & & & \\
\hline \multicolumn{9}{|l|}{$+110.9 \%$} \\
\hline \multicolumn{9}{|l|}{$+13.9 \%$} \\
\hline $0.0 \%$ & $-4.3 \%$ & $0.1 \%$ & $0.0 \%$ & $-11.5 \%$ & & & & \\
\hline $34.8 \%$ & $0.0 \%$ & $96.0 \%$ & $-11.5 \%$ & $41.9 \%$ & $0.3 \%$ & $+54.2 \%$ & & \\
\hline$-10.7 \%$ & $0.0 \%$ & $-46.7 \%$ & $250.0 \%$ & $-18.6 \%$ & $+9.5 \%$ & & & \\
\hline$-12.3 \%$ & $-18.7 \%$ & $-17 \%$ & & & & & & \\
\hline $63.1 \%$ & $25.9 \%$ & $54.6 \%$ & $25.0 \%$ & $24.9 \%$ & $1.6 \%$ & $-23.0 \%$ & $-35 \%$ & \\
\hline 0 & 0 & $+33.3 \%$ & $-50 \%$ & $+10 \%$ & $+9.1 \%$ & $+16.7 \%$ & 0 & 0 \\
\hline $66.7 \%$ & $0.0 \%$ & $20.0 \%$ & $30.4 \%$ & $-16.9 \%$ & $15.4 \%$ & $20.0 \%$ & $19.4 \%$ & $+34.9 \%$ \\
\hline \multicolumn{9}{|l|}{$-73 \%$} \\
\hline$-7.9 \%$ & $-62.7 \%$ & $-60.9 \%$ & & & & & & \\
\hline $0.0 \%$ & $0.0 \%$ & $12.4 \%$ & $-4.1 \%$ & $-7.9 \%$ & & & & \\
\hline $81.8 \%$ & $4.5 \%$ & $-4.3 \%$ & $134.5 \%$ & $0.0 \%$ & $-9.6 \%$ & & & \\
\hline$+40.9 \%$ & $+1.4 \%$ & $-20 \%$ & 0 & $-20 \%$ & $+56.3 \%$ & $-20 \%$ & $+8 \%$ & $+6.5 \%$ \\
\hline$+44.3 \%$ & $-16.1 \%$ & & & & & & & \\
\hline $25.0 \%$ & $3.3 \%$ & $+3.3 \%$ & & & & & & \\
\hline $206.1 \%$ & $104.1 \%$ & $97.8 \%$ & $79.6 \%$ & $+76.7 \%$ & & & & \\
\hline$-7.4 \%$ & $56.7 \%$ & $-11.1 \%$ & & & & & & \\
\hline 0 & 0 & & & & & & & \\
\hline$+46.7 \%$ & 0 & $+45.5 \%$ & $+6.3 \%$ & $+20.6 \%$ & $-9.3 \%$ & & & \\
\hline $0.0 \%$ & $-4.3 \%$ & $30.1 \%$ & $23.1 \%$ & $-11.5 \%$ & & & & \\
\hline $19.0 \%$ & $4.0 \%$ & $4.6 \%$ & $-42.5 \%$ & $-17.9 \%$ & & & & \\
\hline $33.3 \%$ & $-21.4 \%$ & $-5.5 \%$ & $-26.3 \%$ & $0.0 \%$ & $+6.8 \%$ & & & \\
\hline$+1.7 \%$ & & & & & & & & \\
\hline$+13.1 \%$ & $-8.5 \%$ & $+6.6 \%$ & $+26.5 \%$ & $+17.9 \%$ & $-22 \%$ & & & \\
\hline
\end{tabular}




\section{Appendix 7. Interview Consent Form}

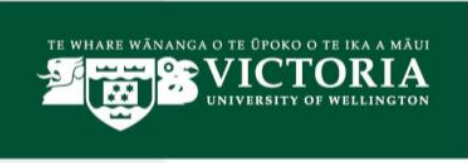

Participant Consent Form
School of Management, Victoria Business School

Orauariki

VICTORIA UNIVERSITY OF WELLINGTON, PO Box 600, Wellington 6140, New Zealand

Email sasha.greig@vuw.ac.nz Web www.victoria.ac.nz

\section{Toward a Better Understanding of High Growth in New Zealand Technology Firms}

By signing this form, I acknowledge that I have been provided a sufficient explanation of the research project described above, and have understood the project. I have been given the opportunity to ask questions, and have them answered satisfactorily. I understand that I may choose to have any or all information I provide excluded from the project before the $1^{\text {st }}$ of March 2016, without needing to provide a reason.

I understand and agree that I will have the option to be provided with copy of the transcribed interview before publication of the thesis.

I understand that my organisation may be identified in the research, and that no personal identifying information of pertaining to me or my colleagues will be published, and that the researcher and supervisor will keep my identity confidential.

I understand that I will be asked to discuss information relating to my organisation that is historical in nature, and available in the public domain.

I understand that any information I provide will be, in the first case, used for the purpose of this thesis. I also understand that this information may also be used for conference publications and/or journal articles, and I will be informed if and when this is the case.

I understand that I am acting as a representative of my organisation.

I agree to participate in this research project

\section{Signed}

Name of Participant

Date 


\section{Appendix 8. Growth Stability Charts}
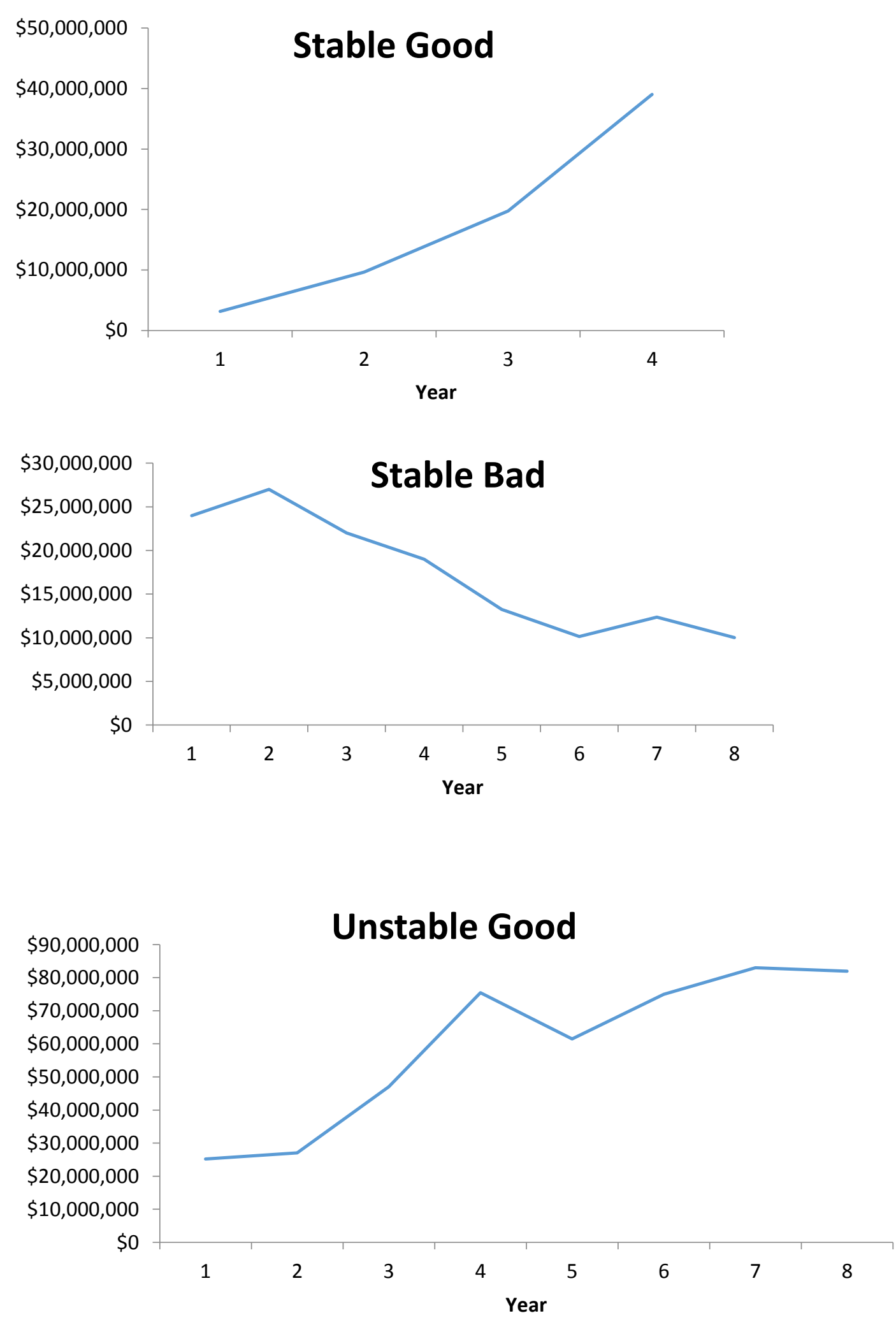


\section{Unstable Bad}

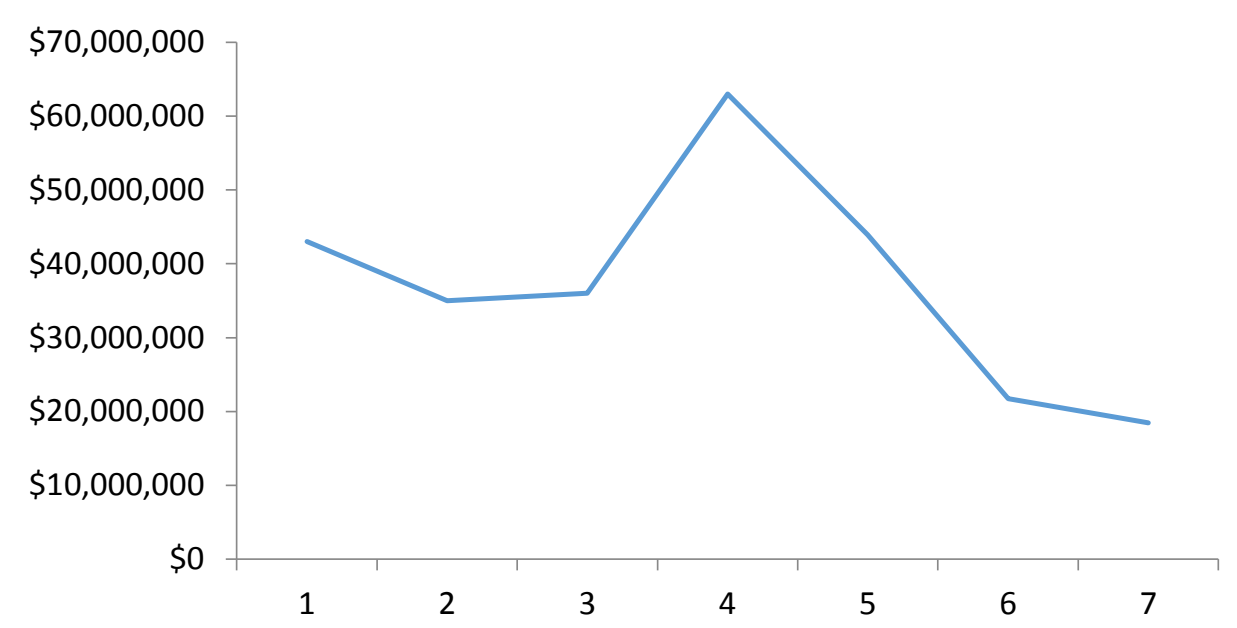

